\title{
Specialization Dynamics, Convergence, and Idea Flows
}

\author{
Liuchun Deng
}

SERIES Working PAPERS N. 09/2016

SERIES sono pubblicati a cura del Dipartimento di Scienze economiche e metodi matematici dell'Università degli Studi di Bari "Aldo Moro". I lavori riflettono esclusivamente le opinioni degli autori e non impegnano la responsabilità del Dipartimento. SERIES vogliono promuovere la circolazione di studi ancora preliminari e incompleti, per suscitare commenti critici e suggerimenti. Si richiede di tener conto della natura provvisoria dei lavori per eventuali citazioni o per ogni altro uso.
SERIES are published under the auspices of the Department of Economics of the University of Bari. Any opinions expressed here are those of the authors and not those of the Department. Often SERIES divulge preliminary or incomplete work, circulated to favor discussion and comment. Citation and use of these paper should consider their provisional character. 


\title{
Specialization Dynamics, Convergence, and Idea Flows*
}

\author{
Liuchun Deng ${ }^{\dagger}$
}

October 3, 2016

\begin{abstract}
This paper studies the dynamics of international trade from the perspective of knowledge spillover. Building into an idea-flow model the industry dimension, I integrate four channels of knowledge spillover: each firm could learn from domestic producers as well as foreign sellers, and learning is both intra- and inter-industry. The theoretical framework yields the law of motion of industry-level productivity across countries, capturing strong interdependence of evolution of comparative advantage. I calibrate the model to a large sample of countries. My quantitative results capture important patterns in the data: strong convergence in comparative advantage and substantial mobility in specialization. Based on the law of motion, my decomposition exercise suggests international and inter-industry channels play a major role in knowledge spillover. Various measures are proposed to identify the "key player", that is, the country or country-industry pair that contributes most to global productivity growth, in the knowledge diffusion network. The calibrated model also suggests dynamic gains from trade are at least one-third of static gains from trade.
\end{abstract}

Keywords: International trade, specialization dynamics, convergence, industrial productivity, comparative advantage, knowledge spillover, economic growth

JEL Classification: F10, F43, O33, O47

${ }^{*}$ I am grateful to Pravin Krishna, M. Ali Khan, and Heiwai Tang for their continued support and encouragement. I wish to thank seminar and conference participants at the Johns Hopkins University, 7th Conference on Economics of Global Interactions, European Trade Study Group, Rimini Conference in Economics and Finance, 5th Annual Workshop on Networks in Trade and Finance for very helpful comments. All errors are mine.

${ }^{\dagger}$ Department of Economics, The Johns Hopkins University. E-mail ldeng5@jhu.edu 


\section{Introduction}

The last few decades have painted an intriguing picture of specialization dynamics. A number of economies have seen dramatic change of their export baskets. China's top export industry shifted from children's toys to computers within less than twenty years (Hanson, 2012). Since 1970s, South Korea has managed to establish their leading position in the shipbuilding industry from scratch. Frequent turnover of main export industries is not just confined to Eastern Asian miracle economies. African countries have also witnessed substantial mobility in their specialization for the last two decades (Easterly and Reshef, 2010). The most salient feature of specialization dynamics is the strong convergence in comparative advantage. Countries that initially exports little in an industry tends to expand its export activity faster in that industry. This convergence pattern has been documented across different country groups and sample periods for a variety of measures of comparative advantage. Given its impact on global economic growth (Rodrik, 2013b) and cross-country income distribution, it is important to understand what is driving specialization dynamics in a quantitative manner.

This paper studies dynamics of specialization patterns, unconditional convergence in comparative advantage in particular, from the perspective of knowledge diffusion. In an interdependent world, knowledge diffusion is ubiquitous. Unprecedented volume of international trade makes it possible for people across the world to be exposed to new products, designs, and ideas therein on a daily basis. Knowledge diffusion is hardly bounded by industrial classifications. The rapid development of the electronic technology in the last twenty years has profound impact on virtually all sectors of the economy, much beyond its own narrowly defined industry. Complexity of technology diffusion calls for a framework in which we can study how the rise of new ideas impacts production across countries and industries through international trade, thereby shedding light on the nexus between growth and trade dynamism.

To account for knowledge diffusion in both geographical and technological spaces, I build up a dynamic model featuring both international and inter-industry flows of ideas. The crosssectional setting is a fully-fledged multi-country multi-industry Ricardian model of international trade with multiple factors and input-output linkages in light of Caliendo and Parro (2014) and Levchenko and Zhang (2016). Industrial productivity, as well as factor endowment, shapes specialization pattern across countries. Along the time dimension, I build into a model of global idea flows (Buera and Oberfield, 2016) the industry dimension. Importantly, flows of ideas go hand in hand with flows of goods. By putting industries into play, I am able to integrate four channels of idea flows: each firm could learn from domestic producers as well as foreign exporters, and technology spillover is both intra- and inter-industry. The theoretical framework yields a law of motion of industry-level productivity across countries, capturing strong interdependence of evolution of comparative advantage.

The law of motion of industry-level productivity is amenable for empirical implementation. Using production and trade data, I calibrate this structural model of knowledge diffusion for a sample of 32 OECD and 40 non-OECD countries. The calibrated model reproduces strong 
convergence in comparative advantage and its magnitude is in line with what we observe in the data for a variety of measures. This demonstrates that technology diffusion serves as a plausible candidate to quantitatively explain convergence in comparative advantage (Hwang, 2006; Rodrik, 2013b; Levchenko and Zhang, 2016), echoing the earlier theoretical prediction that a laggard country tends to grow faster provided that it has equal access to technology. Furthermore, the model generates substantial degree of mobility in specialization especially among non-OECD countries. This is consistent with empirical findings by Proudman and Redding (2000), Redding (2002), and Hanson et al. (2016). A growing body of work documents that what underlies trade dynamism is convergence in comparative advantage, but nevertheless silent on its sources. This paper fills this void by providing a quantitative exploration from the perspective of knowledge diffusion through trade.

Second, my empirical analysis quantifies the contribution of each channel of technology diffusion to industry-level productivity growth across countries. According to my calibration, international technology diffusion on average plays a more important role than domestic technology diffusion, and inter-industry technology diffusion contributes more than half to the overall productivity growth. This result stands in contrast with Keller (2002b) that also integrates four channels of knowledge diffusion. He documents that domestic knowledge diffusion within the same industry plays a major role in shaping industrial productivity. Despite the similarity in diffusion channels, the difference in our decomposition exercise needs to be interpreted with great caution, because this paper focuses on transitional dynamics and therefore productivity growth at the industry level, while Keller (2002b) focuses on level terms of TFP and thus the steady state of the global production pattern. In this sense, this work complements Keller (2002b) in tracing sources of productivity growth.

Moreover, an important implication of the model is that it maps the directly observable trade network to an underlying network of idea flows. Employed with the full structure of idea flows, I identify the "key player" in the global technology diffusion, that is, the country or countryindustry pair that contributes most to the global productivity growth. The model also suggests that distribution of each country's contribution becomes less skewed over time, as emerging market economies play an increasingly larger role.

This paper further joins the recent debate on gains from trade (Arkolakis et al., 2012). Using the calibrated law of motion of industrial productivity, I compute the dynamic gains from trade as additional increase in real income when a country moves from autarky to open trade and enjoys higher productivity growth. The additional gains on average account for at least $8 \%$ of GDP, demonstrating that the dynamic welfare gains proposed by the original work of Buera and Oberfield (2016) are substantial.

From a modeling point of view, this paper is closely related to the recent theoretical literature on "idea flows". In this class of models, agent-to-agent interaction is the engine of growth (Lucas and Moll, 2014; Perla and Tonetti, 2014). Each period, an agent is randomly matched with another agent in the economy and potentially adopts the new insight from the matched agent. Economic growth is thereby characterized by a traveling wave of productivity distribution within 
the economy. Extending this framework into the open-economy setting, a series of theoretical work studies how dynamic gains from trade arise from learning from foreign sellers (Alvarez et al., 2013), change of timing of technology adoption (Perla et al., 2015), and dynamic selection effects due to entry-exit decision (Sampson, 2016). My model builds upon Buera and Oberfield (2016) which itself nests Kortum (1997) and Alvarez et al. (2013). The key departure from this literature is to open up the industry dimension. Agents across different industries are allowed to meet each other and exchange insights. The traveling wave of an industry is therefore determined by productivity distributions of those industries from which this industry draws insights.

The cross-sectional setting of my model closely follows Caliendo and Parro (2014) and Levchenko and Zhang (2016). Following Eaton and Kortum (2002), a large literature employs quantifiable trade models to study how Ricardian comparative advantage shapes international trade. Shikher (2011) and Costinot et al. (2012) first extend the Eaton-Kortum framework into a multi-industry setting. Caliendo and Parro (2014) and Levchenko and Zhang (2016) further extend the framework by incorporating realistic input-output linkages (Acemoglu et al., 2012) and multiple factors of production. Though their theoretical predecessors are dynamic growth models (Kortum, 1997; Eaton and Kortum, 1999), most of the existing structural trade models are static. A recent exception is Somale (2014) that studies the complex two-way relationship between productivity growth and trade pattern in an innovation-based framework. My work adds to this literature by endogenizing industry-level trade patterns through the lens of technology diffusion.

This paper draws insights from the literature that examines economic consequences of technological relatedness of industries spurred by Jaffe (1986). Based on co-export structure, Hidalgo et al. (2007) formalize the concept of the "product space" and document strong path dependence of trade patterns. Follow-up work by Kali et al. (2012) study the structure of the product space in relation to economic growth using cross-country regressions. Cai and Li (2014) builds into an innovation-based growth model industrial linkages of knowledge creation. Using patent citation data, they demonstrate that industrial linkage is important in explaining firms' patenting behavior.

This paper is also related to an earlier literature on international technology diffusion ${ }^{1}$. This strand of literature studies the extent to which technology diffuses across borders via imports, exports, and foreign direct investment. A prominent example is Coe and Helpman (1995). They document that a country's $R \& D$ expenditures have large effects on productivity of its trade partners. Keller (2002a) further demonstrates international spillover of R\&D expenditures is largely localized and correlated with non-trade variables such as language. Much of the existing empirical analysis relies on availability of cross-country sectoral $R \& D$ data, and as a result, analysis is usually carried out across a small sample of industrialized economies. To motivate empirical framework, the existing work typically draws insights from innovation-based growth models Grossman and Helpman (1993). In contrast, this paper complements the literature by taking a different theoretical underpinning. Although this paper is agnostic about sources of knowledge creation, it introduces a much finer process of knowledge diffusion that is micro-

\footnotetext{
${ }^{1}$ Keller (2004) provides an excellent review.
} 
founded by firm-to-firm interactions. By focusing on the very nature of technology spillover, my theoretical framework is more suitable for analyzing technology catchup of the developing world where most countries are technology recipients rather than creators. Because the law of motion of industry-level productivity derived in this paper depends exclusively on variables that can be constructed by using trade and production data, I am also freed from using R\&D data and therefore a much larger sample of developing countries can be included in my quantitative exercise.

Lastly, this paper adds to the discussion of trade and industrial policies. As a seminal work, Hausmann and Rodrik (2003) highlight the problem of appropriability associated with localizing foreign technology. On the contrary, recent case studies on export pioneers (Sabel et al., 2012) suggest that coordination problem is the foremost issue of initiating new export activities. This paper takes a macro perspective on diffusion barriers by offering a systematic industrylevel comparison between international and domestic knowledge spillover. A related but more controversial discussion is about whether what a country exports matters for its future economic growth. Cross-country regressions by Hausmann et al. (2007) suggest that a country tends to achieve higher economic growth if its export basket biases towards those of rich countries. This finding spurs a huge debate on industrial policy ${ }^{2}$. My work joins this debate by quantitatively investigating how a country's production structure and import bundles impact its industrial productivity growth.

The rest of the paper is structured as follows. Section 2 presents the motivating evidence of the paper: specialization dynamics and unconditional convergence. Section 3 describes the model, solves the instantaneous equilibrium, and derives the law of motion of industry-level productivity. Section 4 describes sample construction and the two-step estimation strategy. Section 5 presents main results and demonstrates the internal validity of the model. Section 6 discusses the implications of the model. Section 7 concludes.

\section{Motivating Evidence}

\subsection{Specialization Dynamics}

The first set of evidence concerns change of a country's specialization. Earlier work by Redding (2002) examines evolution of export baskets of seven OECD countries. Employed with an empirical framework of distribution dynamics, he finds substantial mobility in specialization. This finding is further extended by Hanson et al. (2016) in a gravity-equation framework. In a 20-year window, they find the turnover rate of the top 5\% industries is about $60 \%$. Figure 1 plots for four representative countries export shares ${ }^{3}$ of the top 10 export industries and compares with those

\footnotetext{
${ }^{2}$ A collection of critique can be found in Lederman and Maloney (2012).

${ }^{3}$ Export share is admittedly a crude measure, but this pattern is robust under more sophisticated measures of export capabilities. Another criticism is that change in gross exports may simply reflect change in vertical specialization, but similar change in specialization is also found in trade in value-added using TiVA data from OECD-WTO.
} 
values in 1990. Consistent with the literature, there is substantial turnover among emerging market economies and developing countries. The export basket of USA is relatively stable, but the change of export shares is also quite prominent for the top two industries. Figure 2 conducts a similar exercise as Hanson et al. (2016). The small values on the diagonal suggest that many leading export industries in 2010 did not or only exported a little in 1990.

[Figure 1 about here.]

[Figure 2 about here.]

\subsection{Unconditional Convergence}

Despite negative findings of unconditional convergence at the aggregate level, the recent literature suggests that within the manufacturing sector countries (or industries) tend to achieve higher productivity growth if the initial level of productivity is relatively low Rodrik (2013a). Figure 3 illustrates unconditional convergence from a slightly different view. I plot industry-level RCA growth $^{4}$ in the tradeable sector from 1990 to 2010 against the gap between a country's RCA and average RCA of its trade partners weighted by import shares in 1990. There is clearly a positive relationship between the growth rate and the initial gap, meaning that a country tends to experience faster export growth in industries where it falls far behind its trade partners. That being said, a country's export capability converges to not only the world technology frontier that is documented in the literature but also its trade partners' levels. International technology diffusion, or more specifically, learning from trade partners seems to be a plausible explanation of this convergence effect. In the next section, I build up a model of technology diffusion to quantitatively assess how various channels of technology diffusion could give rise to unconditional convergence.

[Figure 3 about here.]

\section{Model}

My model has two main components. The cross-sectional setting is a multi-industry multicountry Hechscher-Ohlin-Ricardian framework with industrial linkages, which closely follows Caliendo and Parro (2014) and Levchenko and Zhang (2016). Dynamics of industry-level productivity is modeled in line with Buera and Oberfield (2016). Diffusion of ideas is the engine of productivity growth. Two-way relationship between international trade and productivity growth is separated into two dimensions: at each moment of time, the trade pattern is determined by cross-country industrial productivity; along the time dimension, productivity growth is shaped by the pattern of international trade. By incorporating the industry dimension into Buera and

\footnotetext{
${ }^{4} \mathrm{As}$ is made clear in the quantitative exercise, unconditional convergence is a salient feature in trade and production data under a variety of measures.
} 
Oberfield (2016), I am able to investigate a rich set of knowledge diffusion and derive the law of motion for industry-level productivity that is amenable to empirical implementation.

In my model, the world consists of $N$ countries indexed by $n$ and $n^{\prime}$. There are $I+1$ industries indexed by $i$ and $i^{\prime}$ among which the first $I$ industries produce tradeable goods and the $(I+1)$-th industry produces non-tradeable goods. Time is continuous, infinite, and indexed by $t$.

\subsection{Cross-sectional Setup}

To simplify the notation, I suppress the time subscript " $\mathrm{t}$ " in presenting the cross-sectional setup.

\subsubsection{Demand}

Goods from $I+1$ industries are combined into final goods which are used for investment and final consumption. The combination is of the form

$$
Y_{n}\left(Y_{n}^{1}, Y_{n}^{2}, \ldots, Y_{n}^{I+1}\right)=\left[\sum_{i=1}^{I}\left(\omega_{n}^{i}\right)^{1-\kappa}\left(Y_{n}^{i}\right)^{\kappa}\right]^{\phi_{n} / \kappa}\left(Y_{n}^{I+1}\right)^{1-\phi_{n}}
$$

where $Y_{n}$ is the output of final goods in country $n$ and $Y_{n}^{i}$ is the goods from industry $i, \omega_{n}^{i}$ is the share parameter of tradeable goods and $\sum_{i=1}^{I} \omega_{n}^{i}=1$ for any country $n ; \phi_{n}$ is country-specific Cobb-Douglas share of tradeable goods; the elasticity of substitution across tradeable goods is given by $1 /(1-\kappa)$. Therefore, a representative consumer in country $n$ is faced with the following per-period decision problem

$$
\max _{Y_{n}^{1}, Y_{n}^{2}, \ldots, Y_{n}^{I+1}} Y_{n}\left(Y_{n}^{1}, Y_{n}^{2}, \ldots, Y_{n}^{I+1}\right) \quad \text { subject to } \sum_{i=1}^{I+1} P_{n}^{i} Y_{n}^{i} \leq E_{n}
$$

where $P_{n}^{i}$ is the industry-level price index and $E_{n}$ is per-period total expenditure. Therefore, consumers have two-tier preferences: the first tier is Cobb-Douglas between tradeable and nontradeable sectors and the second tier exhibits constant elasticity of substitution (CES henceforth) across $I$ tradeable industries. Standard derivation yields

$$
\begin{aligned}
Y_{n}^{i} & =\frac{\omega_{n}^{i} P_{n}^{i \frac{\kappa}{\kappa-1}}}{\sum_{i^{\prime}=1}^{I} \omega_{n}^{i^{\prime}} P_{n}^{i^{\prime} \kappa-1}} \cdot \frac{\phi_{n} E_{n}}{P_{n}^{i}}, \quad i=1,2, \ldots, I, \\
Y_{n}^{I+1} & =\frac{\left(1-\phi_{n}\right) E_{n}}{P_{n}^{I+1}} .
\end{aligned}
$$

\subsubsection{Production}

In each industry $i$, there is a unit mass of intermediate goods indexed by $\nu^{i} \in[0,1]$. Each variety of intermediate good $\nu^{i}$ is produced by using labor, capital, and composite intermediate goods. 
Production technology is of Cobb-Douglas form

$$
q_{n}^{i}\left(\nu^{i}\right)=z_{n}^{i}\left(\nu^{i}\right)\left[\ell_{n}^{i}\left(\nu^{i}\right)\right]^{\gamma^{i L}}\left[k_{n}^{i}\left(\nu^{i}\right)\right]^{\gamma^{i K}} \prod_{i^{\prime}=1}^{I+1}\left[m_{n}^{i i^{\prime}}\left(\nu^{i}\right)\right]^{\gamma_{n}^{i i^{\prime}}},
$$

where $q_{n}^{i}\left(\nu^{i}\right)$ is the output of variety $\nu^{i} ; z_{n}^{i}\left(\nu^{i}\right)$ is the productivity level; $\ell_{n}^{i}\left(\nu^{i}\right)$ and $k_{n}^{i}\left(\nu^{i}\right)$ are labor and capital; $m_{n}^{i i^{\prime}}$ is composite intermediate goods from industry $i^{\prime}$; Cobb-Douglas coefficients $\gamma^{i L}$ and $\gamma^{i K}$ are the labor and capital shares; $\gamma_{n}^{i i^{\prime}}$ is the share of intermediate goods from industry $i^{\prime}$, capturing the important input-output (I-O henceforth) linkage that is emphasized by the recent macroeconomics literature (Carvalho, 2014). Production technology follows constant returns to scale (CRS henceforth), which requires $\gamma^{i L}+\gamma^{i K}+\sum_{i^{\prime}=1}^{I+1} \gamma_{n}^{i i^{\prime}}=1$ for any country $n$. According to the production function, the unit cost of an input bundle $c_{n}^{i}$ can be defined as

$$
c_{n}^{i}=\left(\frac{w_{n}}{\gamma^{i L}}\right)^{\gamma^{i L}}\left(\frac{r_{n}}{\gamma^{i K}}\right)^{\gamma^{i K}} \prod_{i^{\prime}=1}^{I+1}\left(\frac{P_{n}^{i^{\prime}}}{\gamma_{n}^{i i^{\prime}}}\right)^{\gamma_{n}^{i i^{\prime}}},
$$

where $w_{n}$ is the wage rate and $r_{n}$ is the rental rate.

Composite goods in each industry are produced by combining a continuum of varieties within the same industry. Production technology is of CES form

$$
Q_{n}^{i}=\left[\int_{0}^{1} q_{n}^{i}\left(\nu^{i}\right)^{\left(\sigma^{i}-1\right) / \sigma^{i}} d \nu^{i}\right]^{\sigma^{i} /\left(\sigma^{i}-1\right)},
$$

where $\sigma^{i}$ is the elasticity of substitution. Standard derivation yields

$$
q_{n}^{i}\left(\nu^{i}\right)=\left(\frac{p_{n}^{i}\left(\nu^{i}\right)}{P_{n}^{i}}\right)^{-\sigma^{i}} Q_{n}^{i}
$$

with

$$
P_{n}^{i}=\left[\int_{0}^{1} p_{n}^{i}\left(\nu^{i}\right)^{1-\sigma^{i}} d \nu^{i}\right]^{1 /\left(1-\sigma^{i}\right)},
$$

where $p_{n}^{i}\left(\nu^{i}\right)$ is the price of variety $\nu^{i}$ in country $n$.

Composite goods in each industry can be used as either intermediate goods for domestic production or production of final consumption goods. Production technology of composite and final goods is identical across countries. It implies that international trade only occurs at the variety level, which will be specified in the next section.

\subsubsection{International Trade}

Trade cost is of the iceberg form (Samuelson, 1954). It requires shipping $d_{n n^{\prime}}^{i}$ units of goods from country $n^{\prime}$ to deliver one unit of good to country $n$. The triangle inequality is assumed to always hold: $d_{n n^{\prime \prime}}^{i} d_{n^{\prime \prime} n^{\prime}}^{i} \geq d_{n n^{\prime}}^{i}$ for any country $n, n^{\prime}, n^{\prime \prime}$ and industry $i$. It implies re-export is always more costly than direct export in the model, and consequently trade hubs like Singapore and 
Hong Kong are excluded in the empirical implementation of the model. For the non-tradeable sector, $d_{n n^{\prime}}^{I+1}=\infty$ for any $n, n^{\prime}$ such that $n \neq n^{\prime}$. Domestic trade is assumed to be frictionless ${ }^{5}$, so $d_{n n}^{i}=1$ for any $n$ and $i$.

The product market is assumed to be perfectly competitive. Each variety of intermediate inputs is purchased from the supplier with the lowest unit cost adjusted by trade cost. Recall that $c_{n}^{i}$ is the unit cost of an input bundle of industry $i$ in country $n$. Therefore, price of the intermediate good $\nu^{i}$ in country $n$ is given by

$$
p_{n}^{i}\left(\nu^{i}\right)=\min \left\{\frac{c_{1}^{i} d_{n 1}^{i}}{z_{1}^{i}\left(\nu^{i}\right)}, \frac{c_{2}^{i} d_{n 2}^{i}}{z_{2}^{i}\left(\nu^{i}\right)}, \ldots, \frac{c_{N}^{i} d_{n N}^{i}}{z_{N}^{i}\left(\nu^{i}\right)}\right\}
$$

Following Eaton and Kortum (2002), variety-level productivity $z_{n}^{i}$ is a random draw from a Fréchet distribution given by

$$
F_{n}^{i}(z)=\exp \left(-\lambda_{n}^{i} z^{-\theta^{i}}\right)
$$

where $F_{n}^{i}$ is country $n$ 's productivity distribution in industry $i$; the location parameter $\lambda_{n}^{i}$ governs the mean of distribution; $\theta^{i}$ measures the dispersion of the distribution. Denote by $\pi_{n n^{\prime}}^{i}$ the share of expenditure that country $n$ spends on the imports from country $n^{\prime}$ in industry $i$. Utilizing the probabilistic structure, standard derivation yields

$$
\pi_{n n^{\prime}}^{i}=\frac{\lambda_{n^{\prime}}^{i}\left(c_{n^{\prime}}^{i} d_{n n^{\prime}}^{i}\right)^{-\theta^{i}}}{\sum_{n^{\prime \prime}=1}^{N} \lambda_{n^{\prime \prime}}^{i}\left(c_{n^{\prime \prime}}^{i} d_{n n^{\prime \prime}}^{i}\right)^{-\theta^{i}}},
$$

where the denominator captures "multilateral resistance" coined by Anderson and van Wincoop (2003), that is, the fact that bilateral trade flows are shaped by economic variables beyond those of the bilateral trading partners in a multilateral world. The industry-level price index is also determined by the multilateral resistance terms

$$
P_{n}^{i}=\left[\Gamma\left(1+\frac{1-\sigma^{i}}{\theta^{i}}\right)\right]^{1 /\left(1-\sigma^{i}\right)}\left(\sum_{n^{\prime}=1}^{N} \lambda_{n^{\prime}}^{i}\left(c_{n^{\prime}}^{i} d_{n n^{\prime}}^{i}\right)^{-\theta^{i}}\right)^{-1 / \theta^{i}}
$$

where $\Gamma(\cdot)$ is the Gamma function. The usual regularity condition $\theta^{i}+1>\sigma^{i}$ is imposed, so the price index is well defined.

Note that the location parameter $\lambda_{n}^{i}$ varies across time $t$. When turning to the time dimension of the setup, I will use the learning process introduced by Buera and Oberfield (2016) to further endogenize and dynamize the industry-level productivity distribution.

\subsubsection{Market Clearing and Instantaneous Equilibrium}

Denote country $n$ 's total trade deficit by $D_{n}$. Like Caliendo and Parro (2014), I allow international lending and borrowing, and trade deficits are exogenously given. The world-total trade

\footnotetext{
${ }^{5}$ The recent work by Ramondo et al. (n.d.) suggests that assuming each country being fully integrated may not be innocuous.
} 
deficit has to be balanced out, so $\sum_{n=1}^{N} D_{n}=0$. Country $n$ 's expenditure is therefore given by

$$
E_{n}=w_{n} L_{n}+r_{n} K_{n}+D_{n}
$$

where $L_{n}$ and $K_{n}$ is labor and capital endowment.

By definition, the trade deficit is the difference between total imports and exports

$$
D_{n}=\sum_{i=1}^{I+1}\left(P_{n}^{i} Q_{n}^{i}-\sum_{n^{\prime}=1}^{N} P_{n^{\prime}}^{i} Q_{n^{\prime}}^{i} \pi_{n^{\prime} n}^{i}\right)
$$

Recall that the industrial composite goods can be used for either intermediate goods or final consumption goods, so the product market clearing condition in each industry is given by

$$
P_{n}^{i} Q_{n}^{i}=\sum_{i^{\prime}=1}^{I+1} \gamma_{n}^{i^{\prime} i} \sum_{n^{\prime}=1}^{N} P_{n^{\prime}}^{i^{\prime}} Q_{n^{\prime}}^{i^{\prime}} i_{n^{\prime} n}^{i^{\prime}}+P_{n}^{i} Y_{n}^{i}
$$

Given the Cobb-Douglas production function, the share of labor and capita income within each industry is given by $\gamma^{i L}$ and $\gamma^{i K}$, respectively. Therefore, I have

$$
\begin{aligned}
& w_{n} L_{n}^{i}=\gamma^{i L} \sum_{n^{\prime}=1}^{N} P_{n^{\prime}}^{i} Q_{n^{\prime}}^{i} \pi_{n^{\prime} n}^{i} \\
& r_{n} K_{n}^{i}=\gamma^{i K} \sum_{n^{\prime}=1}^{N} P_{n^{\prime}}^{i} Q_{n^{\prime}}^{i} \pi_{n^{\prime} n}^{i},
\end{aligned}
$$

where $L_{n}^{i}$ and $K_{n}^{i}$ are industry-level labor and capital.

Market clearing conditions for labor and capital markets further require

$$
\begin{aligned}
& \sum_{i=1}^{I+1} L_{n}^{i}=L_{n} \\
& \sum_{i=1}^{I+1} K_{n}^{i}=K_{n} .
\end{aligned}
$$

At each moment of time $t$, given labor and capital endowment $\left\{L_{n}\right\}_{n=1}^{N}$ and $\left\{K_{n}\right\}_{n=1}^{N}$, trade deficits $\left\{D_{n}\right\}_{n=1}^{N}$, bilateral industry-level trade costs $\left\{d_{n n^{\prime}}^{i}\right\}_{n=1, n^{\prime}=1, i=1}^{N, N, 1}$, and industrial productivity measures $\left\{\lambda_{n}^{i}\right\}_{n=1, i=1}^{N, I+1}$, an instantaneous equilibrium is characterized by $\left\{r_{n}\right\}_{n=1}^{N},\left\{w_{n}\right\}_{n=1}^{N}$, and $\left\{P_{n}^{i}\right\}_{n=1, i=1}^{N, I+1}$ such that consumers maximize utility (Equation 1, 2), firms maximize profit (Equation 3), decision on international trade is made optimally (Equation 4, 5), product markets clear (Equation 6 - 8), and factor markets clear (Equation 9 - 12), or in short, Equation $1-12$ hold $^{6}$ for any country $n$ and industry $i$.

\footnotetext{
${ }^{6}$ Among these equations, $N$ equations are redundant due to the income-expenditure identity for each country. Proof can be found in Appendix B.1.
} 


\subsection{Dynamic Setup}

\subsubsection{A General Learning Process}

I start with a brief description of a general learning process originally formulated by Buera and Oberfield (2016). Technology advances through adopting new ideas. Arrival of new ideas is modeled as a Poisson process with rate $\tilde{\eta}$. Upon arrival of a new idea, the producer compares the productivity level of her technology with the realized productivity of the new idea. Productivity level associated with each new idea, $z_{G}$, is drawn from a source distribution $G_{n, t}^{i}(\cdot)$. The source distribution evolves over time and potentially varies across countries and industries. I will explicitly specify the source distribution when turning to explain different channels of knowledge diffusion. Producers are faced with uncertainty when adopting new ideas. Randomness of adoption efficiency is captured by another random draw, $z_{H}$, from an exogenous, time-invariant distribution $H^{i}(\cdot)$. In particular, the actual productivity of a new idea is given by a Cobb-Douglas combination of these two draws, $z_{G}^{\beta^{i}} z_{H}^{1-\beta^{i}}$. The new idea is adopted if and only if $z_{G}^{\beta^{i}} z_{H}^{1-\beta^{i}}$ is greater than the productivity level of the existing technology $z$. This process of adopting new ideas yields the following law of motion of industrial productivity distribution $F_{n, t}^{i}$

$$
\frac{d}{d t} \ln F_{n, t}^{i}(z)=-\tilde{\eta} \int_{0}^{\infty}\left[1-G_{n, t}^{i}\left(\frac{z^{1 / \beta^{i}}}{x^{\left(1-\beta^{i}\right) / \beta^{i}}}\right)\right] d H^{i}(x) .
$$

Following Buera and Oberfield (2016), I assume that $H^{i}(\cdot)$ follows a Pareto distribution, $H^{i}(z)=1-\left(z / z_{0}\right)^{-\tilde{\theta}^{i}}$, for $z>z_{0}$. Let $\theta^{i} \equiv \tilde{\theta}^{i} /\left(1-\beta^{i}\right)$ and normalize $\eta \equiv \tilde{\eta} z_{0}^{\tilde{\theta}}$ to be a constant. It can be further shown that

$$
\lim _{z_{0} \rightarrow 0} \frac{d}{d t} \ln F_{n, t}^{i}(z)=-\eta z^{-\theta^{i}} \int_{0}^{\infty} x^{\beta^{i} \theta^{i}} d G_{n, t}^{i}(x),
$$

provided that $\lim _{x \rightarrow \infty}\left[1-G_{n, t}^{i}(x)\right] x^{\beta^{i} \theta^{i}}=0$.

Therefore, I obtain the following industrial productivity distribution

$$
F_{n, t}^{i}(z)=\exp \left(-\lambda_{n, t}^{i} z^{-\theta^{i}}\right)
$$

with the law of motion of the key productivity parameter $\lambda_{n, t}^{i}$

$$
\frac{d \lambda_{n, t}^{i}}{d t}=\eta \int_{0}^{\infty} x^{\beta^{i} \theta^{i}} d G_{n, t}^{i}(x)
$$

Notice that the industrial productivity distribution above coincides with the Fréchet distribution that I assume in the cross-section setting. In this sense, the general learning process endogenizes the industrial productivity distribution.

Now consider firms can learn from multiple sources. Suppose producers draw new ideas from source $s$ with distribution $G_{n, t}^{i, s}$ at a normalized rate $\eta^{s}$. Arrival of new ideas from different sources is independent from each other. Adoption efficiency is assumed to be industry-specific but source- 
invariant. Therefore, I can write the general law of motion of industry-level productivity under multiple sources as follows

$$
\frac{d \lambda_{n, t}^{i}}{d t}=\sum_{s} \eta^{s} \int_{0}^{\infty} x^{\beta^{i} \theta^{i}} d G_{n, t}^{i, s}(x)
$$

\subsubsection{Channels of Idea Flows}

I consider four channels of idea flows: learning from foreign exporters and domestic producers within the same industry as well as across industries. As a benchmark, I start with the assumption that productivity dispersion does not vary across industries: $\theta^{i}=\theta$.

1. Intra-industry learning from domestic producers and foreign sellers

Producers within the same industry can learn from each other. Social learning has long been argued crucial to understanding of productivity growth (Acemoglu, 2008). A growing body of recent work also empirically confirms learning from information neighbors as an important factor of technology adoption (Bandiera and Rasul, 2006; Conley and Udry, 2010). Case studies of Argentinian industries by Artopoulos et al. (2013) suggest domestic knowledge diffusion could significantly impact a country's comparative advantage through learning from export pioneers. Moreover, a large literature studies international technology diffusion through imports at the industry level. This channel is found important for both high-tech industries like capital equipments (Eaton and Kortum, 2001) and more traditional industries like agriculture (Gisselquist and Jean-Marie, 2000). In a more recent study, Acharya and Keller (2009) points out that the import channel operates asymmetrically across advanced economies and plays a predominant role in technology transfers from major European countries.

In the model, a producer randomly meets another seller in the same industry with the Poisson intensity $\tilde{\eta}_{n, t}^{i}$. Assuming that each active seller in the domestic market is drawn with equal probability, I obtain the source distribution of this channel $G_{n, t}^{i}$ as

$$
G_{n, t}^{i}(z)=\int_{0}^{z} \sum_{n^{\prime}=1}^{N} \prod_{n^{\prime \prime} \neq n^{\prime}} F_{n^{\prime \prime}, t}^{i}\left(\frac{c_{n^{\prime \prime}, t}^{i} d_{n n^{\prime \prime}}^{i}}{c_{n^{\prime}, t}^{i} d_{n n^{\prime}}^{i}} x\right) d F_{n^{\prime}, t}^{i}(x),
$$

where $\prod_{n^{\prime \prime} \neq n^{\prime}} F_{n^{\prime \prime}, t}^{i}\left(\frac{c_{n^{\prime \prime}}^{i} d_{n n^{\prime \prime}}^{i}}{c_{n^{\prime}, t}^{i} t_{n n^{\prime}}^{i}}\right) d F_{n^{\prime}, t}^{i}(x)$ can be interpreted as the (infinitesimal) probability that a firm with productivity $x$ from country $n^{\prime}$ is the cheapest seller in country $n$.

2. Inter-industry learning from domestic producers and foreign sellers

By incorporating industry dimension to Buera and Oberfield (2016), I am able to investigate a much richer set of diffusion channels beyond intra-industry interactions. Cai and Li (2014) presents a closed-economy innovation-based growth model with a technology space and their simulation results match well with the key firm-level facts. On the other hand, since 
the earlier contribution by Young (1991), there are a series of theoretical and empirical papers that investigates the impact of technology space on industry-level and aggregate growth in the open-economy context (the companion paper by Cai and Li (2016) is a state-of-the-art example).

Analogously, I allow firms in industry $i$ to learn from active sellers in another industry $i^{\prime}$ of the domestic market. New ideas arrive with rate $\tilde{\eta}_{n, t}^{i i^{\prime}}$. The source distribution is then given by

$$
G_{n, t}^{i i^{\prime}}=\int_{0}^{z} \sum_{n^{\prime}=1}^{N} \prod_{n^{\prime \prime} \neq n^{\prime}} F_{n^{\prime \prime}, t}^{i^{\prime}}\left(\frac{c_{n^{\prime \prime}, t}^{i^{\prime}} i_{n n^{\prime \prime}}^{i^{\prime}}}{c_{n^{\prime}, t}^{i^{\prime}} i_{n n^{\prime}}^{i^{\prime}}} x\right) d F_{n^{\prime}, t}^{i^{\prime}}(x)
$$

Collecting these channels together and using Equation 13, I obtain the law of motion of industry-level productivity as follows ${ }^{7}$

$$
\begin{aligned}
& \text { Intra-industry spillover, domestic Intra-industry spillover, international } \\
& \frac{d \lambda_{n, t}^{i}}{d t}=\overbrace{\eta_{n, t}^{i} \pi_{n n, t}^{i}{ }^{1-\beta^{i}} \lambda_{n, t}^{i} \beta^{i}}+\overbrace{\eta_{n, t}^{i} \sum_{n^{\prime} \neq n} \pi_{n n^{\prime}, t}^{i} 1-\beta^{i} \lambda_{n^{\prime}, t}^{i} \beta^{i}} \\
& +\overbrace{\sum_{i^{\prime} \neq i} \eta_{n, t}^{i i^{\prime}} \pi_{n n, t}^{i^{\prime}}{ }^{1-\beta^{i}} \lambda_{n, t}^{i^{\prime} \beta^{i}}}+\overbrace{\sum_{i^{\prime} \neq i} \eta_{n, t}^{i i^{\prime}} \sum_{n^{\prime} \neq n} \pi_{n n^{\prime}, t}^{i^{\prime}}{ }^{1-\beta^{i}} \lambda_{n^{\prime}, t}^{i^{\prime} \beta^{i}}},
\end{aligned}
$$

where $\eta_{n, t}^{i} \equiv \Gamma\left(1-\beta^{i}\right) \tilde{\eta}_{n, t}^{i}$, and $\eta_{n, t}^{i i^{\prime}} \equiv \Gamma\left(1-\beta^{i}\right) \tilde{\eta}_{n, t}^{i i^{\prime}}$. In the Equation above, $\pi_{n n^{\prime}, t}$ is directly observed in trade data and $\lambda_{n, t}^{i}$ can be estimated by using production and trade data. The main objective of my empirical exercise is to obtain diffusion parameters, $\eta_{n, t}^{i}$ and $\eta_{n, t}^{i i^{\prime}}$. In the most general setting, there are too many diffusion parameters, so I will impose further assumptions on those parameters when turning to the empirical specification.

It might already be noticed that intra-industry domestic technology diffusion is isomorphic to an alternative formulation through the standard narrative of learning-by-doing. Therefore, unlike the development economics literature using micro-data (Foster and Rosenzweig, 1995), I will not distinguish learning-by-doing from learning spillover, so the empirical interpretation of this channel should encompass both mechanisms. Moreover, unlike Buera and Oberfield (2016), I only consider the channel that is called "learning from sellers" in their original paper. Since exporters must also sell in their own domestic market due to the triangle inequality of trade cost, by taking into account learning from domestic sellers, the industry-level diffusion process already captures the idea that domestic producers could learn from each other. Having additional learning channels may potentially improve the prediction of the model, but as suggested by my empirical results, this learning process already captures the salient features in trade data.

I close this part by discussing the simplifying assumption made earlier: $\theta^{i}=\theta$ for any $i$. According to Caliendo and Parro (2014), there is substantial variation of industrial productivity dispersion across industries. In the presence of heterogeneous $\theta^{i}$, when producers in industry $i$ with little productivity dispersion (high $\theta^{i}$ ) learn from producers in industry $i^{\prime}$ with substantial

\footnotetext{
${ }^{7}$ Detailed derivation can be found in Appendix B.2.
} 
productivity dispersion (low $\theta^{i^{\prime}}$ ), the recipient industry's productivity distribution tends to be largely shaped by the extreme values drawn from the source distribution. It can be formally shown that the learning process becomes degenerate if and only if $\theta^{i^{\prime}} \leq \beta^{i} \theta^{i}$. Therefore, to relax the assumption on homogeneous $\theta^{i}$, I have to assume that the learning process is adjusted for industrial dispersion so as to maintain the analytical tractability of the model. In particular, an adjustment parameter $\tau_{i i^{\prime}}$ is introduced into inter-industry spillover. When producers in industry $i$ draws a new insight $z_{G}$ from productivity distribution $G$ of industry $i^{\prime}$ as well as a random draw of adoption efficiency $z_{H}$ from the exogenous distribution $H$, the actual productivity of this new insight is given by $z_{G}^{\tau^{i i^{\prime}} \beta^{i}} z_{H}^{1-\beta^{i}}$ with $\tau^{i i^{\prime}}=\theta^{i^{\prime}} / \theta^{i}$. Under this assumption of dispersion adjustment, the law of motion of industrial productivity (Equation 14) will be unchanged without assuming a uniform industrial productivity dispersion $\theta^{8}$.

\subsubsection{Evolution of Endowment}

To complete the dynamic setting of the model, I specify the law of motion of labor and capital. Population growth rate $\chi_{n, t}$ is country-specific and time varying. It is defined as

$$
\frac{d L_{n, t}}{d t}=\chi_{n, t} L_{n, t}
$$

The equation of capital accumulation is given by

$$
\frac{d K_{n, t}}{d t}=I_{n, t}-\delta_{n, t} K_{n, t}
$$

where $I_{n, t}$ is investment and $\delta_{n, t}$ is depreciation rate. Since international borrowing and lending is allowed in this model, the domestic saving is not necessarily equal to domestic investment. The following accounting identity always holds

$$
D_{n, t}=P_{n, t}\left(I_{n, t}-S_{n, t}\right)
$$

where $S_{n, t}$ is the domestic saving, and $P_{n, t}$ is the price index of final goods given by

$$
P_{n, t}=\left(\sum_{i=1}^{N} \omega_{n}^{i}\left(\frac{P_{n, t}^{i}}{\phi_{n}}\right)^{\frac{\kappa}{\kappa-1}}\right)^{\frac{\kappa-1}{\kappa} \phi_{n}}\left(\frac{P_{n, t}^{I+1}}{1-\phi_{n}}\right)^{1-\phi_{n}} .
$$

The model features both Ricardian and Heckscher-Ohlin motive of international trade. However, since the main theme of the paper is on productivity dynamics, the evolution of endowment structure is treated exogenous. At each moment of time, consumers treat saving rates and trade deficit (and thereby investment rates) as given. By abstracting away from the complex intertemporal consumption-saving decision, a country's investment level goes hand in hand with its total output. This simplifying assumption makes it possible to conduct a battery of counterfactual analysis on the Ricardian side on the model.

\footnotetext{
${ }^{8}$ Proof can be found in Appendix B.3.
} 


\section{Empirical Specification and Data}

\subsection{Sample Construction}

My sample construction mainly follows Levchenko and Zhang (2016). The baseline sample consists of 72 countries and regions among which 42 are non-OECD economies. Data from OECD economies typically have longer time span. Since my second-stage estimation requires a balanced panel, I use data from 1990 to 2010 to maximize the number of countries. As a robustness check, similar analysis will also be performed in a longer time span from 1970 to 2010, but most countries in the former Soviet Union will no longer be included. Although the trade and production data is of annual frequency, I choose the length of each period to be five years to ensure that productivity estimates and calibration of diffusion parameters are not contaminated by short-run business fluctuations. Therefore, the baseline sample is a four-period balanced panel. All the variables are averaged within each period. The sample contains 17 tradeable industries. They are slightly aggregated up from 2-digit ISIC (revision 3) manufacturing industries ${ }^{9}$.

My sample is constructed from two main data sources ${ }^{10}$. Bilateral trade variables are obtained from UN Comtrade database and further aggregated up from 4-digit SITC level into 2-digit ISIC level. Production variables including industry-level output, value added, and wage bills come from UNIDO INDSTAT2 (2015 edition) database. Country-specific variables like wage and rental rates, labor supply, and capital stock are taken from Penn World Table (version 8.1). .

\subsection{Empirical Specification}

My empirical specification consists of two stages. The first stage utilizes the gravity structure in each instantaneous equilibrium repeatedly to estimate trade costs $d_{n n^{\prime}, t}^{i}$ at the industry level, industry-level productivity parameters $\lambda_{n, t}^{i}$ and other cross-sectional structural variables. Estimation of industry-level productivity parameters $\lambda_{n, t}^{i}$ further consists of two steps. The first step is to estimate productivity parameters relative to a benchmark country, in my setting, United States, following the procedure originally proposed by Shikher (2012). The second step is to estimate US industry-level productivity parameters $\left(\lambda_{U S}^{i}\right)$ taking into account the mechanism of Ricardian selection coined by Finicelli et al. (2013). The second stage calibrates the diffusion parameters $\eta_{n, t}^{i}$, and $\eta_{n, t}^{i i^{\prime}}$. This stage requires solving the instantaneous equilibrium every period and applying model-implied trade and production variables to the law of motion of industry-level productivity.

\subsubsection{First Stage: Trade and Production Variables}

The first-stage estimation only needs the production and trade side of the cross-sectional equilibrium structure, so the subscript $t$ is omitted if not needed. I first derive the empirical version

\footnotetext{
${ }^{9}$ In the appendix, Table A1 reports the coverage of countries and availability of trade and production data for each country, and Table A2 lists industry descriptions.

${ }^{10}$ The details of sample construction are delegated to Appendix C. Table A3 gives an overview of construction of key variables and data sources.
} 
of the gravity equation from the model. Using Equation 4, I have

$$
\ln \left(\frac{\pi_{n n^{\prime}}^{i}}{\pi_{n n}^{i}}\right)=\ln \left(\lambda_{n^{\prime}}^{i} c_{n^{\prime}}^{i}{ }^{-\theta^{i}}\right)-\ln \left(\lambda_{n}^{i} c_{n}^{i-\theta^{i}}\right)-\theta^{i} \ln \left(d_{n n^{\prime}}^{i}\right)
$$

where $\lambda_{n}^{i} c_{n}^{i-\theta^{i}}$ measures the competitiveness of country $n$ in industry $i$. Like Eaton and Kortum (2002), define the competitiveness measure as the industry-level productivity parameter adjusted by the unit cost of an input bundle, $S_{n}^{i} \equiv \lambda_{n}^{i} c_{n}^{i-\theta^{i}}$. Assuming the bilateral trade cost is of the form

$$
\ln \left(d_{n n^{\prime}}^{i}\right)=\text { Dist }_{n n^{\prime}}+\text { BilateralVar }{ }_{n n^{\prime}}+\operatorname{Exp}_{n^{\prime}}^{i}+\varepsilon_{n n^{\prime}}^{i}
$$

where Dist $_{n n^{\prime}}$ captures the impact of bilateral distance on trade cost and the impact is discretized by categorizing distance in miles into six intervals, $[0,375),[375,750),[750,1500),[1500$, 3000), [3000, 6000), [6000, maximum). BilateralVar ${ }_{n n^{\prime}}$ includes a set of variables capturing the effects on trade cost if two trading partners have common border, share the same language, belong to a common currency union or free trade area. I also include the industry-level exporter fixed effect $E x p_{n^{\prime}}^{i}$ that is forcefully argued by Waugh (2010) to generate implications more consistent with empirical evidence than the approach using importer fixed effects. The last term is an error term orthogonal to all the importer and exporter fixed effects and bilateral observables mentioned above.

Combining Equation 15 and 16, I obtain

$$
\ln \left(\frac{\pi_{n n^{\prime}}^{i}}{\pi_{n n}^{i}}\right)=\ln S_{n^{\prime}}^{i}-\theta^{i} \operatorname{Exp}_{n^{\prime}}^{i}-\ln S_{n}^{i}-\theta^{i} \text { BilateralVar }_{n n^{\prime}}-\theta^{i} \varepsilon_{n n^{\prime}}^{i}
$$

where $\left(\ln S_{n^{\prime}}^{i}-\theta^{i} \operatorname{Exp}_{n^{\prime}}^{i}\right)$ and $\left(-\ln S_{n}^{i}\right)$ can be captured by two fixed effects. Since we take US as the benchmark country, the competitiveness measure relative to US can be obtained from the importer fixed effects,

$$
\frac{S_{n}^{i}}{S_{U S}^{i}}=\frac{\lambda_{n}^{i}}{\lambda_{U S}^{i}}\left(\frac{c_{n}^{i}}{c_{U S}^{i}}\right)^{-\theta^{i}}
$$

In the benchmark estimation, I pick $\theta^{i}$ to be 4 , the same value across industries $\left(\theta^{i} \equiv \theta\right)$. In the section of robustness check, I will report results using other values of $\theta^{i}$, including industryspecific estimates from Caliendo and Parro (2014). According to the expression above, to obtain the estimates of relative productivity parameters, $\lambda_{n}^{i} / \lambda_{U S}^{i}$, what remains are estimates of relative unit $\operatorname{costs} c_{n}^{i} / c_{U S}^{i}$. As a benchmark, I assume I-O shares are country-invariant. Using Equation 3 , I have

$$
\frac{c_{n}^{i}}{c_{U S}^{i}}=\left(\frac{w_{n}}{w_{U S}}\right)^{\gamma^{i L}}\left(\frac{r_{n}}{r_{U S}}\right)^{\gamma^{i K}} \prod_{i^{\prime}=1}^{I}\left(\frac{P_{n}^{i^{\prime}}}{P_{U S}^{i^{\prime}}}\right)^{\gamma^{i i^{\prime}}}\left(\frac{P_{n}^{I+1}}{P_{U S}^{I+1}}\right)^{\gamma^{i(I+1)}},
$$

where all the Cobb-Douglas coefficients can be calculated using production data and I-O tables. The I-O shares are calibrated to US in the benchmark exercise, while country-specific I-O tables will be used as a robustness check. Relative wage rates and relative rental rates are obtained from the Penn World Table. The relative price indices in the nontradeable sector are obtained from 
the International Comparison Program. To obtain relative price indices in tradeable industries, I follow Shikher (2012). Using Equation 4 and 5, I can show

$$
\frac{\pi_{n n}^{i}}{\pi_{U S U S}^{i}}=\frac{S_{n}^{i}}{S_{U S}^{i}}\left(\frac{P_{n}^{i}}{P_{U S}^{i}}\right)^{\theta}
$$

Collecting Equation 18 - 20, I finally have

$$
\frac{\lambda_{n}^{i}}{\lambda_{U S}^{i}}=\frac{S_{n}^{i}}{S_{U S}^{i}}\left(\frac{w_{n}}{w_{U S}}\right)^{\theta \gamma^{i L}}\left(\frac{r_{n}}{r_{U S}}\right)^{\theta \gamma^{i K}}\left(\frac{P_{n}^{I+1}}{P_{U S}^{I+1}}\right)^{\theta \gamma^{i(I+1)}} \prod_{i^{\prime}=1}^{I}\left(\frac{\pi_{n n}^{i^{\prime}}}{\pi_{U S U S}^{i^{\prime}}} \frac{S_{U S}^{i^{\prime}}}{S_{n}^{i^{\prime}}}\right)^{\gamma^{i i^{\prime}}}
$$

where all the relative terms on the right hand side are either estimated or directly measurable ${ }^{11}$. For the nontradeable sector, estimation of relative productivity parameters is even simpler. Equation 5 implies

$$
\frac{\lambda_{n}^{I+1}}{\lambda_{U S}^{I+1}}=\left(\frac{c_{n}^{I+1}}{c_{U S}^{I+1}} \frac{P_{U S}^{I+1}}{P_{n}^{I+1}}\right)^{\theta}
$$

where $c_{n}^{I+1} / c_{U S}^{I+1}$ is obtained from Equation 19 and 20 , and $P_{n}^{I+1} / P_{U S}^{I+1}$ can be directly obtained from data.

Estimation of Equation 17 also yields the relative competitiveness measure $S_{n^{\prime}}^{i} / S_{n}^{i}$ for every country pair. Plugging this back into Equation 15, I can also obtain a panel of trade costs $d_{n n^{\prime}}^{i}$. Trade cost estimates will be used as exogenous parameters in the second-stage calibration. Based on estimation of the gravity equation at the annual frequency, Figure 4 shows how average trade costs decline during the post-war era and the trend is generally downward across most industries. The decline of median trade cost is much sharper under a balanced panel. The slight increase of trade cost of the pooled sample from 1960s to 1980s is entirely due to compositional change, as countries with longer distance started international trade. The only anomaly under the balanced panel is that the trade cost of the petroleum/fuel industry picked up early 2000s, which is mostly likely to be driven by 2000s energy crisis.

[Figure 4 about here.]

The second step of the first-stage estimation is to estimate US industry-level productivity parameters $\lambda_{U S}^{i}$. By aggregating up output, capital, production and non-production worker hours, and materials from 4-digit SIC level to 2-digit ISIC level, I first estimate 4-factor productivity, TFP $P_{U S}^{i}$, of tradeable industries Bartlesman and Gray (1996). US TFP in the nontradeable sector is obtained by combining information from NBER-CES database and Penn World Table. However, the observed TFP may overestimate a country's underlying productivity level because trade openness forces many unproductive domestic producers to exit the market. According to

\footnotetext{
${ }^{11}$ As a cross validation, I compare the first-stage TFP estimates with those reported in Fadinger and Fleiss (2011). Under similar Ricardo-Heckscher-Ohlin context but with monopolistic competition, they also obtain industry-level TFP estimates relative to US. The cross-sectional comparison is based on 1996 data and it is found that correlation is above 0.5 for a vast majority of industries.
} 
Finicelli et al. (2013), the true productivity level needs to be adjusted by the share of domestic absorption $^{12}$

$$
\lambda_{U S}^{i}=\left(T F P_{U S}^{i}\right)^{\theta} \pi_{U S U S}^{i} .
$$

Combining Equation 21 and 21, I obtain the estimates of productivity parameters across all countries and industries.

\subsubsection{Second Stage: Diffusion and Learning Parameters}

The second stage calibrates the diffusion parameters. To simplify my analysis, I first impose the assumption that each diffusion parameter can be written as a country-specific term and a industry-specific term, that is, $\eta_{n, t}^{i}=\eta_{n, t} \eta^{i}, \eta_{n, t}^{i i^{\prime}}=\eta_{n, t} \eta_{t}^{i i^{\prime}}$. The country-specific term is calibrated to match the country-level TFP growth rates. In the benchmark exercise, I further impose three assumptions: the diffusion parameter $\beta^{i}$ is industry-invariant, $\eta_{n, t}=\eta_{t}$ and inter-industry knowledge linkages are proportional to production I-O linkages. Therefore, I end up with only two parameters to calibrate in each period, a diffusion intensity parameter $\eta_{t}$, and a learning parameter $\beta \equiv \beta^{i}$. Later I will check robustness of the benchmark setting by relaxing each of these assumptions.

Calibration of $\beta$ and $\eta$ works as follow. First take an initial guess of diffusion and learning parameters. Given the first-period estimates of productivity parameters $\lambda_{n, t_{0}}^{i}$, I solve the instantaneous equilibrium for bilateral trade shares ${ }^{13}$. Using the law of motion of productivity parameters (Equation 14), I obtain $\lambda_{n, t}^{i}$ for the next period. Then given the predicted productivity parameters, I solve the next-period instantaneous equilibrium. Iterating this process until the last period of the sample, I obtain a full panel of bilateral trade shares and production variables. Country-level TFP growth rate is chosen as the target of the calibration exercise and I will use predicted industry-level TFP and trade patterns to test internal validity of the model.

Evolution of the endowment structure is treated exogenous. In each period, total labor supply $L_{n, t}$ is given. Capital series is simulated using exogenous investment rates from the Penn World Table. Exogenous trade deficits $D_{n, t}$ are introduced as a wedge between a country's total income and expenditure.

\section{$5 \quad$ Empirical Results}

\subsection{Baseline Results}

Panel I of Table 1 reports the goodness of fit under a full panel of estimated industry-level TFP. The target variables for each cross-sectional equilibrium are country-level labor and capital. The implied trade pattern matches actual trade pattern well. Correlation is consistently above 0.85 and median and mean trade shares are quite close. Panel II reports the goodness of fit under our

\footnotetext{
${ }^{12}$ Notice that $T F P_{U S}^{i}$ needs to be exponentiated, because the mean of a productivity distribution with cdf given by $F(z)=\exp \left(-\lambda z^{-\theta}\right.$ is proportional to $\lambda^{1 / \text { theta }}$.

${ }^{13}$ Details of the solution algorithm can be found in Levchenko and Zhang (2016).
} 
baseline calibration. The first-period TFP is chosen as the estimated TFP from data, so goodness of fit for 1990-1995 stays the same. It is expected that as the number of iterates increases, it becomes difficult for the model to match data. However, correlation between bilateral trade share is still consistently above 0.75 .

[Table 1 about here.]

I now turn to the key prediction of the model, convergence in comparative advantage. Figure 5 compares the pattern of unconditional convergence in RCA implied by the model with data. It can be clearly seen that the simulated trade data also exhibits strong unconditional convergence. Industries with little export volume in 1990 enjoy much higher growth in the next two decades. To establish the pattern of unconditional convergence more formally, I regress the growth rate of the variable of interest on the initial value of that variable and a set of fixed effects,

$$
\left(\ln X_{t_{1}}-\ln X_{t_{0}}\right)=\alpha \ln X_{t_{0}}+\text { FixedEffects }+\varepsilon .
$$

There are a variety of measures of comparative advantage. I consider three alternatives for $X$ : RCA index ${ }^{14}$ because it is directly observable; Industry level TFP, the central variable of interest; export capability ${ }^{15}$ proposed by Hanson et al. (2016). I also include bilateral trade shares (not taking the logarithm) to check if unconditional convergence occurs on a bilateral base. Table 2 presents regression results over cross-sectional observations of 20-year window $\left(t_{1}-t_{0}=20\right)$. The first row reports convergence coefficients of the actual trade and productivity data. They are all estimated negative and statistically significant, which echoes earlier findings in the literature. The second row reports the convergence coefficients of our baseline calibration. The learning efficiency parameter $\beta$ is calibrated to be 0.301 . Given parsimony of the parameters in our calibration exercise, it is surprising to see that the model-implied convergence coefficients are remarkably close to the actual data. OECD countries tend to have lower convergence rate than Non-OECD countries in the data. It is also well captured by the model. In the sample of Non-OECD countries, the convergence rate matches perfectly with data, while in the sample of OECD countries, the model slightly under-predicts the convergence rate. It should also be noticed that this convergence pattern is not the artifact of my calibration exercise, because in the baseline calibration, no country-specific or industry-specific trend is fed into the model.

To check the robustness of the baseline calibration, I consider three alternative calibration strategies. Method II allows $\beta$ to be different across sample periods $(\beta=0.169,0.119,0.500)$. Method III applies actual trade data rather than simulated trade data to the law of motion of industrial TFP $(\beta=0.240)$. Method IV allows $\beta$ to be time-variant and uses actual trade data in TFP updating $(\beta=0.158,0.009,0.484)$. The results are very close to the benchmark case. However, Method IV raises the concern that the value of $\beta$ seems to be sensitive to calibration strategy. Therefore, I redo the benchmark exercise by fixing $\beta$ to 0.5 or 0.7 and report the results

\footnotetext{
${ }^{14}$ The results are robust if symmetric or weighted RCA indices are used (Yu et al., 2009).

${ }^{15}$ Formally, it is obtained as the exporter fixed effect by running the standard gravity model by industry and time.
} 
in the last two rows. They further confirm the finding that the convergence pattern delivered by the model is quite robust.

[Figure 5 about here.]

[Table 2 about here.]

The second test of internal validity concerns the turnover of export industries. Following Proudman and Redding (2000), I construct a transition matrix in terms of industry-level TFP. To account for industrial variation, I divide the TFP estimates by the 90-percentile TFP for each industry. Then for each country, I rank 17 industries by its adjusted TFP measure. In each sub-table of Table 3, the $i j$-element in a transition matrix represents the conditional probability that a group- $i$ industry in 1990 moves to the $j$ th group in 2010. More concretely, according to the first sub-table in Table 3, if an industry is among the top 4 industries in 1990, this industry is expected to remain top 4 after 20 years with probability $51 \%$. Diagonal terms in a transition matrix indicate persistence in specialization, while off-diagonal terms capture mobility in specialization. Comparing the two transition matrices in each panel, I find the model tends to under-predict mobility of comparative advantage than data. However, if we restrict our attention to the sample of non-OECD countries, the model delivers much closer prediction to the data. It once again suggests that this model of technology diffusion is more applicable to developing countries which are precisely the group of countries that receive not enough attention from innovation-based growth models.

[Table 3 about here.]

As a last test of internal validity, Figure 6 reports the distribution of share of top 1 and 3 export industry (industries) in a country's total export. This is meant to capture hyperspecialization pointed out by Hanson et al. (2016). Consistent with actual data, the model implies that top 1 industry should account for $37 \%$ of a country's total export volume and top 3 industries should account for almost $2 / 3$ of the total export volume. This suggests that strong mean reversion and skewness of export share could well co-exist, so our empirical exercise offers a potential mechanism that solves the puzzle raised by Hanson et al. (2016).

[Figure 6 about here.]

Given the assumptions on diffusion and learning parameters, the baseline law of motion of industry-level productivity parameters can be written as

$$
\begin{aligned}
\frac{d \lambda_{n, t}^{i}}{d t}= & \eta_{t}\left(\pi_{n n, t}^{i}{ }^{1-\beta} \lambda_{n, t}^{i} \beta+\sum_{n^{\prime}=1}^{N} \pi_{n n^{\prime}, t}^{i}{ }^{1-\beta} \lambda_{n^{\prime}, t}^{i} \beta\right. \\
& \left.+\sum_{i^{\prime} \neq i} \gamma^{i i^{\prime}} \pi_{n n, t}^{i^{\prime} \quad{ }^{1-\beta}} \lambda_{n, t}^{i^{\prime} \beta}+\sum_{i^{\prime} \neq i} \gamma^{i i^{\prime}} \sum_{n^{\prime}=1}^{N} \pi_{n n^{\prime}, t}^{i^{\prime}}{ }^{1-\beta} \lambda_{n^{\prime}, t}^{i^{\prime}} \beta\right)
\end{aligned}
$$


This equation can be used to decompose productivity growth into four different channels: interand intra- industry idea flows within and across borders. Although learning and diffusion parameters are not country-specific, decomposition of productivity growth still varies across countries because each country has different trade partners, thereby different learning opportunities. Figure 7 illustrates the decomposition of productivity growth. The domestic technology diffusion on average accounts for about $36 \%$ of the overall industry-level productivity growth, while the rest $64 \%$ of the productivity growth can be attributed to international technology diffusion. In other words, producers tend to learn more from foreign sellers in the domestic markets than from their fellows. Under the assumption that inter-industry diffusion intensity is proportional to I-O coefficients, I find that inter-industry knowledge diffusion can explain about $58 \%$ of the over productivity growth. It suggests that ignoring inter-industry knowledge linkages may substantially bias the prediction of productivity dynamics across industries as well as the contribution of cross-border relative to within-border technology diffusion because international technology diffusion mainly arises from inter-industry learning.

[Figure 7 about here.]

Figure 8 illustrates decomposition of productivity growth among OECD and non-OECD countries. The decomposition looks very similar across these two country groups in the benchmark setting. At first glance, this may seem counter-intuitive, because rich countries tend to trade more with rich countries, thus having better sources of learning. But rich countries also have higher domestic productivity, so this balances out international technology diffusion and makes the contribution of each channel similar to developing countries. Figure 9 further plots decomposition by industry. Traditional industries like food and cloth seem to have different pattern of knowledge diffusion than modern industries like machinery and electronics.

[Figure 8 about here.]

[Figure 9 about here.]

Although different values of $\beta$ suggest similar convergence rate according to Table 2 , this does not mean $\beta$ plays little role in understanding dynamics of comparative advantage. Figure 10 plots the contribution of each channel against $\beta$. Contribution of domestic knowledge diffusion decreases with $\beta$. This is a direct consequence of the learning specification from Buera and Oberfield (2016). As the learning efficiency becomes smaller, high-quality ideas from foreign exporters get heavily discounted and sources with different quality of ideas become less distinguishable from each other.

[Figure 10 about here.] 


\subsection{Robustness Check}

This section checks the robustness of our baseline results. Our first set of robustness check concerns different methods of estimating the baseline industry-level TFP. Table A4 summarize the convergence pattern of the variables of interest under five alternative estimates of industrylevel TFP. The first panel reports the convergence pattern of the alternative TFP estimates from data. The second panel reports for comparison the convergence pattern of simulated TFP from the model where the first-period TFP is obtained from corresponding alternative specifications. The last panel reports convergence in trade patterns suggested by the model. In column (1), I re-estimate the main gravity equation using Poisson pseudo-maximum likelihood method (PPML henceforth) proposed by Silva and Tenreyro (2006) to address the issue of "zeros" in bilateral trade flows. Accordingly, bilateral trade costs are also obtained from PPML regressions. The model predicts stronger convergence than what data suggests, but if we break the sample into OECD and non-OECD countries, the convergence rate in each subsample is reasonably close to the data. Column (2) - (5) re-estimates the model using country-specific and time-variant I-O tables ${ }^{16}$. In column (2) and (3), I maintain the baseline setting that trade elasticity is industry invariant and simulate the model using both OLS and PPML TFP estimates. According to Caliendo and Parro (2014), trade elasticity varies substantially across industries, so column (4) and (5) are based on TFP estimates using their industry-specific $\theta^{i}$. Overall the model delivers similar degree of convergence of TFP as data in terms of both statistical and economic significance. Notice that the simulated model in column (4) and (5) suggests much stronger convergence in trade variables. This is due to the fact that some industries have very high trade elasticity (for example $\theta^{i}=50$ for petroleum industry), which leads to more outliers of $\lambda^{i}$ in the first-stage estimation. The convergence rate largely agrees with data if these outliers are dropped ${ }^{17}$.

The second set of robustness check concerns the choice of diffusion matrices. In the first panel of Table 4, I report the convergence pattern using country-specific I-O tables as diffusion matrices. Compared with the benchmark simulation, the results are highly robust. Moreover, since the pattern of inter-industry knowledge diffusion may be different from what is suggested by production I-O tables, I also construct a matrix of inter-industry knowledge flow in light of Cai and $\mathrm{Li}$ (2014). Each element in the diffusion matrix is defined as the share of patent citation from industry $i$ to $j$. The simulated model slightly outperforms the one using I-O tables.

[Table 4 about here.]

The third robustness check concerns the sample choice. Table 5 reports the results of unconditional convergence from 1970 to 2010. The cost of using a longer sample period is that I have only 55 countries among which 25 are OECD countries. The results are generally consistent with

\footnotetext{
${ }^{16}$ The country-specific I-O tables are constructed from WIOD database (Timmer et al., 2015). Details can be found in the appendix.

${ }^{17}$ In light of Levchenko and Zhang (2016), I also reestimate the model using alternative interest rates (marginal product of capital (Caselli and Feyrer, 2007); full financial integration; WDI lending rates). The baseline results are essentially unchanged.
} 
those obtained from the benchmark sample. The model predicts lower rate of convergence in TFP than data, mainly because some important sources of idea flows like Germany are no longer in the sample and neither are many technology receives such as Eastern European countries ${ }^{18}$ Column (5) reports results of import share, an indirect reduced-form measure of a country's export capability. The convergence rate suggested by the model is remarkably similar to the data. Table 6 compares convergence in TFP by industry ${ }^{19}$. For a majority of industries, the rate of convergence is comparable. For industries that are heavily endowment-driven like Coke and petroleum products, the model fails to capture lack of convergence in the data, which suggests alternative mechanisms might be at work in these industries.

[Table 5 about here.]

[Table 6 about here.]

I also allow the diffusion parameter to be industry-specific. The convergence results are comparable to the benchmark simulation and reported in the online appendix. Table 7 reports calibrated industry-specific $\beta^{i}$ under two methods. Interestingly, $\beta^{i}$ is very similar across industries, ranging from 0.280 to 0.455 . This suggests that the baseline calibration which assumes industry-invariant $\beta$ is a good approximation.

[Table 7 about here.]

The implied decomposition of contribution to TFP growth is very robust across different specifications and samples. The calibrated model consistently suggests that international technology diffusion contributes about $60-70 \%$ to TFP growth while domestic knowledge exchange contributes the rest 30-40\%. The only exception is when I use the patent citation matrix as the diffusion matrix. According to Figure 11, international technology diffusion explains almost $80 \%$ of productivity growth, because the diffusion parameter $\beta$ is calibrated highest under this specification $^{20}$. Moreover, inter-industry diffusion also plays a larger role because off-diagonal terms are much larger in the patent citation matrix than production I-O tables.

Various specifications also yield comparable transition matrices. The model tends to underpredict transition probability in TFP, but for non-OECD countries, the model produces closer predictions to the data. Table 8 compares transition matrices over the longer sample period from 1970 to 2010 and suggests a similar finding. Given how well the convergence pattern has been reproduced in the model, it calls for additional channels to explain dynamism in industrial productivity beyond unconditional convergence.

[Figure 11 about here.]

[Table 8 about here.]

\footnotetext{
${ }^{18}$ Due to similar reason, the bilateral trade share tends to be over-estimated. The issue becomes increasingly severe over time because those emerging market economies that are excluded from the sample play a more and more important role in global trade.

${ }^{19}$ I also report convergence in RCA by industry in Table A5 in the appendix.

${ }^{20}$ The data is obtained from Method III $(\beta=0.397)$ using patent citation matrix.
} 


\section{Implications}

\section{1 "Key Players" in Technology Diffusion}

The calibrated model of technology diffusion gives rise to a complex network of industry-level technology diffusion. By putting industries into play, complexity arises from both international and inter-industry technology diffusion. For example, the textile industry in Pakistan may be affected by the electronics industry in Germany through imports. Therefore, each countryindustry pair potentially learns from $N \times I$ sources ( $N$ countries, $I$ industries). Denote the direct knowledge contribution from industry $i^{\prime}$ in country $n^{\prime}$ to industry $i$ in country $n$ by $\alpha_{n n^{\prime}}^{i i^{\prime}}$. I obtain $\alpha_{n n^{\prime}}^{i i^{\prime}}$ using Equation 24 and by construction $\sum_{n^{\prime}, i^{\prime}} \alpha_{n n^{\prime}}^{i i^{\prime}}=1$. If each country-industry pair is treated as a node, then the matrix $\alpha \equiv\left\{\alpha_{n n^{\prime}}^{i{ }^{\prime}}\right\}_{N I \times N I}$ is the adjacency matrix of a weighted directed network.

To find "key players", those countries (or country-industry pairs) that contribute most to the global productivity growth through technology diffusion, I need to define centrality measures ${ }^{21}$ in the global diffusion network. The first centrality measure is defined as a country's average direct contribution to world productivity growth

$$
C_{n}^{\text {Direct }}=\frac{\sum_{n^{\prime}, i, i^{\prime}} \alpha_{n^{\prime} i}^{i^{\prime} i}}{\sum_{n, n^{\prime}, i, i^{\prime}} \alpha_{n^{\prime} n}^{i^{\prime} i}} ; \quad C_{n, i}^{\text {Direct }}=\frac{\sum_{n^{\prime}, i^{\prime}} \alpha_{n^{\prime} n}^{i^{\prime} i}}{\sum_{n, n^{\prime}, i, i^{\prime}} \alpha_{n^{\prime} n}^{i^{\prime} i}} .
$$

Table A7 reports each of top 5 OECD country's contribution to global technology diffusion from 1990 to 2010. I also report the weighted-average contribution of which weights are given by industry-level output share. It can be seen from the table that simple average yields similar rankings as weighted average, but the share of contribution varies substantially. The weightedaverage centrality measure suggests that USA and Germany contribute to almost $40 \%$ of global knowledge spillover. As a comparison, I also include five major emerging market economies ("BRICS") in the table, among which China's contribution is very close to those leading OECD countries. Table A7 also reports rankings under two alternatives of the diffusion matrix: countryspecific production I-O tables and the patent citation matrix. The results are qualitatively unchanged. In the appendix, Table A6 reports contribution to TFP growth by period. It can be clearly seen from the table that China plays an increasingly important in global technology diffusion. By the end of the sample, China's contribution to global TFP growth has surpassed major industrialized economies like UK, Italy and France, being very close to Japan, the third main contributor to idea flows for last two decades.

\section{[Table 9 about here.]}

Table 10 reports each of top 10 country-industry pair's contribution to global technology diffusion. Across different measures, the ranking largely agrees with each other. The top-10

\footnotetext{
${ }^{21} \mathrm{~A}$ variety of centrality measures have been proposed by earlier work such as Duernecker et al. (2014) and Kali and Reyes (2007) and studied in relation to economic growth. In contrast, my centrality measures are closely tied to the model, thereby having more structural interpretations.
} 
list is almost exclusively comprised of four high-tech industries, vehicles, machinery, electronics, and measurement, from USA, Japan, and Germany. This table also suggests that distribution of contribution to technology diffusion is extremely skewed. According to the weighted-average centrality, among 1224 (72 countries multiplied by 17 industries), the top 10 country-industry pairs contribute more than one-quarter to global TFP growth.

[Table 10 about here.]

Our second centrality measure concerns the extensive margin of global knowledge flows. Define the degree centrality of a country or a country-industry pair as follows

$$
C_{n}^{\text {Degree }}=\sum_{n^{\prime}, i, i^{\prime}} \mathbf{1}_{\alpha_{n^{\prime} n}^{i^{\prime} i} \geq \zeta} ; \quad C_{n, i}^{\text {Degree }}=\sum_{n^{\prime}, i^{\prime}} \mathbf{1}_{\alpha_{n^{\prime} n}^{i^{\prime} i} \geq \zeta},
$$

where $\mathbf{1}$ is an indicator function and $\zeta$ is a pre-specified cutoff. The list of "key players" can be found in the appendix. Under this definition, global diffusion network is reduced to an unweighted directed graph. Figure 12 illustrates the evolution of global diffusion network. When $\zeta=10^{-4}$, the approximately-linear fitted line in the log-log plot suggests that the degree distribution resembles a scale-free distribution ${ }^{22}$ and this line seems flattened out over time. When I pick a smaller cutoff $\zeta=10^{-5}$, the degree distribution becomes more interesting. In the last period, the distribution is U-shaped with a very heavy right tail, suggesting that many country-industry pairs play a significant role in global knowledge diffusion. Similar to Kali and Reyes (2007), Figure 13 plots the Lorenz curve of degree in knowledge diffusion. I also plot import share for comparison. The global diffusion network is highly asymmetric where knowledge mainly comes from a handful of countries.

[Figure 12 about here.]

[Figure 13 about here.]

The third centrality measure concerns substitutability of a country in the global diffusion network. Suppose that country $n$ completely closes its border. In the absence of trade between country $n$ and the rest of the world, the structure of idea flows changes. A country's importance in technology diffusion can be assessed by the change of TFP growth under this counter-factual. Table 11 reports change of TFP growth from 1990 to 2010 if a given country becomes autarkic. The second and fifth columns are the simple average of counter-factual TFP growth of the rest of the world. Dropping a country from the global trade network always has a negative impact on world TFP growth, although the TFP growth may accelerate for some countries under the counter-factual. Consistent with the first centrality measure, US, Germany, and Japan remain the top three countries that have the greatest impact on technology diffusion. However, the difference between leading economies and laggards are no longer significant, because if a country's

\footnotetext{
${ }^{22}$ However, it is a not a scale-free network, because the estimated scale parameter (slope of the fitted line) is close to one, not in between two and three.
} 
trade partner becomes autarkic, this country can always find a second best from the rest of the world. Taking into account endogenous change of trade pattern, the counter-factual exercise suggests that substitutability of a country is not as high as is traditionally thought from the perspective of technology diffusion. On the other hand, the third and sixth columns indicate that a country's TFP growth is significantly dampened under autarky, and this is even true for developed countries. The average decline of TFP growth of its own economy is comparable between OECD and non-OECD economies.

[Table 11 about here.]

\subsection{Dynamic Gains from Trade}

Another important implication of the quantitative model is that idea flows give rise to dynamic gains from trade. As opening up to trade exposes a country to exporters with better technology, improved learning opportunity speeds up TFP growth and thus real income growth. To decompose total gains from trade into static and dynamic components, I conduct two thought experiments. I first consider the change of real income for a country to move from Autarky to the level of openness of the period 2005 - 2010. This captures the standard static gains from trade. On average the static gains from trade are about $20 \%$ of a country's real income. This echoes the earlier findings in the literature that static gains from trade are generally modest (Arkolakis et al., 2012; Costinot and Rodríguez-Clare, 2014). Notice that static gains from trade decreases with trade elasticity $(\theta)$ and elasticity of substitution $(1 /(1-\kappa))$ across industries. Therefore, the static gains from trade become substantially larger if Cobb-Douglas aggregator is used for final consumption goods $(\kappa=0)$, and if higher trade elasticity is picked then the gains from trade become much smaller ${ }^{23}$.

The second thought experiment concerns dynamic gains from trade. It is defined as the percentage-point change of a country's real income if this country learns from its trade partners rather than only its domestic producers, conditional on the fact that in both scenarios it opens up to international trade. In other words, the dynamic gains from trade are the additional welfare gains for a country to move from autarky to openness in the sense of knowledge diffusion. Similar to earlier theoretical work (Redding, 1999), I calculate discounted sum of future real incomes to measure dynamic effects of international trade. The dynamic gains from trade account for on average $6.07 \%$ of real GDP for OECD economies and $12.34 \%$ for non-OECD economies. NonOECD economies enjoy much higher dynamic gains because of the strong convergence effects. According to the baseline calibration, dynamic gains from trade are about one third of the static gains from trade, but this should be treated as a lower bound. I use the baseline calibrated diffusion parameters $(\beta=0.285 ; \eta=14.18)$ for calculation of all the future periods, which has the implication that the TFP growth rate of the global economy converges to zero. If $\eta$ is also allowed to grow (as is suggested by data), the dynamic gains from trade will be even larger.

[Figure 14 about here.]

\footnotetext{
${ }^{23}$ For example, the gains from trade decline by two-thirds if $\theta=8.28$.
} 


\section{Conclusion}

In this paper, I build up a dynamic multi-industry model of international trade and technology diffusion to investigate the sources of comparative advantage. By putting industries into play, my model generates quantitative implications on evolution of Ricardian comparative advantage. Dynamic properties implied by the calibrated model is broadly consistent with key features in the data: unconditional convergence and substantial turnover of export industries. Our empirical results suggest that international technology diffusion plays a more important role than domestic technology diffusion in shaping a country's comparative advantage.

This paper can be extended in several dimensions. First, it would be of great interest to incorporate multinational production into this framework. A large literature studies how multinational production affects productivity of domestic firms, but little work has been done at the industry level concerning how technology diffuses through multinational production in a dynamic general equilibrium framework. The main barrier is the availability of data. Even the most comprehensive industry-level database of multinational production only covers less than 10 years of data and predominantly consists of OECD countries (Alviarez, 2015; Fukui and Lakatos, 2012). Second, while the assumption of perfectly competitive markets buys tractability of the model, it also eliminates the problem of free-riding that is identified as the major hurdle to successful localization of foreign technology in developing countries (Hausmann and Rodrik, 2003). Introducing alternative market structures that lead to negative externality of knowledge diffusion is another promising avenue for future research. Last, since firms do not internalize the benefits of idea flows, it opens the door for government intervention. Questions on optimal trade and industrial policies call for a richer framework amenable for quantitative policy analysis.

\section{References}

Acemoglu, Daron, Introduction to Modern Economic Growth, Princeton University Press, 2008.

_ , Vasco M Carvalho, Asuman Ozdaglar, and Alireza Tahbaz-Salehi, "The Network Origins of Aggregate Fluctuations," Econometrica, 2012, 80 (5), 1977-2016.

Acharya, Ram C and Wolfgang Keller, "Technology Transfer Through Imports," Canadian Journal of Economics/Revue canadienne d'économique, 2009, 42 (4), 1411-1448.

Alvarez, Fernando E, Francisco J Buera, and Robert E Lucas Jr, "Idea Flows, Economic Growth, and Trade," NBER Working Paper, 2013.

Alviarez, Vanessa, "Multinational Production and Comparative Advantage," Working Paper, 2015.

Anderson, James E and Eric van Wincoop, "Gravity with Gravitas: A Solution to the Border Puzzle," American Economic Review, 2003, 93 (1), 170-192. 
Arkolakis, Costas, Arnaud Costinot, and Andrés Rodríguez-Clare, "New trade models, same old gains?," The American Economic Review, 2012, 102 (1), 94-130.

Artopoulos, Alejandro, Daniel Friel, and Juan Carlos Hallak, "Export Emergence of Differentiated Goods from Developing Countries: Export Pioneers and Business Practices in Argentina," Journal of Development Economics, 2013, 105, 19-35.

Bandiera, Oriana and Imran Rasul, "Social Networks and Technology Adoption in Northern Mozambique*," Economic Journal, 2006, 116 (514), 869-902.

Bartlesman, Eric and Wayne B Gray, "The NBER Manufacturing Productivity Database," 1996.

Buera, Francisco J and Ezra Oberfield, "The Global Diffusion of Ideas," NBER Working Paper, 2016.

Cai, Jie and Nan Li, "Growth Through Intersectoral Knowledge Linkages," Working Paper, 2014.

_ and _ , "The Composition of Knowledge and Cross-Country Income Differences," Working Paper, 2016.

Caliendo, Lorenzo and Fernando Parro, "Estimates of the Trade and Welfare Effects of NAFTA," Review of Economic Studies, 2014, 82 (1), 1-44.

Carvalho, Vasco M., "From Micro to Macro via Production Networks," Journal of Economic Perspectives, 2014, 28 (4), 23-47.

Caselli, Francesco and James Feyrer, "The Marginal Product of Capital," The Quarterly Journal of Economics, 2007, pp. 535-568.

Coe, David T and Elhanan Helpman, "International R\&D Spillovers," European Economic Review, 1995, $39(5), 859-887$.

Conley, Timothy G. and Christopher R. Udry, "Learning about a New Technology: Pineapple in Ghana," American Economic Review, 2010, 100 (1), 35-69.

Costinot, Arnaud and Andrés Rodríguez-Clare, "Trade Theory with Numbers: Quantifying the Consequences of Globalization," Handbook of International Economics, 2014, 4, 197-261.

_ , Dave Donaldson, and Ivana Komunjer, "What Goods Do Countries Trade? A Quantitative Exploration of Ricardo's Ideas," Review of Economic Studies, 2012, 79 (2), 581-608.

Duernecker, Georg, Moritz Meyer, and Fernando Vega-Redondo, "The Network Origins of Economic Growth," Working Paper, 2014.

Easterly, William and Ariell Reshef, "African Export Successes: Surprises, Stylized Facts, and Explanations," NBER Working Paper, 2010.

Eaton, Jonathan and Samuel Kortum, "International Technology Diffusion: Theory and Measurement," International Economic Review, 1999, 40 (3), 537-570.

_ and _ , "Trade in Capital Goods," European Economic Review, 2001, 45 (7), 1195-1235.

_ and _ , "Technology, Geography, and Trade," Econometrica, 2002, 70 (5), 1741-1779.

Fadinger, Harald and Pablo Fleiss, "Trade and Sectoral Productivity," Economic Journal, 2011, 121 (555), $958-989$. 
Feenstra, Robert C, Robert E Lipsey, Haiyan Deng, Alyson C Ma, and Hengyong Mo, "World Trade Flows: 1962-2000," NBER Working Paper, 2005.

_ , Robert Inklaar, and Marcel P Timmer, "The next generation of the Penn World Table," The American Economic Review, 2015, 105 (10), 3150-3182.

Finicelli, Andrea, Patrizio Pagano, and Massimo Sbracia, "Ricardian Selection," Journal of International Economics, 2013, 89 (1), 96-109.

Foster, Andrew D and Mark R Rosenzweig, "Learning by Doing and Learning from Others: Human Capital and Technical Change in Agriculture," Journal of Political Economy, 1995, pp. 1176-1209.

Fukui, Tani and Csilla Lakatos, "A Global Database of Foreign Affiliate Activity," Working Paper, 2012.

Gisselquist, David and Grether Jean-Marie, "An Argument for Deregulating the Transfer of Agricultural Technologies to Developing Countries," World Bank Economic Review, 2000, 14 (1), 111-127.

Grossman, Gene M and Elhanan Helpman, Innovation and Growth in the Global Economy, MIT press, 1993.

Hall, Bronwyn H, Adam B Jaffe, and Manuel Trajtenberg, "The NBER patent citation data file: Lessons, insights and methodological tools," NBER Working Paper, 2001.

Hanson, Gordon H, "The Rise of Middle Kingdoms: Emerging Economies in Global Trade," Journal of Economic Perspectives, 2012, 26 (2), 41-64.

Hanson, Gordon H., Nelson Lind, and Marc-Andreas Muendler, "The Dynamics of Comparative Advantage," NBER Working Paper, 2016.

Hausmann, Ricardo and Dani Rodrik, "Economic Development as Self-Discovery," Journal of Development Economics, 2003, 72 (2), 603-633.

_ , Jason Hwang, and Dani Rodrik, "What You Export Matters," Journal of Economic Growth, 2007,12 (1), 1-25.

Head, Keith, Thierry Mayer et al., "Gravity Equations: Toolkit, Cookbook, Workhorse," Handbook of International Economics, 2013, 4, 131-195.

Hidalgo, César A, Bailey Klinger, A-L Barabási, and Ricardo Hausmann, "The Product Space Conditions the Development of Nations," Science, 2007, 317 (5837), 482-487.

Hwang, Jason, "Introduction of New goods, Convergence and Growth," Working Paper, 2006.

Jaffe, Adam B, "Technological Opportunity and Spillovers of R \& D: Evidence from Firms' Patents, Profits, and Market Value," American Economic Review, 1986, pp. 984-1001.

Kali, Raja and Javier Reyes, "The Architecture of Globalization: a Network Approach to International Economic Integration," Journal of International Business Studies, 2007, 38 (4), 595-620.

_ , _, Josh McGee, and Stuart Shirrell, "Growth Networks," Journal of Development Economics, 2012.

Keller, Wolfgang, "Geographic Localization of International Technology Diffusion," American Economic Review, 2002, 92 (1), 120-142.

_ , "Trade and the Transmission of Technology," Journal of Economic Growth, 2002, 7 (1), 5-24. 
_ , "International Technology Diffusion," Journal of Economic Literature, 2004, 42 (3), 752-782.

Kortum, Samuel S, "Research, Patenting, and Technological Change," Econometrica, 1997, pp. 1389-1419.

Lederman, Daniel and William Maloney, Does what You Export Matter?: In Search of Empirical Guidance for Industrial Policies, World Bank Publications, 2012.

Levchenko, Andrei A and Jing Zhang, "The evolution of sectoral productivity: Measurement and welfare implications," Journal of Monetary Economics, 2016, 78, 96-111.

Lucas, Robert E and Benjamin Moll, "Knowledge Growth and the Allocation of Time," Journal of Political Economy, 2014, 122 (1), 1-51.

Perla, Jesse and Christopher Tonetti, "Equilibrium Imitation and Growth," Journal of Political Economy, 2014, 122 (1), 52-76.

_ , _, and Michael E Waugh, "Equilibrium Technology Diffusion, Trade, and Growth," NBER Working Paper, 2015.

Proudman, James and Stephen Redding, "Evolving Patterns of International Trade," Review of International Economics, 2000, 8 (3), 373-396.

Ramondo, Natalia, Andrés Rodríguez-Clare, and Milagro Saborío-Rodríguez, "Trade, Domestic Frictions, and Scale effects," American Economic Review, forthcoming.

Redding, Stephen, "Dynamic comparative advantage and the welfare effects of trade," Oxford economic papers, 1999, 51 (1), 15-39.

_ , "Specialization Dynamics," Journal of International Economics, 2002, 58 (2), 299-334.

Rodrik, Dani, "The Past, Present, and Future of Economic Growth," Working Paper, 2013.

_ , "Unconditional Convergence in Manufacturing," Quarterly Journal of Economics, 2013, 128 (1), 165-204.

Sabel, Charles, Eduardo Fernández-Arias, Ricardo Hausmann, Andrlés Rodríguez-Clare, and Ernesto H. Stein, Export Pioneers in Latin America, Inter-American Development Bank, 2012.

Sampson, Thomas, "Dynamic selection: an idea flows theory of entry, trade and growth," 2016, 131 (1), 315-380.

Samuelson, Paul A, "The Transfer Problem and Transport Costs, II: Analysis of Effects of Trade Impediments," Economic Journal, 1954, pp. 264-289.

Shikher, Serge, "Capital, technology, and specialization in the neoclassical model," Journal of international Economics, 2011, 83 (2), 229-242.

_ , "Putting Industries into the Eaton-Kortum Model," The Journal of International Trade 83 Economic Development, 2012, 21 (6), 807-837.

Silva, JMC Santos and Silvana Tenreyro, "The log of gravity," The Review of Economics and statistics, 2006, 88 (4), 641-658.

Somale, Mariano, "Comparative Advantage in Innovation and Production," Working Paper, 2014. 
Timmer, Marcel P, Erik Dietzenbacher, Bart Los, Robert Stehrer, and Gaaitzen J Vries, "An illustrated user guide to the world input-output database: the case of global automotive production," Review of International Economics, 2015, 23 (3), 575-605.

Waugh, Michael, "International Trade and Income Differences," American Economic Review, 2010,100 (5), 2093-2124.

Young, Alwyn, "Learning by Doing and the Dynamic Effects of International Trade," Quarterly Journal of Economics, 1991, pp. 369-405.

Yu, Run, Junning Cai, and PingSun Leung, "The Normalized Revealed Comparative Advantage Index," The Annals of Regional Science, 2009, 43 (1), 267-282. 


\section{A List of Symbols}

\begin{tabular}{|c|c|}
\hline$N, I$ & number of countries, number of industries \\
\hline$w_{n, t}, r_{n, t}$ & wage rate, rental rate \\
\hline$s_{n, t}$ & saving rate \\
\hline$D_{n, t}$ & trade deficit \\
\hline$E_{n, t}$ & total expenditure \\
\hline$I_{n, t}$ & total investment \\
\hline$Y_{n, t}, Y_{n, t}^{i}$ & country-level, industry-level demand of final goods \\
\hline$L_{n, t}, L_{n, t}^{i}, \ell_{n, t}^{i}$ & country-, industry-, variety-level input of labor \\
\hline$K_{n, t}, K_{n, t}^{i}, k_{n, t}^{i}$ & country-, industry-, variety-level input of capital \\
\hline$P_{n, t}, P_{n, t}^{i}, p_{n, t}^{i}$ & country-, industry-, variety-level price \\
\hline$Q_{n, t}^{i}, q_{n, t}^{i}$ & industry-level, variety level total demand \\
\hline$c_{n, t}^{i}$ & industry-level unit cost of an input bundle \\
\hline$F_{n, t}^{i}$ & industry-level productivity distribution (Fréchet) \\
\hline$G_{n, t}^{i, D}, G_{n, t}^{i, F}$ & source distribution of intra-industry learning from domestic and foreign producers \\
\hline$G_{n, t}^{i i^{\prime}, D}, G_{n, t}^{i i^{\prime}, F}$ & source distribution of inter-industry learning from domestic and foreign producers \\
\hline$z_{n, t}^{i}$ & variety-level productivity \\
\hline$m_{n, t}^{i i^{\prime}}$ & variety-level input of composite intermediate goods from industry $i^{\prime}$ \\
\hline$d_{n n^{\prime}, t}^{i}$ & iceberg shipping cost from country $n^{\prime}$ to $n$ \\
\hline$\kappa$ & elasticity of substitution across tradeable industries $=1 /(1-\kappa)$ \\
\hline$\phi_{n}$ & share of tradeable consumption \\
\hline$\chi_{n, t}$ & population growth rate \\
\hline$\delta_{n, t}$ & depreciation rate \\
\hline$\beta^{i}$ & Cobb-Douglas share of learning from other firms \\
\hline$\nu^{i}$ & variety of industry $i$ \\
\hline$\sigma^{i}$ & elasticity of substitution across varieties \\
\hline$\theta^{i}$ & dispersion parameter of Fréchet distribution (trade elasticity) \\
\hline$\tau^{i i^{\prime}}$ & dispersion adjustment parameter in inter-industry learning \\
\hline$\omega_{n}^{i}$ & share parameter of industry $i$ across tradeable goods \\
\hline$\gamma^{i L}, \gamma^{i K}$ & variety-level labor share, capital share \\
\hline$\gamma_{n}^{i i^{\prime}}$ & variety-level input share from industry $i^{\prime}$ to industry $i$ \\
\hline$\lambda_{n, t}^{i}$ & location parameter of Fréchet distribution (industrial productivity) \\
\hline$\eta_{n, t}^{i}$ & arrival rate of intra-industry learning from domestic and foreign producers \\
\hline$\eta_{n, t}^{i i^{\prime}}$ & arrival rate of inter-industry learning from domestic and foreign producers \\
\hline$\pi_{n n^{\prime}, t}^{i}$ & share of expenditure on imports from country $n^{\prime}$ \\
\hline
\end{tabular}




\section{B Proofs and Theoretical Extensions}

\section{B.1 Instantaneous Equilibrium}

Given labor and capital endowment $\left\{L_{n}\right\}_{n=1}^{N}$ and $\left\{K_{n}\right\}_{n=1}^{N}$, trade deficits $\left\{D_{n}\right\}_{n=1}^{N}$, bilateral industry-level trade costs $\left\{d_{n n^{\prime}}^{i}\right\}_{n=1, n^{\prime}=1, i=1}^{N, N, I}$ instantaneous equilibrium is obtained by solving Equation 1 - 12 for total expenditures $\left\{E_{n}\right\}_{n=1}^{N}$, wage rates $\left\{w_{n}\right\}_{n=1}^{N}$, rental rates $\left\{r_{n}\right\}_{n=1}^{N}$, industrial price levels $\left\{P_{n}^{i}\right\}_{n=1, i=1}^{N, I+1}$, industrial final demand $\left\{Y_{n}^{i}\right\}_{n=1, i=1}^{N, I+1}$, industrial unit costs of input bundle, $\left\{c_{n}^{i}\right\}_{n=1, i=1}^{N, I+1}$, industrial total demand $\left\{Q_{n}^{i}\right\}_{n=1, i=1}^{N, I+1}$, industrial labor employment $\left\{L_{n}^{i}\right\}_{n=1, i=1}^{N, I+1}$, industrial capital stock $\left\{K_{n}^{i}\right\}_{n=1, i=1}^{N, I+1}$, and industrial trade flows $\left\{\pi_{n n^{\prime}}^{i}\right\}_{n=1, n^{\prime}=1, i=1}^{N, N, I+1}$. There are in total $N^{2}(I+1)+6 N(I+1)+3 N$ unknowns. Equilibrium conditions $1-12$ consist of $N^{2}(I+1)+6 N(I+1)+4 N$ equations, but $N$ equations are redundant, which can be seen as follows

$$
\begin{aligned}
E_{n}= & w_{n} L_{n}+r_{n} K_{n}+D_{n} \\
= & \sum_{i=1}^{I+1}\left(\gamma^{i L} \sum_{n^{\prime}=1}^{N} P_{n^{\prime}}^{i} Q_{n^{\prime}}^{i} \pi_{n^{\prime} n}^{i}+\gamma^{i K} \sum_{n^{\prime}=1}^{N} P_{n^{\prime}}^{i} Q_{n^{\prime}}^{i} \pi_{n^{\prime} n}^{i}+P_{n}^{i} Q_{n}^{i}-\sum_{n^{\prime}=1}^{N} P_{n^{\prime}}^{i} Q_{n^{\prime}}^{i} \pi_{n^{\prime} n}^{i}\right) \\
= & \sum_{i=1}^{I+1}\left(\gamma^{i L} \sum_{n^{\prime}=1}^{N} P_{n^{\prime}}^{i} Q_{n^{\prime}}^{i} \pi_{n^{\prime} n}^{i}+\gamma^{i K} \sum_{n^{\prime}=1}^{N} P_{n^{\prime}}^{i} Q_{n^{\prime}}^{i} \pi_{n^{\prime} n}^{i}-\sum_{n^{\prime}=1}^{N} P_{n^{\prime}}^{i} Q_{n^{\prime}}^{i} \pi_{n^{\prime} n}^{i}\right) \\
& +\sum_{i=1}^{I+1}\left(\sum_{i^{\prime}=1}^{I+1} \gamma_{n}^{i^{\prime} i} \sum_{n^{\prime}=1}^{N} P_{n^{\prime}}^{i^{\prime}} Q_{n^{\prime}}^{i^{\prime}} i_{n^{\prime} n}^{i^{\prime}}+P_{n}^{i} Y_{n}^{i}\right) \\
= & \sum_{i=1}^{I+1} P_{n}^{i} Y_{n}^{i}
\end{aligned}
$$

\section{B.2 Derivation of the Law of Motion of Industry-level Productivity}

Recall that the general form of law of motion of industry-level productivity under multiple channels of idea flows is given by

$$
\frac{d \lambda_{n, t}^{i}}{d t}=\sum_{s} \eta^{s} \int_{0}^{\infty} x^{\beta^{i} \theta^{i}} d G_{n, t}^{i, s}(x)
$$

In light of Buera and Oberfield (2016), I first derive expression of $\int_{0}^{\infty} x^{\beta^{i} \theta^{i}} d G_{n, t}^{i, s}(x)$ for each channel. 
1. Intra-industry learning from domestic and foreign sellers

$$
\begin{aligned}
\int_{0}^{\infty} x^{\beta^{i} \theta^{i}} d G_{n, t}^{i}(z) & =\int_{0}^{\infty} x^{\beta^{i} \theta^{i}} \sum_{n^{\prime}=1}^{N} \prod_{n^{\prime \prime} \neq n^{\prime}} F_{n^{\prime \prime}, t}^{i}\left(\frac{c_{n^{\prime \prime}, t}^{i} d_{n n^{\prime \prime}, t}^{i}}{c_{n^{\prime}, t}^{i} d_{n n^{\prime}, t}^{i}}\right) d F_{n^{\prime}, t}^{i}(x) \\
& =\sum_{n^{\prime}=1}^{N} \int_{0}^{\infty} x^{\beta^{i} \theta^{i}} \exp \left(-\sum_{n^{\prime \prime} \neq n^{\prime}} \lambda_{n^{\prime \prime}, t}^{i}\left(\frac{c_{n^{\prime \prime}, t}^{i} d_{n n^{\prime \prime}, t}^{i}}{c_{n^{\prime}, t}^{i} d_{n n^{\prime}, t}^{i}}\right)^{-\theta^{i}}\right) d \exp \left(-\lambda_{n^{\prime}, t}^{i} x^{-\theta^{i}}\right) \\
& =\sum_{n^{\prime}=1}^{N} \int_{0}^{\infty} y^{-\beta^{i}} \exp \left(-\sum_{n^{\prime \prime}=1}^{N} \lambda_{n^{\prime \prime}, t}^{i}\left(\frac{c_{n^{\prime \prime}, t}^{i} d_{n n^{\prime \prime}, t}^{i}}{c_{n^{\prime}, t}^{i} d_{n n^{\prime}, t}^{i}}\right)^{-\theta^{i}} y\right) d\left(\lambda_{n^{\prime}, t}^{i} y\right) \\
& =\sum_{n^{\prime}=1}^{N} \int_{0}^{\infty} y^{-\beta^{i}} \exp \left(-\frac{\lambda_{n^{\prime}, t}^{i} y}{\pi_{n n^{\prime}, t}^{i}}\right) d\left(\lambda_{n^{\prime}, t}^{i} y\right) \\
& =\Gamma\left(1-\beta^{i}\right) \sum_{n^{\prime}=1}^{N} \pi_{n n^{\prime}, t}^{i}{ }^{1-\beta^{i}} \lambda_{n^{\prime}, t}^{i} .
\end{aligned}
$$

2. Inter-industry learning from domestic and foreign sellers

$$
\begin{aligned}
& \int_{0}^{\infty} x^{\beta^{i} \theta^{i}} d G_{n, t}^{i i^{\prime}}(z)=\int_{0}^{\infty} x^{\beta^{i} \theta^{i}} \sum_{n^{\prime}=1}^{N} \prod_{n^{\prime \prime} \neq n^{\prime}} F_{n^{\prime \prime}, t}^{i^{\prime}}\left(\frac{c_{n^{\prime \prime}, t}^{i^{\prime}} i_{n n^{\prime \prime}, t}^{i^{\prime}}}{c_{n^{\prime}, t}^{j} i_{n n^{\prime}, t}^{\prime}}\right) d F_{n^{\prime}, t}^{i^{\prime}}(x) \\
& =\sum_{n^{\prime}=1}^{N} \int_{0}^{\infty} x^{\beta^{i} \theta^{i}} \exp \left(-\sum_{n^{\prime \prime} \neq n^{\prime}} \lambda_{n^{\prime \prime}, t}^{i^{\prime}}\left(\frac{c_{n^{\prime \prime}, t}^{i^{\prime}} d_{n n^{\prime \prime}, t}^{i^{\prime}}}{c_{n^{\prime}, t}^{i^{\prime}} d_{n n^{\prime}, t}^{i^{\prime}}}\right)^{-\theta^{i^{\prime}}}\right) d \exp \left(-\lambda_{n^{\prime}, t}^{i^{\prime}} x^{-\theta^{i^{\prime}}}\right) \\
& =\sum_{n^{\prime}=1}^{N} \int_{0}^{\infty} y^{-\beta^{i} \theta^{i} / \theta^{i^{\prime}}} \exp \left(-\sum_{n^{\prime \prime}=1}^{N} \lambda_{n^{\prime \prime}, t}^{i}\left(\frac{c_{n^{\prime \prime}, t}^{i} d_{n n^{\prime \prime}, t}^{i}}{c_{n^{\prime}, t}^{i} d_{n n^{\prime}, t}^{i}}\right)^{-\theta^{i}} y\right) d\left(\lambda_{n^{\prime}, t}^{i} y\right) \\
& =\sum_{n^{\prime}=1}^{N} \int_{0}^{\infty} y^{-\beta^{i} \theta^{i} / \theta^{i^{\prime}}} \exp \left(-\frac{\lambda_{n^{\prime}, t}^{i} y}{\pi_{n n^{\prime}, t}^{i}}\right) d\left(\lambda_{n^{\prime}, t}^{i} y\right) \\
& =\Gamma\left(1-\beta^{i} \theta^{i} / \theta^{i^{\prime}}\right) \sum_{n^{\prime}=1}^{N} \pi_{n n^{\prime}, t}^{i^{\prime}}{ }^{1-\beta^{i} \theta^{i} / \theta^{i^{\prime}}} \lambda_{n^{\prime}, t}^{i^{\prime} \beta^{i} \theta^{i} / \theta^{i^{\prime}}} .
\end{aligned}
$$

In the benchmark case, $\theta^{i}=\theta$ for any industry $i$. Given Equation B.2 and B.3, I obtain the law-of-motion of productivity as Equation 14.

\section{B.3 Adjustment of Industry-level Productivity Dispersion}

Consider firms in industry $i$ learn from firms in industry $i^{\prime}$. Once a new insight is drawn (with arrival rate $\tilde{\eta}$ ), the actual productivity is given by $z_{G}^{\tau^{i i^{\prime}} \beta^{i}} z_{H}^{1-\beta^{i}}$ where $z_{G}$ is a random drawn from the source distribution $G_{n, t}^{i i^{\prime}}(\cdot)$ and $z_{H}$ is drawn from an exogenous distribution $H^{i}(\cdot)$. With the adjustment parameter $\tau^{i i^{\prime}}$ of industrial productivity dispersion, the law of motion of industrial 
productivity can be rewritten as

$$
\frac{d}{d t} \ln F_{n, t}^{i}(z)=-\tilde{\eta} \int_{0}^{\infty}\left[1-G_{n, t}^{i i^{\prime}}\left(\frac{z^{1 /\left(\beta^{i} \tau^{i i^{\prime}}\right)}}{x^{\left(1-\beta^{i}\right) /\left(\beta^{i} \tau^{i i^{\prime}}\right)}}\right)\right] d H^{i}(x) .
$$

Assume that $H^{i}(z)=1-\left(z / z_{0}\right)^{-\tilde{\theta}^{i}}$. Let $\theta^{i} \equiv \tilde{\theta}^{i} /\left(1-\beta^{i}\right)$ and normalize $\eta \equiv \tilde{\eta} z_{0}^{\tilde{\theta}}$ to be a constant. It can be shown that

$$
\lim _{z_{0} \rightarrow 0} \frac{d}{d t} \ln F_{n, t}^{i}(z)=-\eta z^{-\theta^{i}} \int_{0}^{\infty} x^{\beta^{i} \theta^{i} \tau^{i i^{\prime}}} d G_{n, t}^{i}(x)
$$

if $\lim _{x \rightarrow \infty}\left[1-G_{n, t}^{i}(x)\right] x^{\beta^{i} \theta^{i} \tau^{i i^{\prime}}}=0$. Therefore, the industry-level productivity distribution still follows Fréchet with the law of motion of the position parameter $\lambda_{n, t}^{i}$ given by

$$
\frac{d \lambda_{n, t}^{i}}{d t}=\eta \int_{0}^{\infty} x^{\beta^{i} \theta^{i} \tau^{i i^{\prime}}} d G_{n, t}^{i}(x)
$$

Let $\tau^{i i^{\prime}}=\theta^{i^{\prime}} / \theta^{i}$. Equation B.3 is modified as follows

$$
\int_{0}^{\infty} x^{\beta^{i} \theta^{i}} d G_{n, t}^{i i^{\prime}}(z)=\Gamma\left(1-\beta^{i}\right) \sum_{m=1}^{N} \pi_{n m}^{i^{\prime}{ }^{1-\beta^{i}}} \lambda_{m}^{i^{\beta^{i}}}
$$

which coincide the results under the assumption of homogeneous industrial productivity dispersion.

\section{Data Description}

\section{C.1 Sample}

Following Levchenko and Zhang (2016), my sample consists of 72 countries and 17 manufacturing industries. The original data covers from 1963 to 2011. Details of the sample can be found in Table A1 and A2. I treat each five-year window as one period. To maximize the number of countries, especially non-OECD countries, the baseline sample is chosen to start from 1990 and end in 2010, so there are four periods in the baseline sample: 1991-1995, 1996-2000, 20012005, and 2006-2010. Within each five-year window, I calculate the median of each trade and production variable.

[Table A1 about here.]

[Table A2 about here.]

[Table A3 about here.] 


\section{C.2 Trade data}

The trade data is obtained from World Trade Flows bilateral data (Feenstra et al., 2005) and further extended using UN comtrade database for post-2000 periods. The original trade sample is organized at the level of 4-digit SITC code (rev. 2). It is aggregated up to the level of 2-digit ISIC code (rev. 3) by using two concordances from 4-digit SITC (rev. 2) to 3-digit ISIC (rev. 2) and from 3-digit $\operatorname{ISIC}^{24}$ (rev. 2) to 2-digit $\operatorname{ISIC}^{25}$ (rev. 3). By restricting the sample to 72 countries, about one quarter of the total trade volume is excluded. I also include zero trade flows in the sample whenever PPML is employed in estimation.

\section{C.3 Production data}

The production data is obtained from UNIDO INDSTAT 2 database (version 2015). The database includes seven production variables at the cross-country industry level: output, value added, wages and salaries, gross fixed capital formation, employment, female employment, and number of establishments. Since the database contains information both at the industry level and for the whole manufacturing sector. Observations are dropped if the aggregated manufacturing total is more than $20 \%$ larger or smaller than the reported total. For countries with missing production data but non-missing trade data, I impute industrial output level using linear interpolation and extrapolation. Observations are dropped if total output (original or imputed) is smaller than total export.

\section{C.4 Other data}

Bilateral variables. CEPII gravity database (Head et al., 2013) provides me with most of the bilateral gravity variables: bilateral distance weighted by population, dummy variables of contiguity, common official primary language, common currency union, and free trade areas. The database is updated until 2006, so it is extended to incorporate new regional trade agreements ${ }^{26}$ and currency unions from 2006 onwards.

Production parameters. For tradeable industries, share of wage bill $\gamma^{i L}$ is obtained by the cross-country median of industry-level wage and salary payment as share of industrial output, and share of rental payment $\gamma^{i K}$ is obtained by the cross-country median of difference between value added and wage bill as share of output. These variables all come from UNIDO INDSTAT database. For the nontradeable industry, $\gamma^{i L}$ and $\gamma^{i K}$ are obtained from US 1997 I-O table. I also use US 1997 I-O table to obtain country-invariant I-O coefficients $\gamma^{i i^{\prime}}$ and cross check $\gamma^{i L}$ and $\gamma^{i K}$ of tradeable industries obtained from cross-country data.

I also obtain country-specific and time-variant I-O tables from WIOD database (Timmer et al., 2015). Among 72 economies in my sample, 34 economies are included in WIOD database (Brazil, Bulgaria, Canada, China, Czech, Denmark, Finland, France, Germany, Greece, Hungary,

\footnotetext{
${ }^{24}$ Source: Marc Muendler's personal website, last retrieved: 8/11/2015.

${ }^{25}$ Source: United Nations Statistics Division, last retrieved: 8/15/2015.

${ }^{26}$ Source: WTO Regional Trade Agreements Database, last retrieved: 6/20/2016.
} 
India, Indonesia, Ireland, Italy, Japan, Korea, Mexico, Netherlands, Poland, Portugal, Romania, Russia, Solvakia, Slovenia, Spain, Sweden, Taiwan, Turkey, UK, USA). I apply the rest-of-world (ROW) I-O table to the rest 38 economies. The database covers the period from 1995 to 2011. The data is at 2-digit ISIC level, which is slightly modified to match the industry aggregation of the sample.

Preference parameters. share parameters of tradeable goods $\omega^{i}$ is obtained from Levchenko and Zhang (2016). For the share of tradeable goods consumption $\phi_{n}$, I first aggregate up consumption shares of current-price durable, semi-durable, and non-durable goods using national accounts from OECD countries ${ }^{27}$. Then I estimate the tradeable consumption share of other countries by fitting a linear relationship between the share of manufacturing consumption and GDP per capita. Elasticity of substitution across tradeable consumption goods $1 /(1-\kappa)$ is given by 2 .

Relative cost terms. To calculate cross-country wage rate $w_{n, t}$, I first obtain aggregate labor income by multiplying PPP-adjusted real GDP by labor income share where both variables are available in PWT. If labor income share is missing, I use the share of wage bills in value-added from INDSTAT2 if available and fill out the rest missing observations by interpolation. The total effective employment count is given by the product of the number of persons engaged and average country-level human capital where both variables also come from PWT. For very few countries (such as Ethiopia and Nigeria), I fill out their human capital by fitting a linear relationship between human capital and real GDP per capita. As a crude measure, rental rate $r_{n, t}$ is given by the non-labor income divided by real capital stock. Relative price indices of tradeable industries can be obtained from competitiveness measure (estimated as fixed effect in the gravity equation) and domestic absorption rate (obtained from bilateral trade and output data) according to Equation 20. Relative price in the nontradeable sector is obtained from the International Comparison Program. I use observations from seven benchmark years (1970, 1975, 1980, 1985, 1996, 2005, and 2011) to fit a linear relationship between nontradeable price index and GDP per capita ${ }^{28}$. Before plugging in these relative terms for Equation 21, the last complication arises from the fact that competitiveness estimates may not be available for each industry while it is essential for calculation of relative costs due to input-output linkages. To address this, I scale up input shares of those industries who competitiveness estimates are nonmissing proportionally so that the sum of input shares remains equal to one. All variables are normalized by US levels.

US TFP series. US industry-level TFP in the tradeable sector is obtained from NBER-CES Manufacturing Industry Database. The TFP series in the nontradeable sector is obtained in two steps. I first calculate the nontradeable TFP for the benchmark year, 2005, by combining information from NBER-CES database and PWT. Then the time series is obtained by using TFP growth rate in the US nontradeable sector from World-KLEMS database.

Country-specific variables: PWT also gives me the following country-specific variables: labor

\footnotetext{
${ }^{27}$ Source: OECD Final Consumption Expenditure of Households (Detailed National Accounts, SNA 2008), last retrieved: $6 / 20 / 2016$.

${ }^{28} \mathrm{~A}$ variety of alternative fitting schemes are discussed in detail by Feenstra et al. (2015).
} 
and capital endowment $L_{n, t}$ and $K_{n, t}$, saving rate $S_{n, t} /\left(w_{n, t} L_{n, t}+r_{n, t} K_{n, t}\right)$, investment rate $I_{n, t} /\left(w_{n, t} L_{n, t}+r_{n, t} K_{n, t}\right)$, depreciation rate $\delta_{n, t}$, country-level price index $P_{n, t}$, real GDP $Y_{n, t}$, and country-level TFP growth rate.

Patent citation: The NBER US patent citation data (Hall et al., 2001) contains pairwise patent citation information from 1976 to 2006. I construct the citation matrix at 2-digit ISIC level by mapping international patent classification code to US SIC code ${ }^{29}$ and then to ISIC code. The time-variant diffusion matrix is simply constructed by calculating the share of inter-industry patent citation for each 5-year window.

\section{Additional Tables}

[Table A4 about here.]

[Table A5 about here.]

[Table A6 about here.]

[Table A7 about here.]

\footnotetext{
${ }^{29}$ The concordance can be found in Brian Silverman's personal website, last retrieved: 8/19/2016.
} 
Figure 1: Export Share: 1990 versus 2010

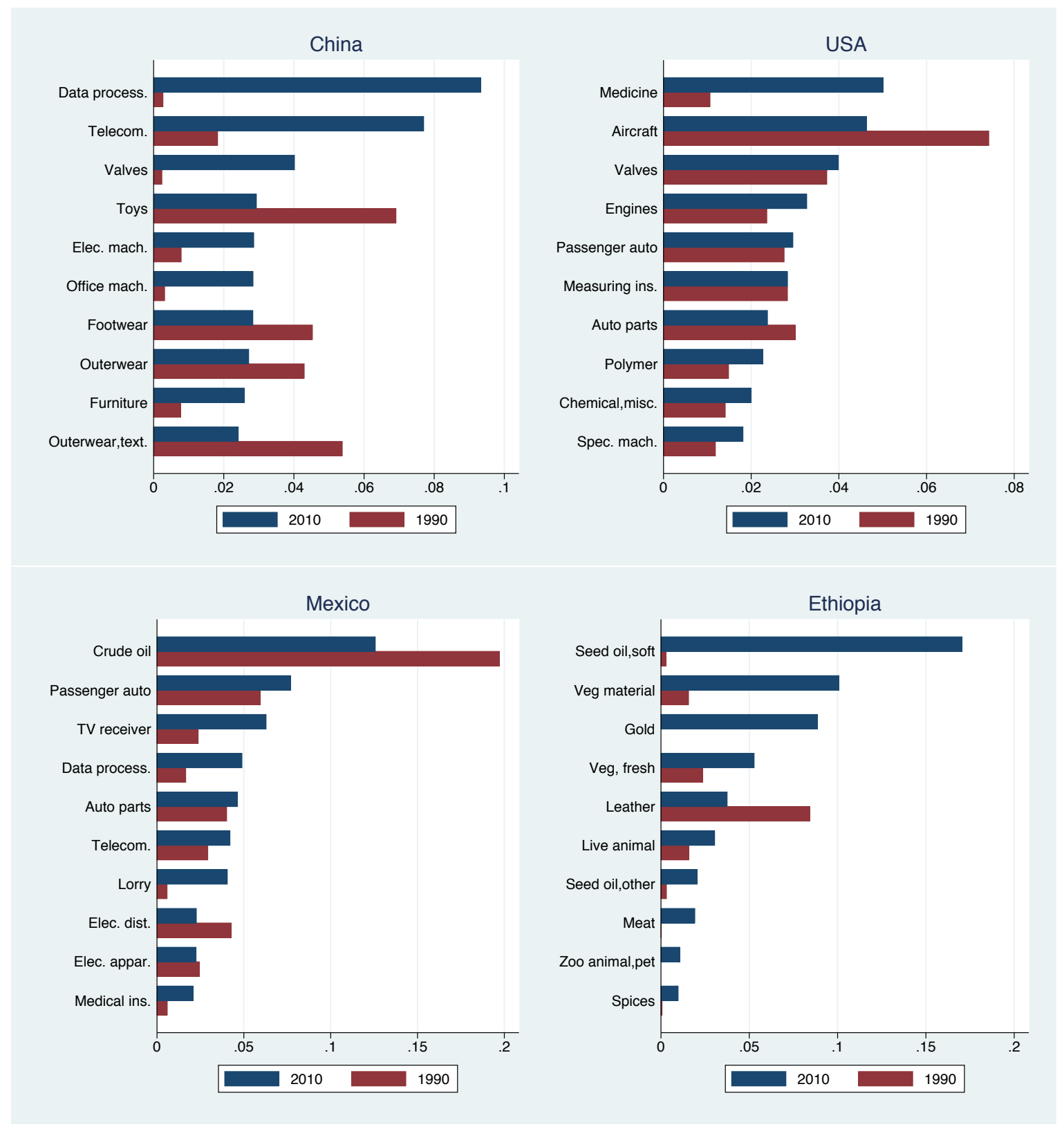

Notes: (1) The data source is comtrade (3-digit SITC, Rev. 2); (2) I pick top 10 industries in terms of export share in 2009-2011 and compare their export shares in 1989-1991. The only exception is that I omit coffee industry in Ethiopia (export share drops from $61 \%$ to $34 \%$ ) for better scaling. 
Figure 2: Transition Matrix from 1990 to 2010

\begin{tabular}{|c|c|c|c|c|c|c|}
\hline & \multicolumn{6}{|c|}{ Percentile in 1990} \\
\hline & & $0-5$ & $5-10$ & $10-15$ & $15-25$ & $25-100$ \\
\hline$\approx$ & $0-5$ & 0.33 & 0.07 & 0.04 & 0.06 & 0.50 \\
\hline.$\$$ & $5-10$ & 0.25 & 0.21 & 0.10 & 0.12 & 0.33 \\
\hline 跑 & $10-15$ & 0.10 & 0.19 & 0.13 & 0.16 & 0.43 \\
\hline है & $15-25$ & 0.04 & 0.09 & 0.11 & 0.18 & 0.58 \\
\hline & $25-100$ & 0.01 & 0.02 & 0.03 & 0.09 & 0.84 \\
\hline
\end{tabular}

Notes: (1) The data source is comtrade (3-digit SITC, Rev. 2); (2) Industries are ranked according to RCA index. The $i j$-th entry is the share of the $i$-th percentile industries in 2009-2011 that were in $j$-th percentile in 1989-1991; (3) Due to skewness in trade share, percentiles are divided unevenly. 
Figure 3: Convergence to Trade Partners

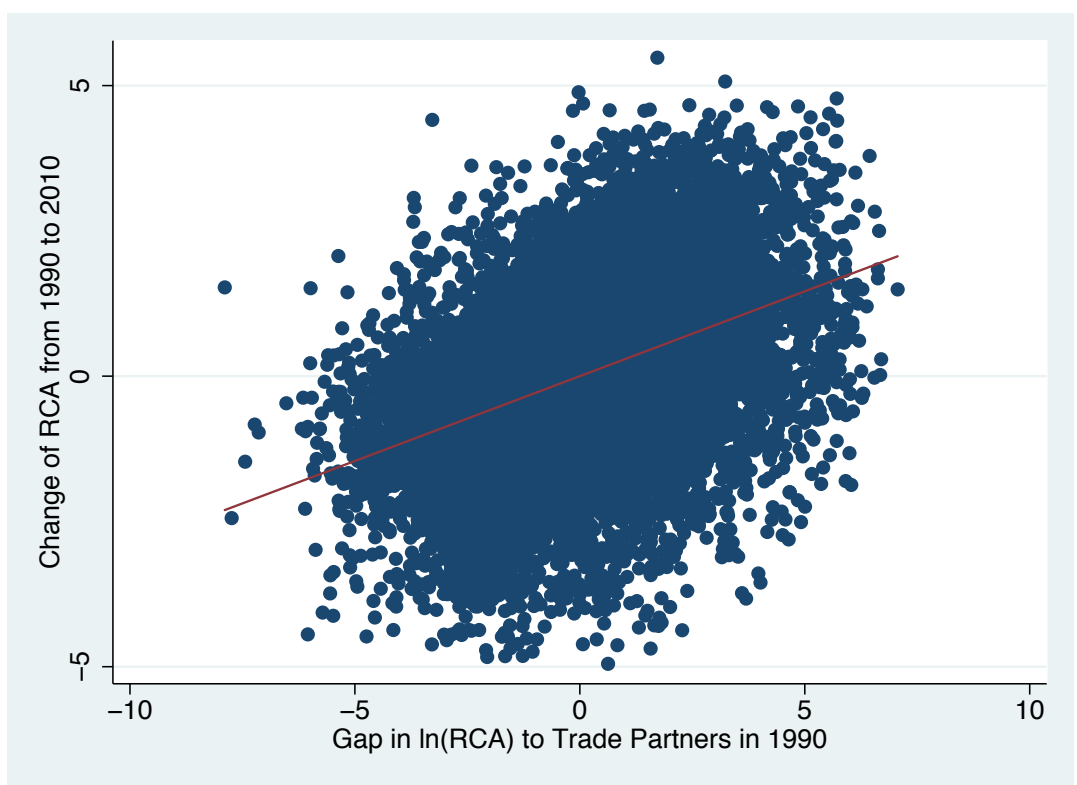

Notes: (1) The data source is comtrade (3-digit SITC, Rev. 2); (2) Gap in $\ln (R C A)$ to trade partners is calculated as the average difference in $\ln (R C A)$ between a country and its trade partners weighted by import share; (3) The RCA index is all three-year average (1989-1991, 2009-2011) and controlled for industry and country fixed effects. 
Figure 4: Evolution of Median Trade Costs: Pooled and by-Industry, 1960 - 2010
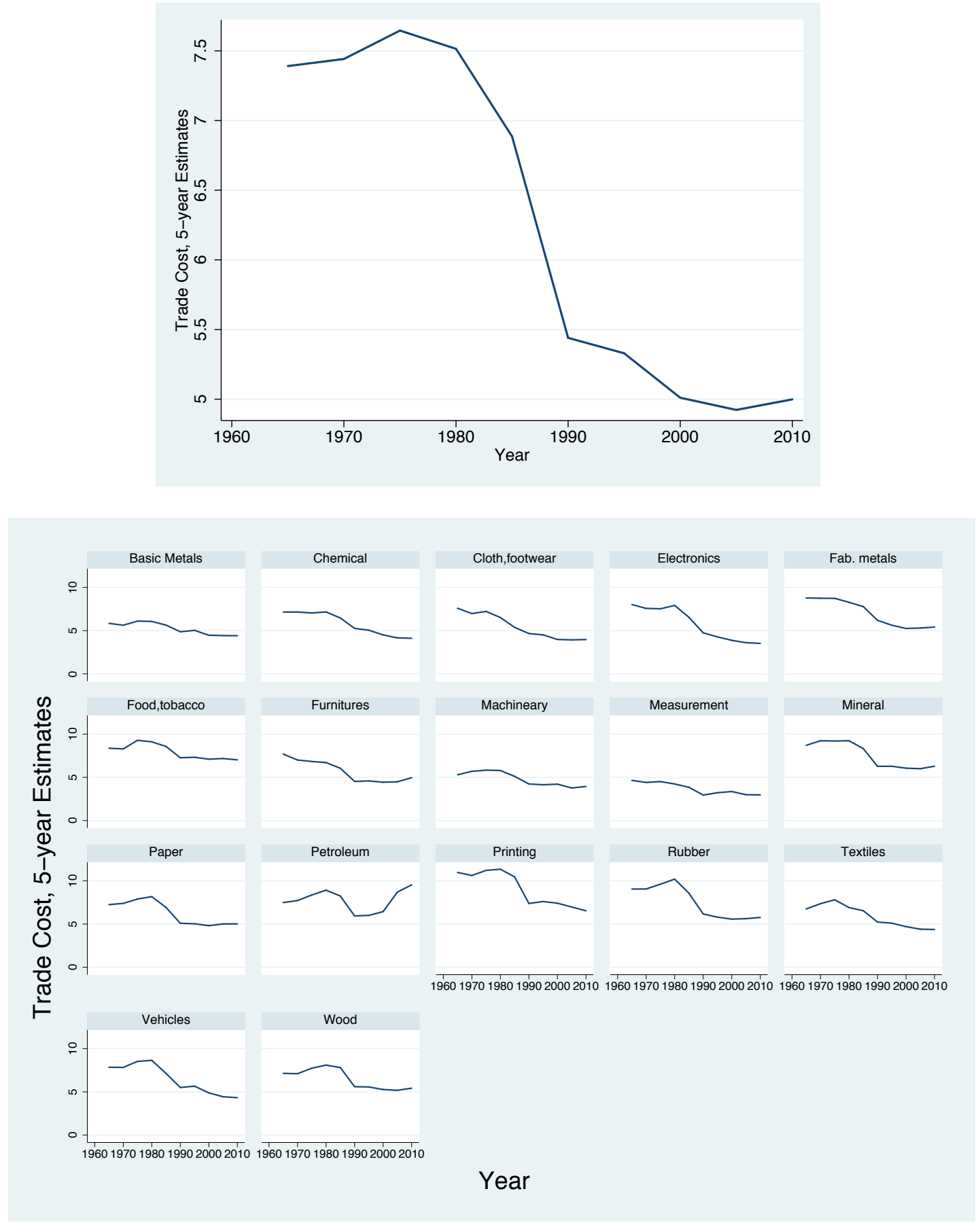

Notes: The median trade cost is calculated using an unbalanced 5-year panel of trade cost estimates. 
Figure 5: Unconditional Convergence: Model versus Data
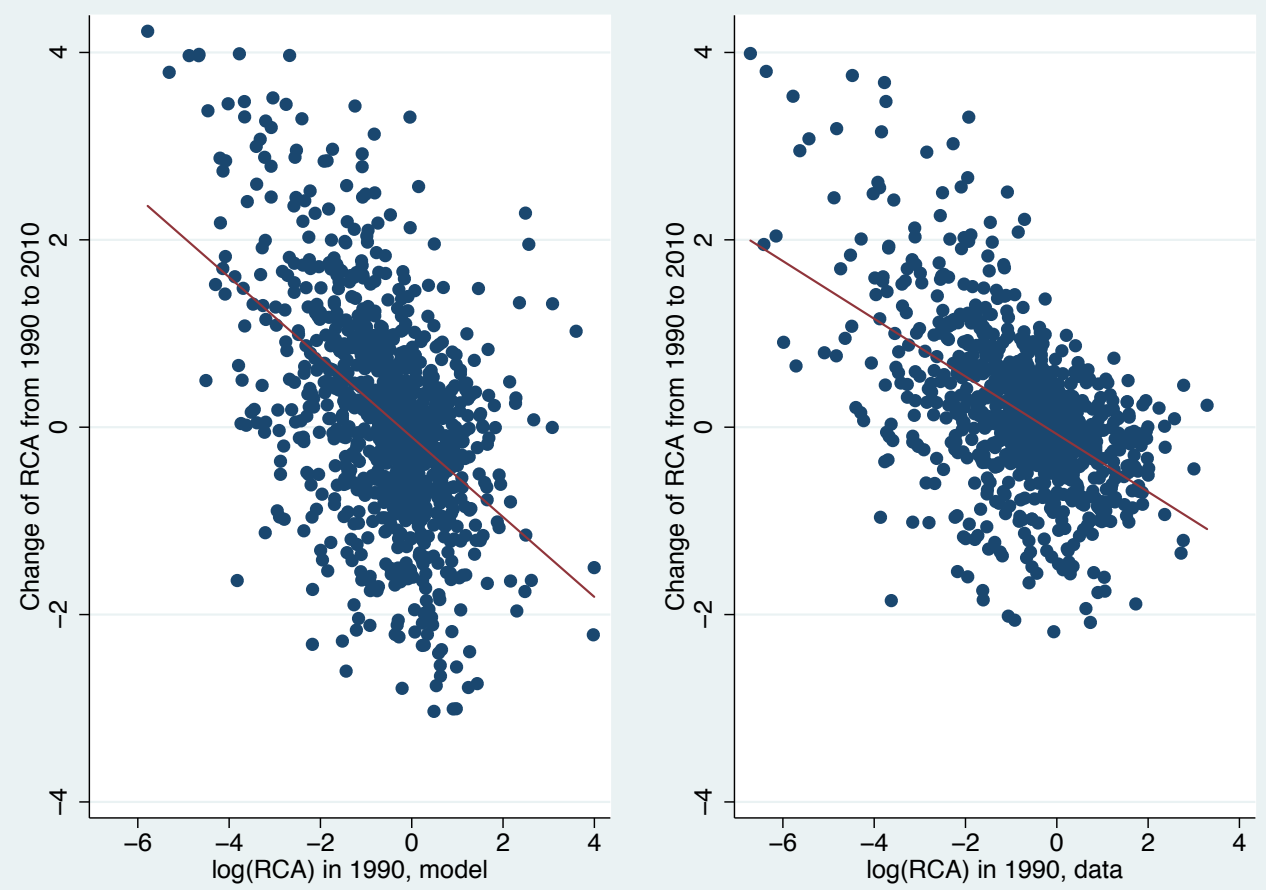
Figure 6: Share of Top Export Industries
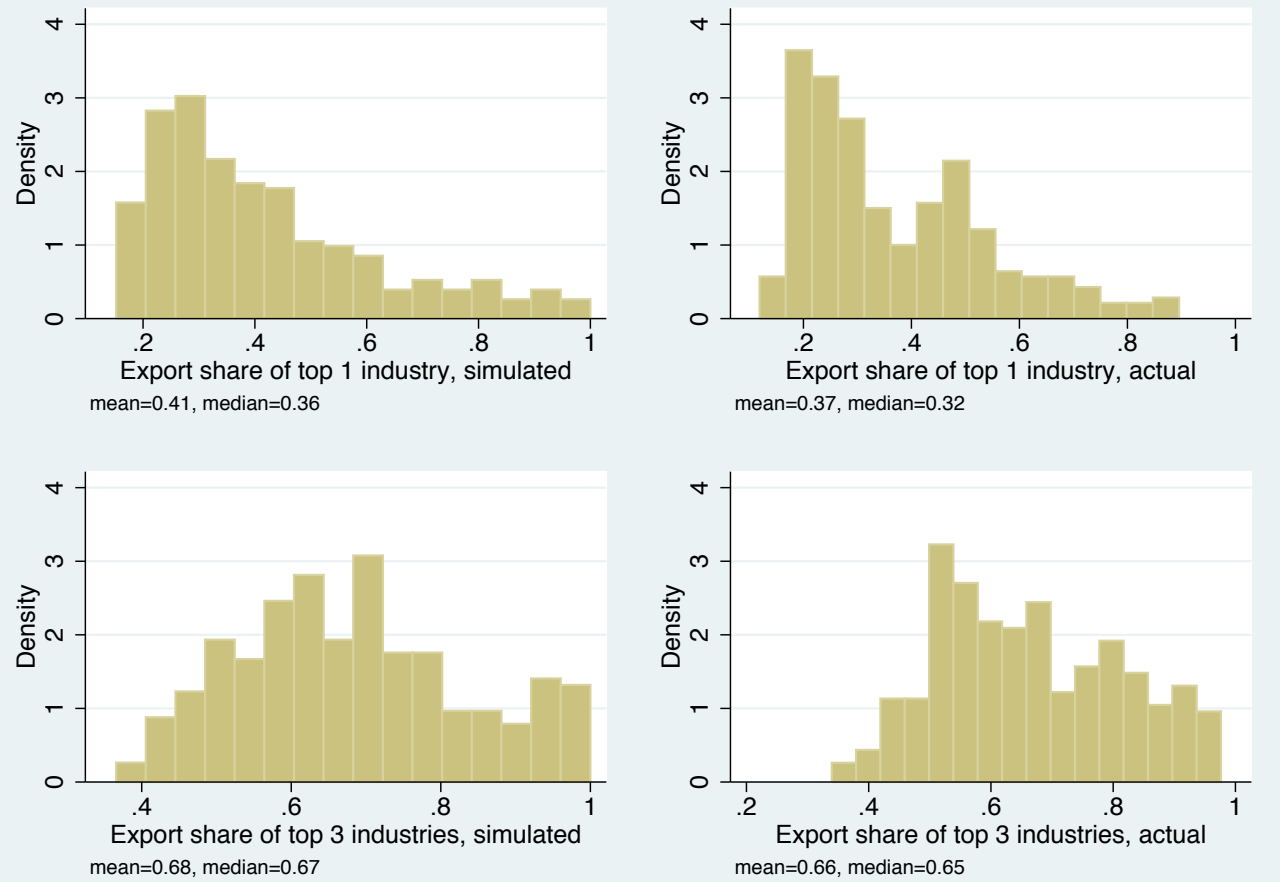
Figure 7: Contribution to Productivity Growth: 1990 - 2010
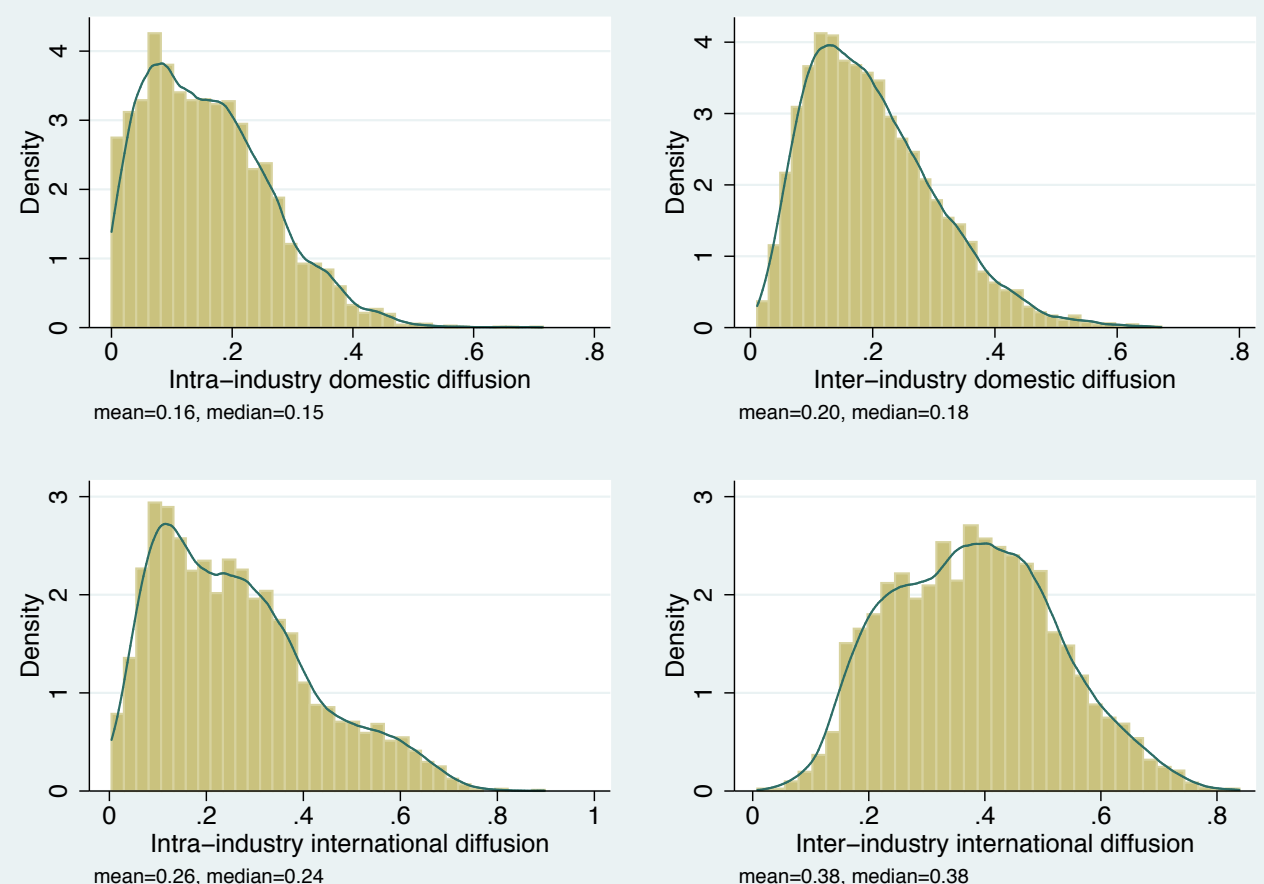
Figure 8: Contribution to Productivity Growth: OECD versus non-OECD

\section{OECD Economies}
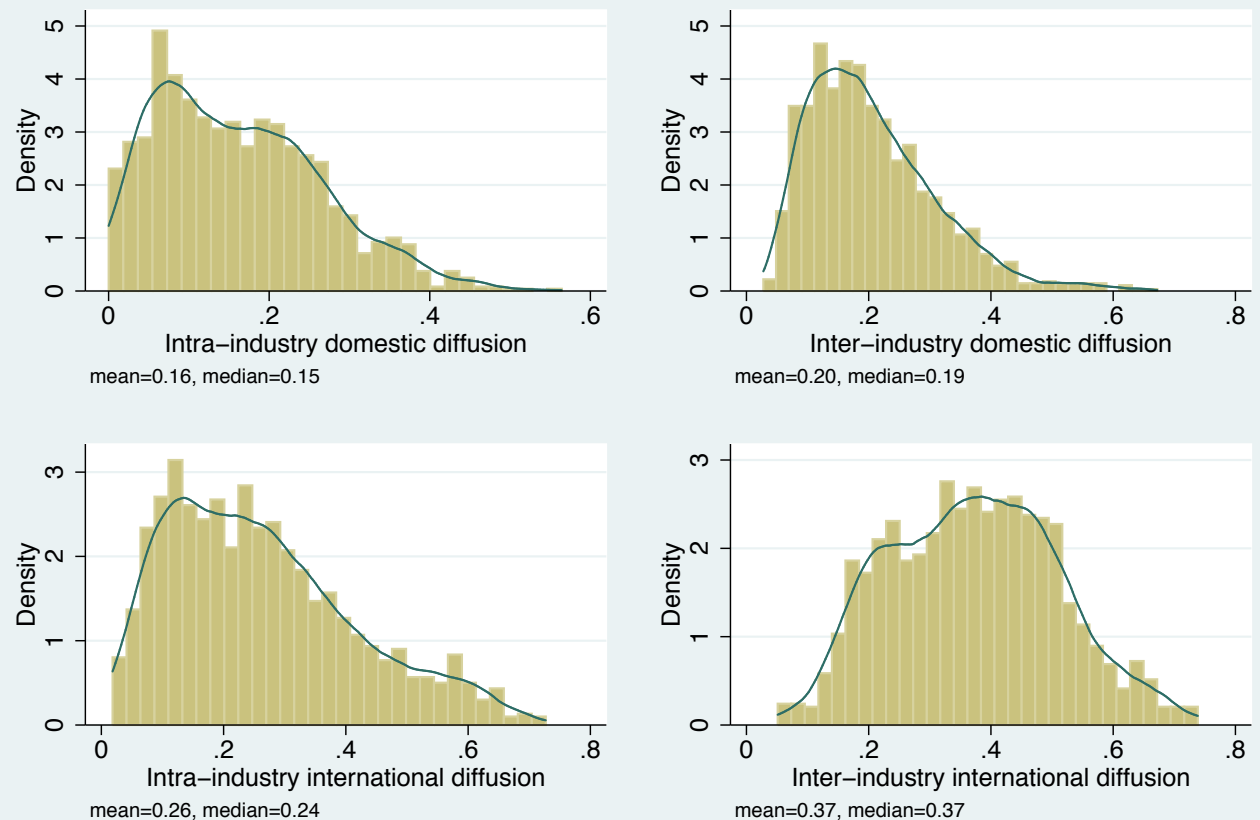

\section{Non-OECD Economies}
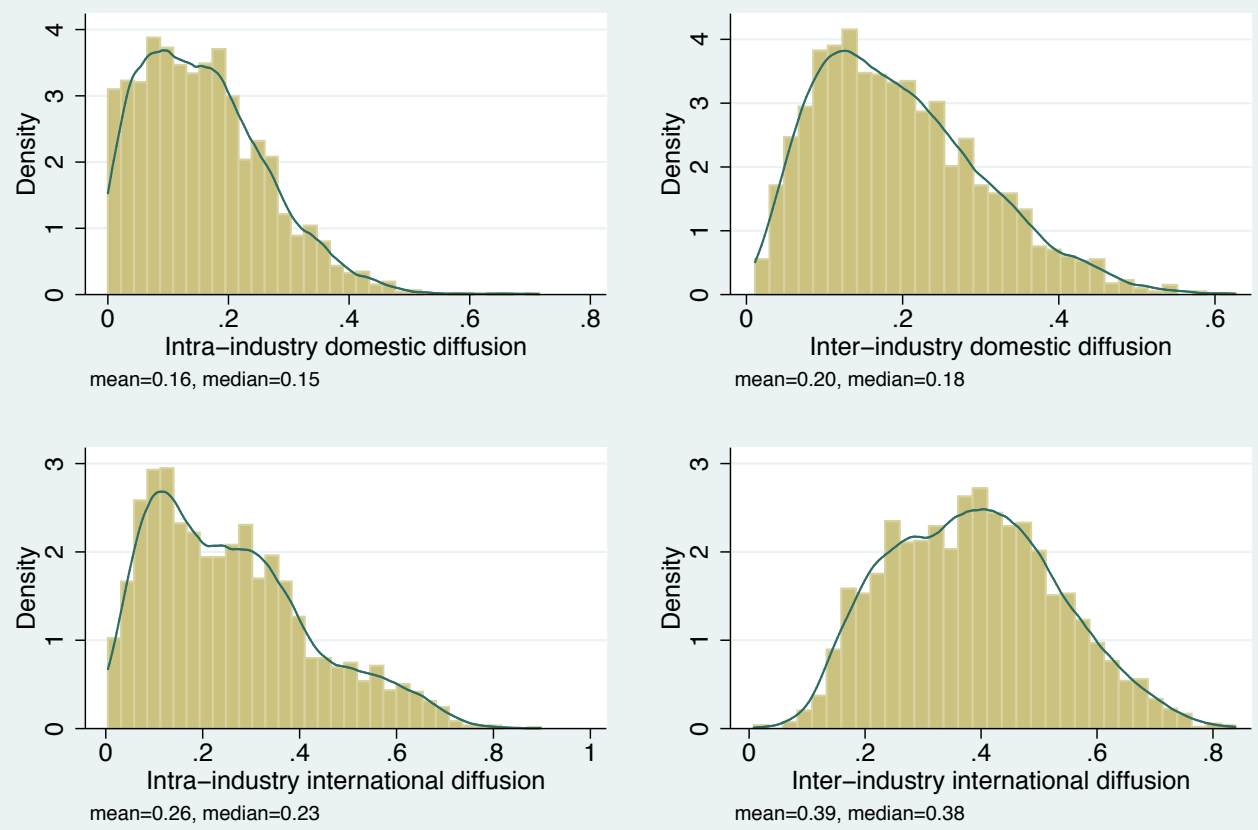
Figure 9: Contribution to Productivity Growth by Industry

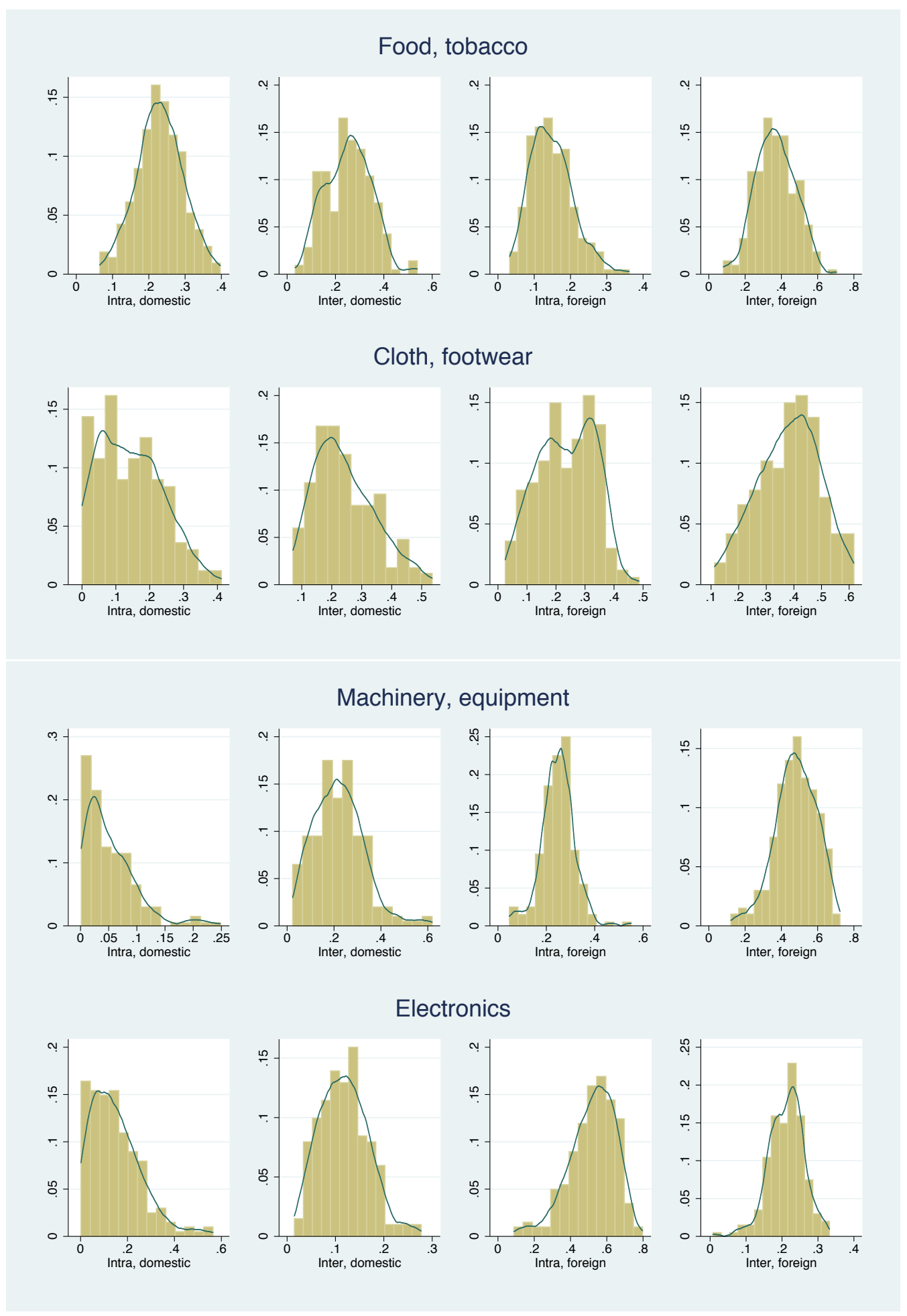


Figure 10: Contribution to Productivity Growth versus $\beta$

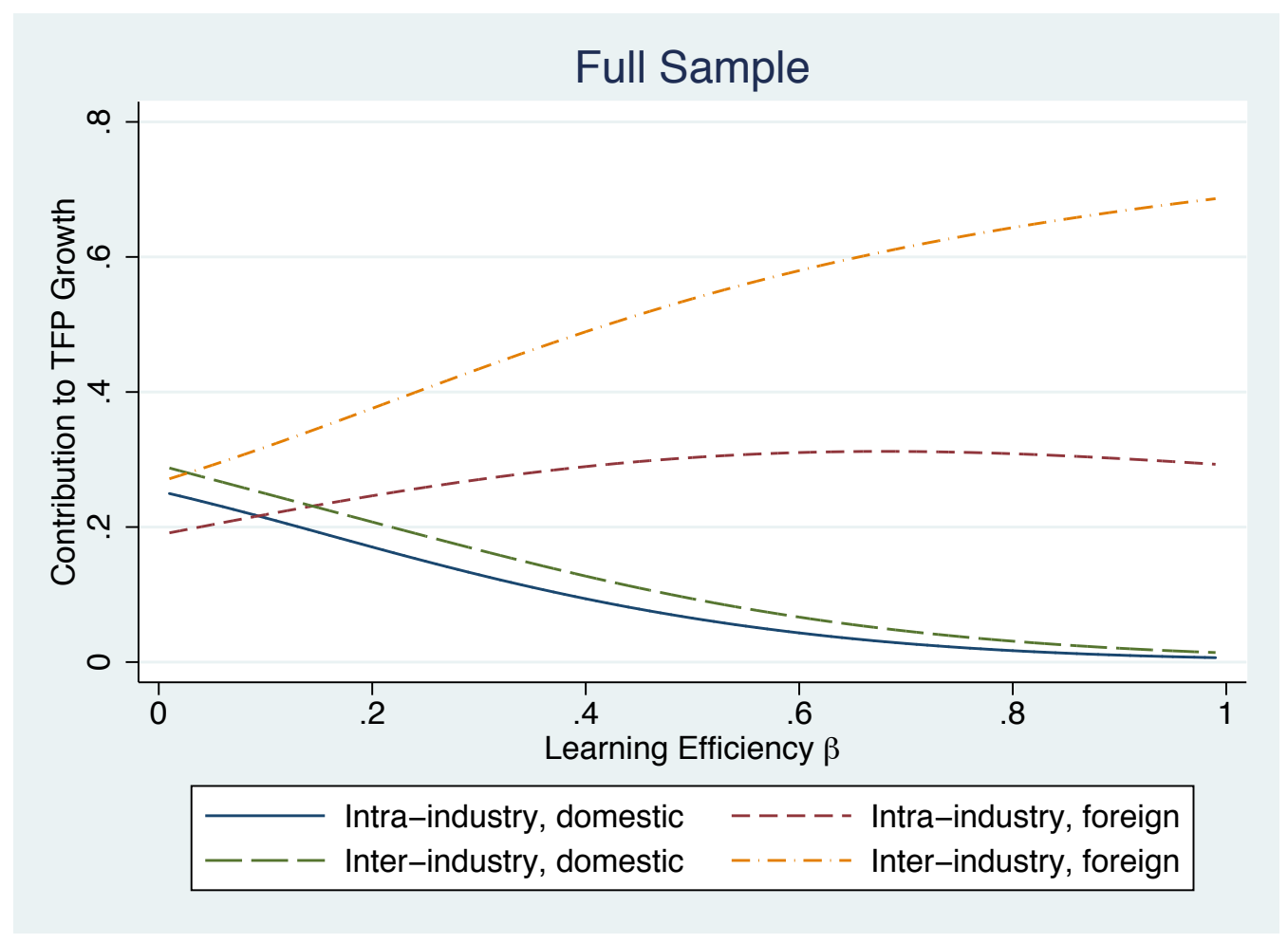


Figure 11: Contribution to Productivity Growth: 1990 - 2010
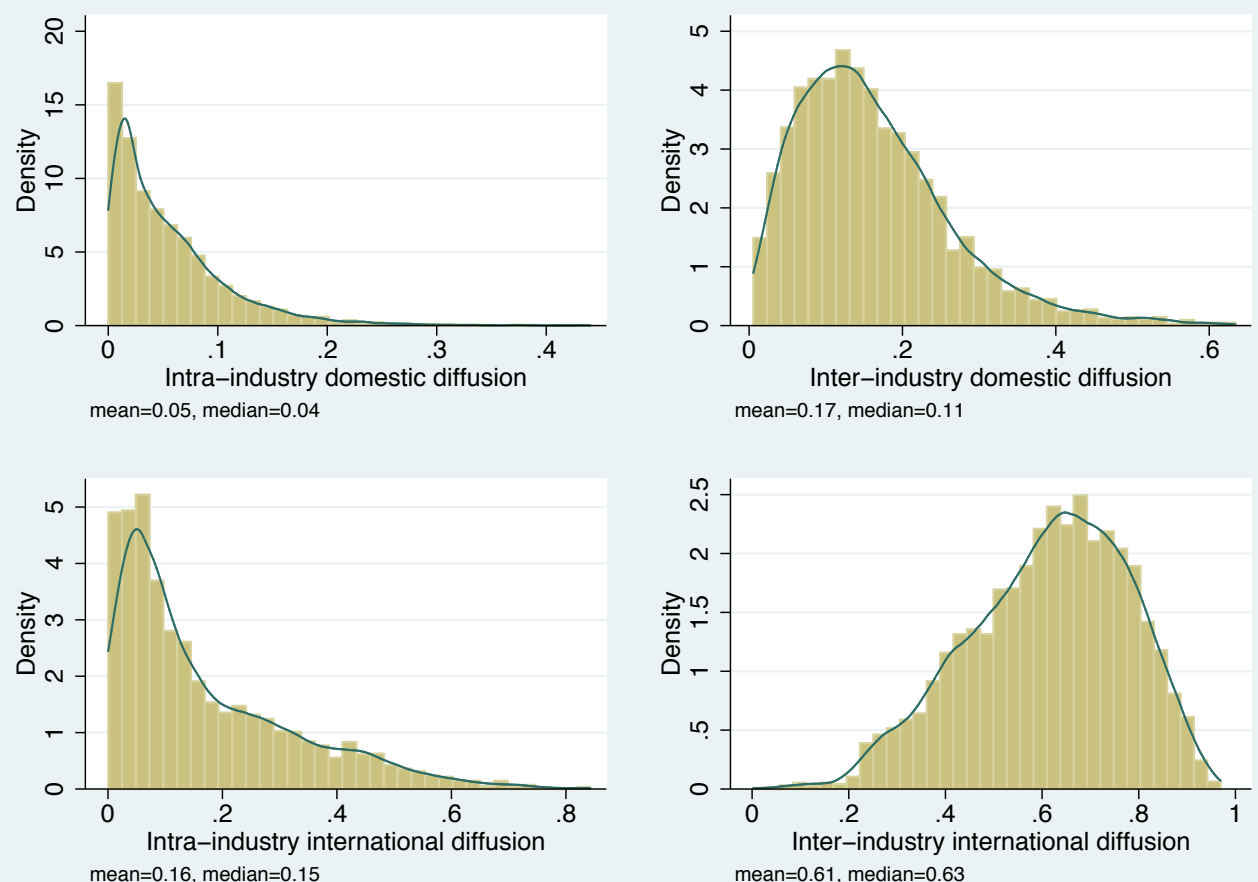
Figure 12: Degree Distribution of Global Diffusion Network: 1990 - 2010
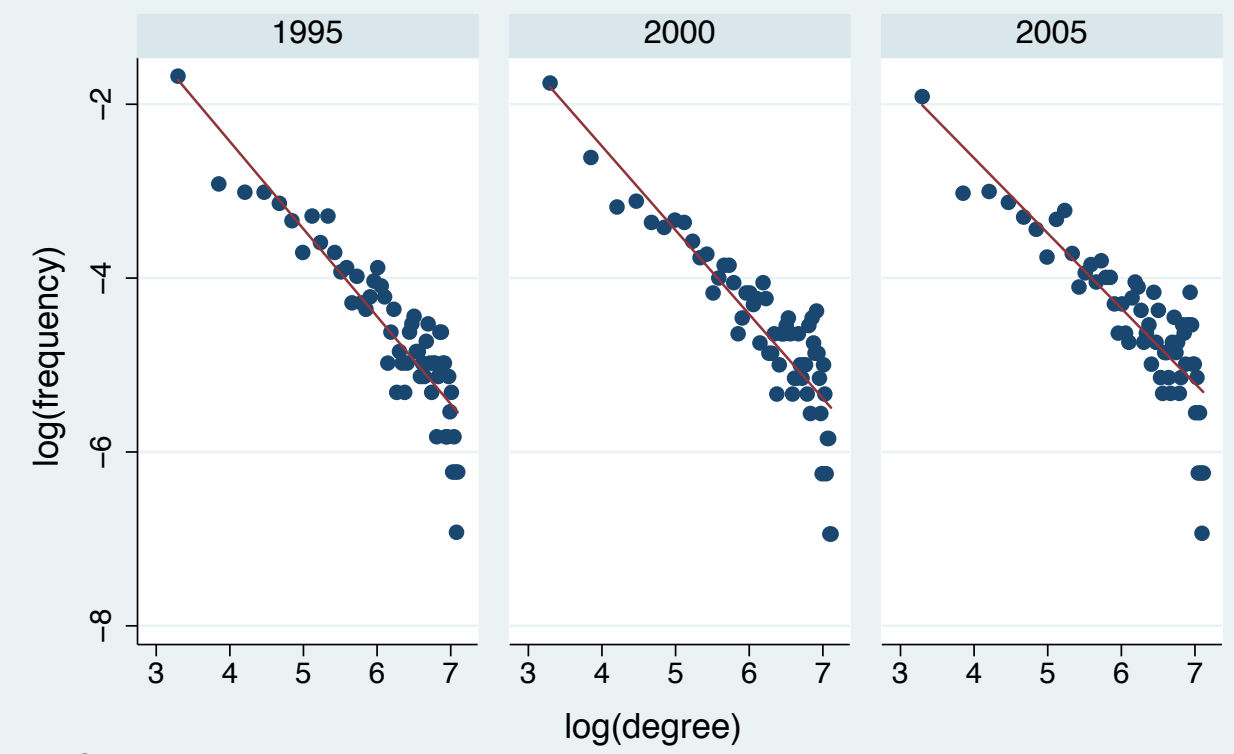

Cutoff $=1 \mathrm{e}-4$
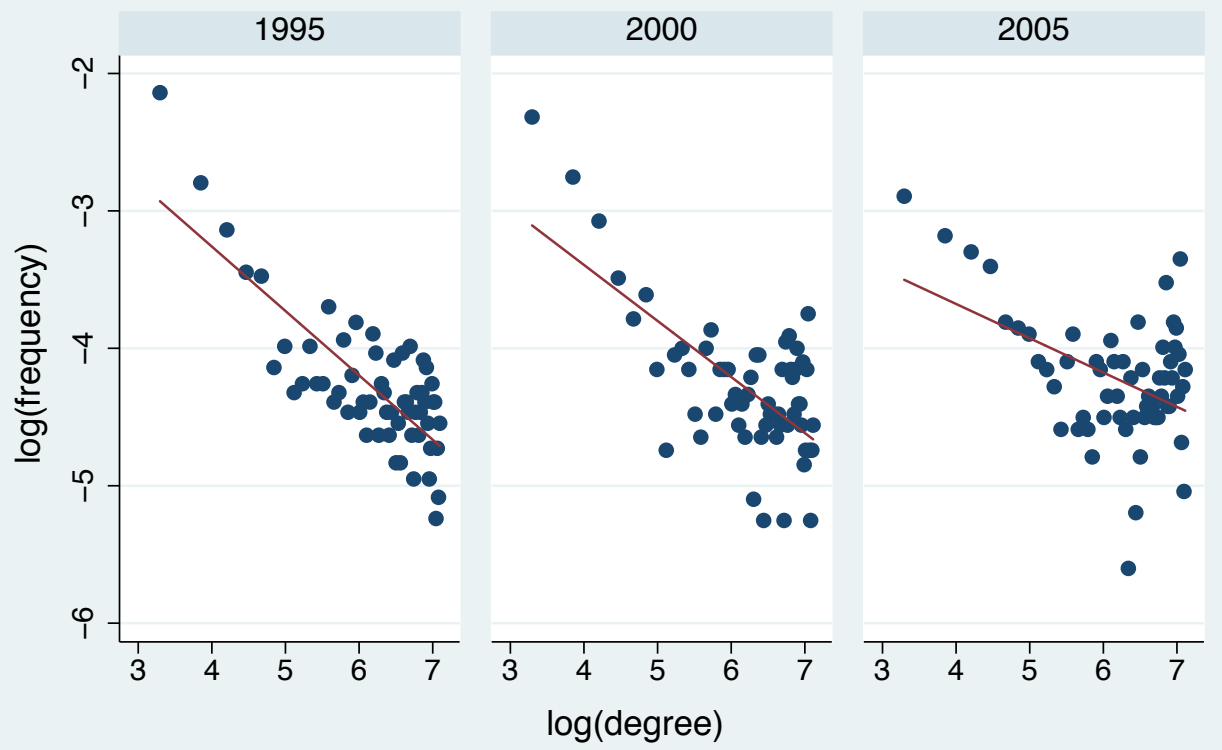

Cutoff $=1 \mathrm{e}-5$

Notes: (1) The diffusion network is constructed using diffusion parameters obtained from the baseline calibration (Method II); (2) The cutoff $10^{-4}$ is about the average contribution to global productivity growth and $10^{-5}$ is the 75 -percentile. 
Figure 13: Lorenz Curve of Degree: 1990 - 2010
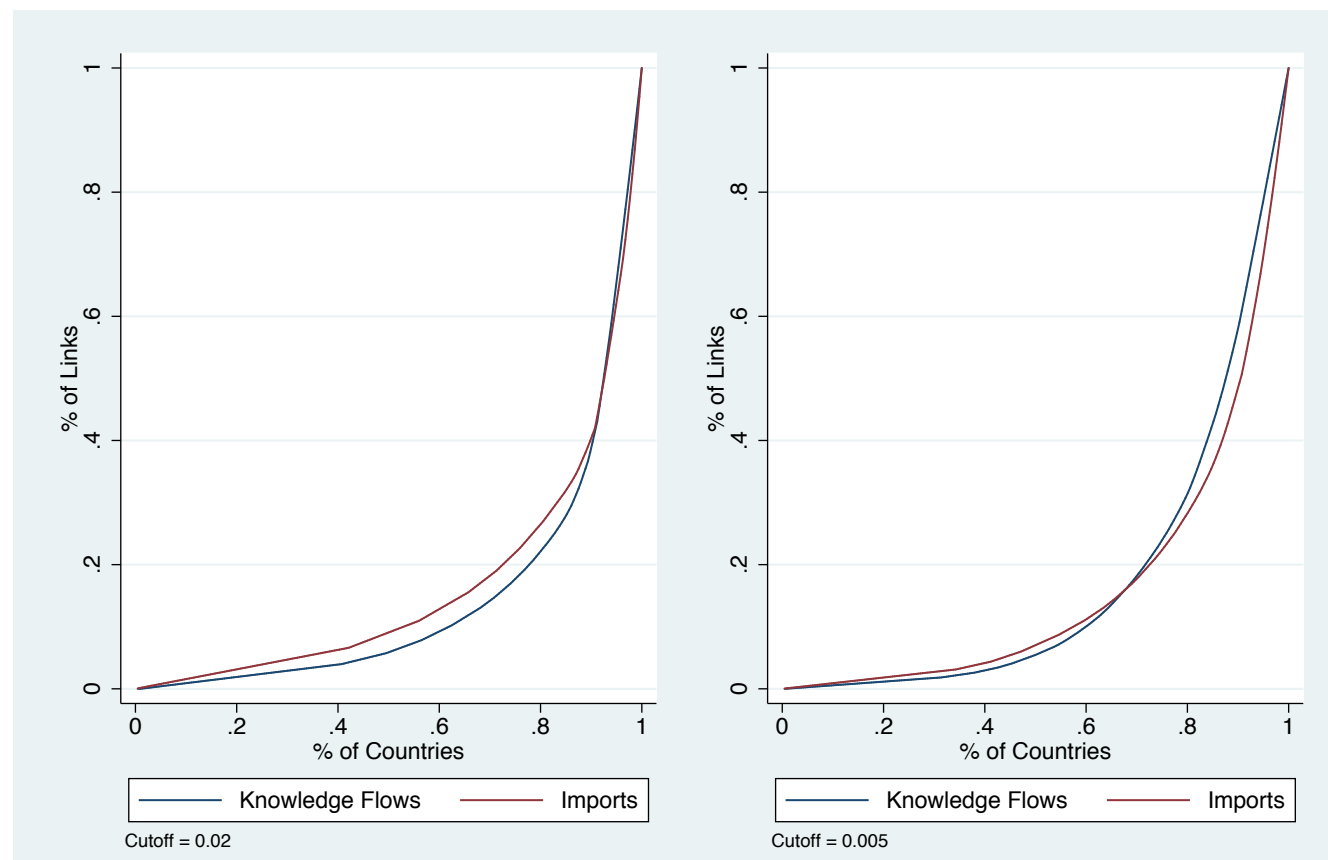

Notes: (1) The diffusion network is constructed using diffusion parameters obtained from the baseline calibration (Method II); (2) The average contribution to global productivity growth is about $1.4 \%$; (3) Country-level degree data are pooled together for all three periods. 
Figure 14: Gains from Trade

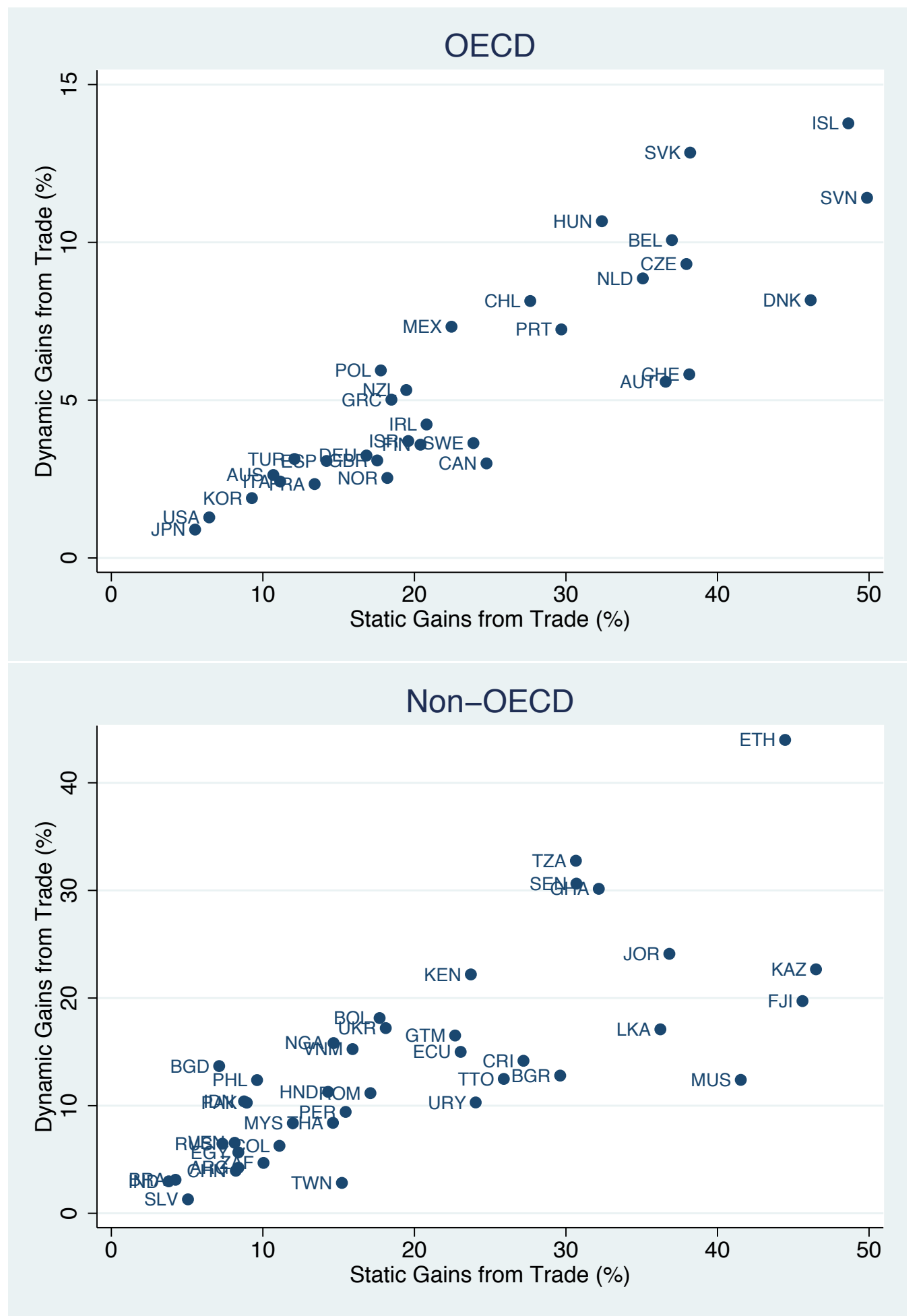

Note: (1) The benchmark period is 2000 - 2005, and diffusion parameters are borrowed from benchmark calibration Method I; (3) The annual discount rate is 3\%, and the results are robust for the plausible range of annual discount rates ( $1 \%$ to $10 \%)$. 
Table 1: Goodness of Fit

\begin{tabular}{|c|c|c|c|c|c|}
\hline Period & Data Mean & Model Mean & Data Median & Model Median & Corr. \\
\hline \multicolumn{6}{|c|}{ Panel I: Actual TFP } \\
\hline \multicolumn{6}{|c|}{ Wage (2005 US \$) } \\
\hline 1990-1995 & 6,165 & 5,071 & 4,647 & 3,995 & 0.96 \\
\hline $1996-2000$ & 6,451 & 5,337 & 4,759 & 4,407 & 0.96 \\
\hline 2001-2005 & 6,651 & 5,344 & 4,728 & 3,958 & 0.94 \\
\hline 2006-2010 & 6,934 & 5,993 & 5,053 & 4,116 & 0.93 \\
\hline \multicolumn{6}{|l|}{ Rent } \\
\hline 1990-1995 & 0.18 & 0.16 & 0.17 & 0.16 & 0.66 \\
\hline $1996-2000$ & 0.18 & 0.15 & 0.16 & 0.14 & 0.61 \\
\hline $2001-2005$ & 0.19 & 0.14 & 0.16 & 0.13 & 0.40 \\
\hline $2006-2010$ & 0.20 & 0.12 & 0.17 & 0.12 & 0.05 \\
\hline \multicolumn{6}{|c|}{ Bilateral Trade Share } \\
\hline $1990-1995$ & $4.5 \mathrm{e}-3$ & $3.8 \mathrm{e}-3$ & 0 & 0 & 0.89 \\
\hline $1996-2000$ & $5.2 \mathrm{e}-3$ & $4.4 \mathrm{e}-3$ & $1.5 \mathrm{e}-5$ & $1.7 \mathrm{e}-5$ & 0.91 \\
\hline $2001-2005$ & $4.9 \mathrm{e}-3$ & $4.2 \mathrm{e}-3$ & $4.0 \mathrm{e}-5$ & $3.7 \mathrm{e}-5$ & 0.89 \\
\hline 2006-2010 & $4.6 \mathrm{e}-3$ & $3.9 \mathrm{e}-3$ & $3.7 \mathrm{e}-5$ & $1.3 \mathrm{e}-5$ & 0.87 \\
\hline \multicolumn{6}{|c|}{ Domestic Absorption Share } \\
\hline $1990-1995$ & 0.61 & 0.66 & 0.67 & 0.75 & 0.91 \\
\hline $1996-2000$ & 0.55 & 0.62 & 0.59 & 0.69 & 0.92 \\
\hline $2001-2005$ & 0.51 & 0.56 & 0.54 & 0.63 & 0.92 \\
\hline $2006-2010$ & 0.47 & 0.52 & 0.50 & 0.59 & 0.90 \\
\hline \multicolumn{6}{|c|}{ Panel II: Model-implied TFP } \\
\hline \multicolumn{6}{|c|}{ Wage (2005 US \$) } \\
\hline $1990-1995$ & 6,165 & 5,127 & 4,647 & 4,044 & 0.97 \\
\hline $1996-2000$ & 6,451 & 5,350 & 4,759 & 4,302 & 0.97 \\
\hline $2001-2005$ & 6,651 & 5,717 & 4,728 & 4,485 & 0.96 \\
\hline $2006-2010$ & 6,934 & 5,872 & 5,053 & 4,517 & 0.94 \\
\hline \multicolumn{6}{|l|}{ Rent } \\
\hline 1990-1995 & 0.18 & 0.16 & 0.17 & 0.16 & 0.67 \\
\hline $1996-2000$ & 0.18 & 0.19 & 0.16 & 0.16 & 0.73 \\
\hline $2001-2005$ & 0.19 & 0.21 & 0.16 & 0.18 & 0.77 \\
\hline $2006-2010$ & 0.20 & 0.24 & 0.17 & 0.20 & 0.72 \\
\hline \multicolumn{6}{|c|}{ Bilateral Trade Share } \\
\hline 1990-1995 & $4.5 \mathrm{e}-3$ & $3.8 \mathrm{e}-3$ & 0 & 0 & 0.89 \\
\hline $1996-2000$ & $5.2 \mathrm{e}-3$ & $4.7 \mathrm{e}-3$ & $1.5 \mathrm{e}-5$ & $0.9 \mathrm{e}-5$ & 0.86 \\
\hline $2001-2005$ & $4.9 \mathrm{e}-3$ & $4.5 \mathrm{e}-3$ & $4.0 \mathrm{e}-5$ & $3.2 \mathrm{e}-5$ & 0.83 \\
\hline 2006-2010 & $4.6 \mathrm{e}-3$ & $4.0 \mathrm{e}-3$ & $3.7 e-5$ & $1.6 \mathrm{e}-5$ & 0.78 \\
\hline \multicolumn{6}{|c|}{ Domestic Absorption Share } \\
\hline $1990-1995$ & 0.61 & 0.66 & 0.67 & 0.75 & 0.91 \\
\hline $1996-2000$ & 0.55 & 0.64 & 0.59 & 0.70 & 0.62 \\
\hline 2001-2005 & 0.51 & 0.64 & 0.54 & 0.70 & 0.42 \\
\hline 2006-2010 & 0.47 & 0.66 & 0.50 & 0.71 & 0.27 \\
\hline
\end{tabular}

Note: Goodness of fit is reported for the baseline sample. Panel I reports simulation using actual TFP estimates. Panel II reports simulation using TFP series obtained from method I. 
Table 2: Unconditional Convergence: Model versus Data

\begin{tabular}{|c|c|c|c|c|c|c|}
\hline Variable & $\begin{array}{c}(1) \\
\text { RCA Index }\end{array}$ & $\begin{array}{c}(2) \\
\text { TFP }\end{array}$ & $\begin{array}{c}(3) \\
\text { TFP }\end{array}$ & $\begin{array}{c}(4) \\
\text { TFP }\end{array}$ & $\begin{array}{c}(5) \\
\text { Trade Share }\end{array}$ & $\begin{array}{c}(6) \\
\text { Export } \\
\text { Capability }\end{array}$ \\
\hline Sample & Full & Full & OECD & Non-OECD & Full & Full \\
\hline Data & $\begin{array}{c}-0.310 \\
(0.023)^{* * *}\end{array}$ & $\begin{array}{c}-0.258 \\
(0.037)^{* * *}\end{array}$ & $\begin{array}{c}-0.243 \\
(0.062)^{* * *}\end{array}$ & $\begin{array}{c}-0.342 \\
(0.054)^{* * *}\end{array}$ & $\begin{array}{c}-0.065 \\
(0.011)^{* * *}\end{array}$ & $\begin{array}{c}-0.248 \\
(0.024)^{* * *}\end{array}$ \\
\hline $\begin{array}{l}\text { Method I } \\
(\beta=0.285)\end{array}$ & $\begin{array}{c}-0.395 \\
(0.035) * * *\end{array}$ & $\begin{array}{c}-0.287 \\
(0.022)^{* * *}\end{array}$ & $\begin{array}{c}-0.186 \\
(0.033)^{* * *}\end{array}$ & $\begin{array}{c}-0.358 \\
(0.028) * * *\end{array}$ & $\begin{array}{c}-0.072 \\
(0.009)^{* * *}\end{array}$ & $\begin{array}{c}-0.363 \\
(0.040)^{* * *}\end{array}$ \\
\hline Method II & $\begin{array}{c}-0.394 \\
(0.035)^{* * *}\end{array}$ & $\begin{array}{c}-0.282 \\
(0.021)^{* * *}\end{array}$ & $\begin{array}{c}-0.177 \\
(0.032)^{* * *}\end{array}$ & $\begin{array}{c}-0.352 \\
(0.027)^{* * *}\end{array}$ & $\begin{array}{c}-0.071 \\
(0.009)^{* * *}\end{array}$ & $\begin{array}{c}-0.361 \\
(0.040)^{* * *}\end{array}$ \\
\hline $\begin{array}{l}\text { Method III } \\
(\beta=0.240)\end{array}$ & $\begin{array}{c}-0.383 \\
(0.035)^{* * *}\end{array}$ & $\begin{array}{c}-0.257 \\
(0.021)^{* * *}\end{array}$ & $\begin{array}{c}-0.158 \\
(0.031)^{* * *}\end{array}$ & $\begin{array}{c}-0.325 \\
(0.027)^{* * *}\end{array}$ & $\begin{array}{c}-0.066 \\
(0.009)^{* * *}\end{array}$ & $\begin{array}{c}-0.351 \\
(0.041)^{* * *}\end{array}$ \\
\hline Method IV & $\begin{array}{c}-0.385 \\
(0.036)^{* * *}\end{array}$ & $\begin{array}{c}-0.268 \\
(0.022)^{* * *}\end{array}$ & $\begin{array}{c}-0.181 \\
(0.038)^{* * *}\end{array}$ & $\begin{array}{c}-0.331 \\
(0.027)^{* * *}\end{array}$ & $\begin{array}{c}-0.068 \\
(0.009)^{* * *}\end{array}$ & $\begin{array}{c}-0.357 \\
(0.042)^{* * *}\end{array}$ \\
\hline $\begin{array}{l}\text { Method I } \\
\text { Fix } \beta=0.5\end{array}$ & $\begin{array}{c}-0.396 \\
(0.035)^{* * *}\end{array}$ & $\begin{array}{c}-0.286 \\
(0.022)^{* * *}\end{array}$ & $\begin{array}{c}-0.179 \\
(0.031)^{* * *}\end{array}$ & $\begin{array}{c}-0.357 \\
(0.027)^{* * *}\end{array}$ & $\begin{array}{c}-0.071 \\
(0.009)^{* * *}\end{array}$ & $\begin{array}{c}-0.358 \\
(0.040)^{* * *}\end{array}$ \\
\hline $\begin{array}{l}\text { Method I } \\
\text { Fix } \beta=0.7\end{array}$ & $\begin{array}{c}-0.389 \\
(0.036)^{* * *}\end{array}$ & $\begin{array}{c}-0.283 \\
(0.021)^{* * *}\end{array}$ & $\begin{array}{c}-0.170 \\
(0.029)^{* * *}\end{array}$ & $\begin{array}{c}-0.355 \\
(0.027)^{* * *}\end{array}$ & $\begin{array}{c}-0.073 \\
(0.009)^{* * *}\end{array}$ & $\begin{array}{c}-0.358 \\
(0.040)^{* * *}\end{array}$ \\
\hline $\begin{array}{l}\text { Exporter FE } \\
\text { Importer FE } \\
\text { Industry FE }\end{array}$ & Yes & Yes & Yes & Yes & $\begin{array}{l}\text { Yes } \\
\text { Yes } \\
\text { Yes }\end{array}$ & Yes \\
\hline No. of Obs. & 967 & 992 & 483 & 509 & 83,464 & 952 \\
\hline
\end{tabular}

Notes: (1) Growth rate of each variable is calculated between 1990-1995 and 2005-2010. The table only reports the convergence parameter $\alpha$ specified in Equation 23; (2) Top and bottom 1\% observations in terms of growth rate are dropped; (3) Robust standard errors are reported in the parentheses. *, **, and $* * *$ indicate significance at the $10 \%, 5 \%$, and $1 \%$ levels, respectively. 
Table 3: Transition Probability in TFP: Model versus Data

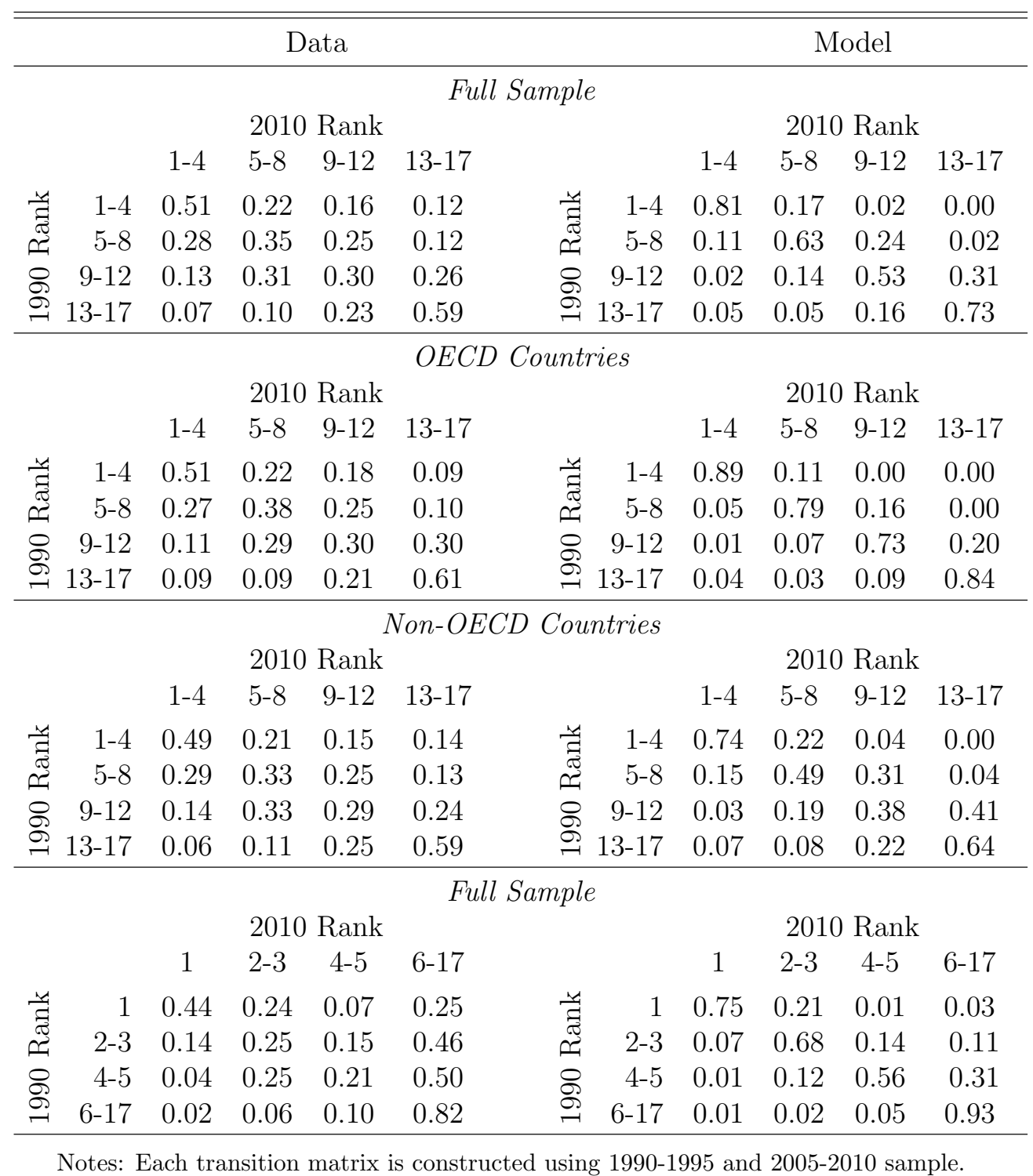


Table 4: Unconditional Convergence: Alternative Diffusion Matrices

\begin{tabular}{|c|c|c|c|c|c|c|}
\hline Variable & $\begin{array}{c}\text { (1) } \\
\text { RCA Index }\end{array}$ & $\begin{array}{c}\text { (2) } \\
\text { TFP }\end{array}$ & $\begin{array}{c}\text { (3) } \\
\text { TFP }\end{array}$ & $\begin{array}{c}\text { (4) } \\
\text { TFP }\end{array}$ & $\begin{array}{c}(5) \\
\text { Trade Share }\end{array}$ & $\begin{array}{c}(6) \\
\text { Export } \\
\text { Capability }\end{array}$ \\
\hline Sample & Full & Full & OECD & Non-OECD & Full & Full \\
\hline \multirow[t]{2}{*}{ Data } & $\begin{array}{c}-0.310 \\
(0.023)^{* * *}\end{array}$ & $\begin{array}{c}-0.252 \\
(0.037)^{* * *}\end{array}$ & $\begin{array}{c}-0.239 \\
(0.062)^{* * *}\end{array}$ & $\begin{array}{c}-0.320 \\
(0.053)^{* * *}\end{array}$ & $\begin{array}{c}-0.066 \\
(0.011)^{* * *}\end{array}$ & $\begin{array}{c}-0.248 \\
(0.024)^{* * *}\end{array}$ \\
\hline & \multicolumn{6}{|c|}{ Country-specific I-O Table } \\
\hline $\begin{array}{l}\text { Method I } \\
(\beta=0.319)\end{array}$ & $\begin{array}{c}-0.398 \\
(0.036)^{* * *}\end{array}$ & $\begin{array}{c}-0.304 \\
(0.021)^{* * *}\end{array}$ & $\begin{array}{c}-0.200 \\
(0.037)^{* * *}\end{array}$ & $\begin{array}{c}-0.372 \\
(0.026)^{* * *}\end{array}$ & $\begin{array}{c}-0.076 \\
(0.010)^{* * *}\end{array}$ & $\begin{array}{c}-0.362 \\
(0.038)^{* * *}\end{array}$ \\
\hline Method II & $\begin{array}{c}-0.399 \\
(0.036)^{* * *}\end{array}$ & $\begin{array}{c}-0.295 \\
(0.020)^{* * *}\end{array}$ & $\begin{array}{c}-0.191 \\
(0.034)^{* * *}\end{array}$ & $\begin{array}{c}-0.362 \\
(0.026)^{* * *}\end{array}$ & $\begin{array}{c}-0.078 \\
(0.010)^{* * *}\end{array}$ & $\begin{array}{c}-0.366 \\
(0.039)^{* * *}\end{array}$ \\
\hline $\begin{array}{l}\text { Method III } \\
(\beta=0.244)\end{array}$ & $\begin{array}{c}-0.387 \\
(0.036)^{* * *}\end{array}$ & $\begin{array}{c}-0.276 \\
(0.020)^{* * *}\end{array}$ & $\begin{array}{c}-0.175 \\
(0.036)^{* * *}\end{array}$ & $\begin{array}{c}-0.342 \\
(0.026)^{* * *}\end{array}$ & $\begin{array}{c}-0.072 \\
(0.009)^{* * *}\end{array}$ & $\begin{array}{c}-0.343 \\
(0.037)^{* * *}\end{array}$ \\
\hline Method IV & $\begin{array}{c}-0.393 \\
(0.036)^{* * *}\end{array}$ & $\begin{array}{c}-0.280 \\
(0.021)^{* * *}\end{array}$ & $\begin{array}{c}-0.175 \\
(0.034)^{* * *}\end{array}$ & $\begin{array}{c}-0.349 \\
(0.027)^{* * *}\end{array}$ & $\begin{array}{c}-0.074 \\
(0.009)^{* * *}\end{array}$ & $\begin{array}{c}-0.347 \\
(0.038)^{* * *}\end{array}$ \\
\hline & \multicolumn{6}{|c|}{ Patent Citation Matrix } \\
\hline $\begin{array}{l}\text { Method I } \\
(\beta=0.319)\end{array}$ & $\begin{array}{c}-0.368 \\
(0.036)^{* * *}\end{array}$ & $\begin{array}{c}-0.282 \\
(0.023) * * *\end{array}$ & $\begin{array}{c}-0.194 \\
(0.040)^{* * *}\end{array}$ & $\begin{array}{c}-0.334 \\
(0.028) * * *\end{array}$ & $\begin{array}{c}-0.065 \\
(0.009)^{* * *}\end{array}$ & $\begin{array}{c}-0.322 \\
(0.040)^{* * *}\end{array}$ \\
\hline Method II & $\begin{array}{c}-0.366 \\
(0.036)^{* * *}\end{array}$ & $\begin{array}{c}-0.282 \\
(0.024)^{* * *}\end{array}$ & $\begin{array}{c}-0.192 \\
(0.040)^{* * *}\end{array}$ & $\begin{array}{c}-0.336 \\
(0.028)^{* * *}\end{array}$ & $\begin{array}{c}-0.065 \\
(0.009)^{* * *}\end{array}$ & $\begin{array}{c}-0.320 \\
(0.040)^{* * *}\end{array}$ \\
\hline $\begin{array}{l}\text { Method III } \\
(\beta=0.397)\end{array}$ & $\begin{array}{c}-0.360 \\
(0.036)^{* * *}\end{array}$ & $\begin{array}{c}-0.251 \\
(0.022)^{* * *}\end{array}$ & $\begin{array}{c}-0.171 \\
(0.038)^{* * *}\end{array}$ & $\begin{array}{c}-0.300 \\
(0.027)^{* * *}\end{array}$ & $\begin{array}{c}-0.063 \\
(0.009)^{* * *}\end{array}$ & $\begin{array}{c}-0.310 \\
(0.039)^{* * *}\end{array}$ \\
\hline Method IV & $\begin{array}{c}-0.356 \\
(0.037)^{* * *}\end{array}$ & $\begin{array}{c}-0.273 \\
(0.021)^{* * *}\end{array}$ & $\begin{array}{c}-0.202 \\
(0.045)^{* * *}\end{array}$ & $\begin{array}{c}-0.313 \\
(0.028)^{* * *}\end{array}$ & $\begin{array}{c}-0.061 \\
(0.009)^{* * *}\end{array}$ & $\begin{array}{c}-0.316 \\
(0.041)^{* * *}\end{array}$ \\
\hline Exporter FE & Yes & Yes & Yes & Yes & Yes & Yes \\
\hline $\begin{array}{l}\text { Importer FE } \\
\text { Industry FE }\end{array}$ & Yes & Yes & Yes & Yes & $\begin{array}{l}\text { Yes } \\
\text { Yes }\end{array}$ & Yes \\
\hline No. of Obs. & 967 & 992 & 483 & 509 & 83,464 & 952 \\
\hline
\end{tabular}

Notes: (1) Growth rate of each variable is calculated between 1990-1995 and 2005-2010. The table only reports the convergence parameter $\alpha$ specified in Equation 23; (2) Top and bottom 1\% observations in terms of growth rate are dropped; (3) TFP estimates are based on country-specific I-O tables; (4) Robust standard errors are reported in the parentheses. $*^{* *}$, and ${ }^{* * *}$ indicate significance at the $10 \%, 5 \%$, and $1 \%$ levels, respectively. 
Table 5: Unconditional Convergence: 1970 - 2010

\begin{tabular}{|c|c|c|c|c|c|}
\hline & (1) & (2) & (3) & (4) & $(5)$ \\
\hline Variable & RCA Index & TFP & TFP & TFP & Import Share \\
\hline Sample & Full & Full & OECD & Non-OECD & Full \\
\hline Data & $\begin{array}{c}-0.500 \\
(0.028) * * *\end{array}$ & $\begin{array}{c}-0.596 \\
(0.048) * * *\end{array}$ & $\begin{array}{c}-0.533 \\
(0.054) * * *\end{array}$ & $\begin{array}{c}-0.665 \\
(0.075)^{* * *}\end{array}$ & $\begin{array}{c}-0.746 \\
(0.045)^{* * *}\end{array}$ \\
\hline \multicolumn{6}{|c|}{ Benchmark } \\
\hline Method II & $\begin{array}{c}-0.493 \\
(0.038)^{* * *}\end{array}$ & $\begin{array}{c}-0.356 \\
(0.025)^{* * *}\end{array}$ & $\begin{array}{c}-0.287 \\
(0.045)^{* * *}\end{array}$ & $\begin{array}{c}-0.454 \\
(0.030)^{* * *}\end{array}$ & $\begin{array}{c}-0.752 \\
(0.049)^{* * *}\end{array}$ \\
\hline Method IV & $\begin{array}{c}-0.482 \\
(0.036)^{* * *}\end{array}$ & $\begin{array}{c}-0.334 \\
(0.025)^{* * *}\end{array}$ & $\begin{array}{c}-0.263 \\
(0.044)^{* * *}\end{array}$ & $\begin{array}{c}-0.432 \\
(0.030)^{* * *}\end{array}$ & $\begin{array}{c}-0.732 \\
(0.050)^{* * *}\end{array}$ \\
\hline \multicolumn{6}{|c|}{ Country-specific I-O Tables } \\
\hline Method II & $\begin{array}{c}-0.492 \\
(0.037)^{* * *}\end{array}$ & $\begin{array}{c}-0.363 \\
(0.025)^{* * *}\end{array}$ & $\begin{array}{c}-0.287 \\
(0.043)^{* * *}\end{array}$ & $\begin{array}{c}-0.439 \\
(0.029)^{* * *}\end{array}$ & $\begin{array}{c}-0.747 \\
(0.049)^{* * *}\end{array}$ \\
\hline Method IV & $\begin{array}{c}-0.485 \\
(0.038)^{* * *}\end{array}$ & $\begin{array}{c}-0.340 \\
(0.025)^{* * *}\end{array}$ & $\begin{array}{c}-0.260 \\
(0.042)^{* * *}\end{array}$ & $\begin{array}{c}-0.419 \\
(0.030)^{* * *}\end{array}$ & $\begin{array}{c}-0.729 \\
(0.050)^{* * *}\end{array}$ \\
\hline \multicolumn{6}{|c|}{ Patent Citation Matrix } \\
\hline Method II & $\begin{array}{c}-0.479 \\
(0.037)^{* * *}\end{array}$ & $\begin{array}{c}-0.357 \\
(0.029)^{* * *}\end{array}$ & $\begin{array}{c}-0.294 \\
(0.048)^{* * *}\end{array}$ & $\begin{array}{c}-0.455 \\
(0.038)^{* * *}\end{array}$ & $\begin{array}{c}-0.723 \\
(0.050)^{* * *}\end{array}$ \\
\hline Method IV & $\begin{array}{c}-0.473 \\
(0.039)^{* * *}\end{array}$ & $\begin{array}{c}-0.340 \\
(0.029)^{* * *}\end{array}$ & $\begin{array}{c}-0.277 \\
(0.048)^{* * *}\end{array}$ & $\begin{array}{c}-0.443 \\
(0.038)^{* * *}\end{array}$ & $\begin{array}{c}-0.733 \\
(0.053)^{* * *}\end{array}$ \\
\hline Country FE & Yes & Yes & Yes & Yes & Yes \\
\hline Industry FE & Yes & Yes & Yes & Yes & Yes \\
\hline No. of Obs. & 782 & 732 & 377 & 355 & 908 \\
\hline
\end{tabular}

Notes: (1) Growth rate of each variable is calculated between 1970-1975 and 2005-2010. The table only reports the convergence parameter $\alpha$ specified in Equation 23; (2) Top and bottom $1 \%$ observations in terms of growth rate are dropped; (3) TFP estimates are based on country-specific I-O tables; (4) Robust standard errors are reported in the parentheses. ${ }^{*}, * *$, and $* * *$ indicate significance at the $10 \%, 5 \%$, and $1 \%$ levels, respectively. 
Table 6: Unconditional Convergence in TFP by Industry: 1970 - 2010

\begin{tabular}{|c|c|c|c|c|c|}
\hline & $\begin{array}{c}(1) \\
\text { Data }\end{array}$ & $\begin{array}{c}(2) \\
\text { Benchmark }\end{array}$ & $\begin{array}{c}(3) \\
\text { WIOD }\end{array}$ & $\begin{array}{c}(4) \\
\text { Patent }\end{array}$ & Obs. \\
\hline Food, tobacco & $\begin{array}{c}-0.388 \\
(0.082)^{* * *}\end{array}$ & $\begin{array}{c}-0.417 \\
(0.042)^{* * *}\end{array}$ & $\begin{array}{c}-0.369 \\
(0.042)^{* * *}\end{array}$ & $\begin{array}{c}-0.482 \\
(0.040)^{* * *}\end{array}$ & 51 \\
\hline Textiles & $\begin{array}{c}-0.344 \\
(0.162)^{* *}\end{array}$ & $\begin{array}{c}-0.540 \\
(0.069)^{* * *}\end{array}$ & $\begin{array}{c}-0.516 \\
(0.072)^{* * *}\end{array}$ & $\begin{array}{c}-0.502 \\
(0.070)^{* * *}\end{array}$ & 49 \\
\hline Apparel, footwear & $\begin{array}{c}-0.458 \\
(0.137)^{* * *}\end{array}$ & $\begin{array}{c}-0.104 \\
(0.015)^{* * *}\end{array}$ & $\begin{array}{c}-0.091 \\
(0.014)^{* * *}\end{array}$ & $\begin{array}{c}-0.085 \\
(0.013)^{* * *}\end{array}$ & 35 \\
\hline Wood & $\begin{array}{c}-0.188 \\
(0.088)^{* *}\end{array}$ & $\begin{array}{c}-0.441 \\
(0.038)^{* * *}\end{array}$ & $\begin{array}{c}-0.409 \\
(0.037)^{* * *}\end{array}$ & $\begin{array}{c}-0.478 \\
(0.033)^{* * *}\end{array}$ & 48 \\
\hline Paper & $\begin{array}{c}-0.349 \\
(0.072) * * *\end{array}$ & $\begin{array}{c}-0.543 \\
(0.041)^{* * *}\end{array}$ & $\begin{array}{c}-0.659 \\
(0.032)^{* * *}\end{array}$ & $\begin{array}{c}-0.533 \\
(0.041)^{* * *}\end{array}$ & 49 \\
\hline Printing, Publishing & $\begin{array}{l}-0.126 \\
(0.098)\end{array}$ & $\begin{array}{c}-0.011 \\
(0.002)^{* * *}\end{array}$ & $\begin{array}{c}-0.017 \\
(0.003)^{* * *}\end{array}$ & $\begin{array}{c}-0.008 \\
(0.002)^{* * *}\end{array}$ & 49 \\
\hline Coke, petroleum & $\begin{array}{c}0.157 \\
(0.143)\end{array}$ & $\begin{array}{c}-0.779 \\
(0.035)^{* * *}\end{array}$ & $\begin{array}{c}-0.652 \\
(0.050) * * *\end{array}$ & $\begin{array}{c}-0.908 \\
0.015)^{* * *}\end{array}$ & 51 \\
\hline Chemical & $\begin{array}{c}-0.360 \\
(0.089) * * *\end{array}$ & $\begin{array}{c}-0.357 \\
(0.033)^{* * *}\end{array}$ & $\begin{array}{c}-0.292 \\
(0.031)^{* * *}\end{array}$ & $\begin{array}{c}-0.313 \\
(0.031)^{* * *}\end{array}$ & 43 \\
\hline Rubber, plastic & $\begin{array}{c}-0.461 \\
(0.090)^{* * *}\end{array}$ & $\begin{array}{c}-0.267 \\
(0.033)^{* * *}\end{array}$ & $\begin{array}{c}-0.281 \\
(0.034)^{* * *}\end{array}$ & $\begin{array}{c}-0.215 \\
(0.028) * * *\end{array}$ & 48 \\
\hline Non-metallic mineral & $\begin{array}{c}-0.339 \\
(0.064)^{* * *}\end{array}$ & $\begin{array}{c}-0.163 \\
(0.023)^{* * *}\end{array}$ & $\begin{array}{c}-0.149 \\
(0.022)^{* * *}\end{array}$ & $\begin{array}{c}-0.164 \\
(0.022)^{* * *}\end{array}$ & 47 \\
\hline Basic metals & $\begin{array}{l}-0.118 \\
(0.100)\end{array}$ & $\begin{array}{c}-0.429 \\
(0.023)^{* * *}\end{array}$ & $\begin{array}{c}-0.449 \\
(0.027)^{* * *}\end{array}$ & $\begin{array}{l}-0.408 \\
(0.022)\end{array}$ & 42 \\
\hline Fabricated metal & $\begin{array}{c}-0.159 \\
(0.068)^{* *}\end{array}$ & $\begin{array}{c}-0.172 \\
(0.016)^{* * *}\end{array}$ & $\begin{array}{c}-0.143 \\
(0.015)^{* * *}\end{array}$ & $\begin{array}{c}-0.122 \\
(0.014)^{* * *}\end{array}$ & 48 \\
\hline Machinery, equipment & $\begin{array}{c}-0.311 \\
(0.125)^{* *}\end{array}$ & $\begin{array}{c}-0.568 \\
(0.047)^{* * *}\end{array}$ & $\begin{array}{c}-0.597 \\
(0.048)^{* * *}\end{array}$ & $\begin{array}{c}-0.483 \\
(0.053)^{* * *}\end{array}$ & 41 \\
\hline Electronics & $\begin{array}{c}-0.370 \\
(0.114)^{* * *}\end{array}$ & $\begin{array}{c}-0.349 \\
(0.045)^{* * *}\end{array}$ & $\begin{array}{c}-0.415 \\
(0.052)^{* * *}\end{array}$ & $\begin{array}{c}-0.274 \\
(0.041)^{* * *}\end{array}$ & 40 \\
\hline Medical, precision & $\begin{array}{c}0.069 \\
(0.171)\end{array}$ & $\begin{array}{c}-0.026 \\
(0.013)^{* *}\end{array}$ & $\begin{array}{c}-0.029 \\
(0.014)^{* *}\end{array}$ & $\begin{array}{c}-0.012 \\
(0.006)^{* *}\end{array}$ & 33 \\
\hline Vehicles & $\begin{array}{l}-0.230 \\
(0.152)\end{array}$ & $\begin{array}{c}-0.393 \\
(0.031)^{* * *}\end{array}$ & $\begin{array}{c}-0.409 \\
(0.031)^{* * *}\end{array}$ & $\begin{array}{c}-0.279 \\
(0.026)^{* * *}\end{array}$ & 46 \\
\hline Other manufacturing & $\begin{array}{c}-0.310 \\
(0.140)^{* *}\end{array}$ & $\begin{array}{c}-0.075 \\
(0.024)^{* * *}\end{array}$ & $\begin{array}{c}-0.078 \\
(0.026)^{* * *}\end{array}$ & $\begin{array}{c}-0.055 \\
(0.017)^{* * *}\end{array}$ & 47 \\
\hline
\end{tabular}

Notes: (1) Calibration (Method III) is performed on the sample from 1970 to 2010 estimated using country-specific TFP (2) Robust standard errors are reported in the parentheses. *, **, and *** indicate significance at the $10 \%, 5 \%$, and $1 \%$ levels, respectively. 
Table 7: Calibration of Industry-specific Diffusion Parameter $\beta^{i}$

\begin{tabular}{|c|c|c|}
\hline & $\begin{array}{c}(1) \\
\text { Method I }\end{array}$ & $\begin{array}{c}(2) \\
\text { Method III }\end{array}$ \\
\hline Food, tobacco & 0.361 & 0.364 \\
\hline Textiles & 0.368 & 0.383 \\
\hline Apparel, footwear & 0.284 & 0.337 \\
\hline Wood & 0.299 & 0.424 \\
\hline Paper & 0.284 & 0.402 \\
\hline Printing, Publishing & 0.349 & 0.305 \\
\hline Coke, petroleum & 0.312 & 0.448 \\
\hline Chemical & 0.443 & 0.353 \\
\hline Rubber, plastic & 0.421 & 0.331 \\
\hline Non-metallic mineral & 0.289 & 0.379 \\
\hline Basic metals & 0.387 & 0.343 \\
\hline Fabricated metal & 0.312 & 0.317 \\
\hline Machinery, equipment & 0.455 & 0.336 \\
\hline Electronics & 0.320 & 0.306 \\
\hline Medical, precision & 0.347 & 0.307 \\
\hline Vehicles & 0.451 & 0.304 \\
\hline Other manufacturing & 0.280 & 0.334 \\
\hline
\end{tabular}

Notes: (1) Calibration is performed on the baseline sample (2) $\beta^{i}$ is industry-specific but time-invariant 
Table 8: Transition Probability in TFP: Model versus Data

\begin{tabular}{|c|c|c|c|c|c|c|c|c|c|c|}
\hline \multicolumn{7}{|c|}{ Data } & \multicolumn{4}{|c|}{ Model } \\
\hline \multicolumn{11}{|c|}{ Full Sample } \\
\hline \multicolumn{7}{|c|}{2010 Rank } & \multicolumn{4}{|c|}{2010 Rank } \\
\hline & $1-4$ & $5-8$ & $9-12$ & $13-17$ & & & $1-4$ & $5-8$ & $9-12$ & $13-17$ \\
\hline $1-4$ & 0.39 & 0.22 & 0.17 & 0.21 & $\ddot{q}$ & $1-4$ & 0.83 & 0.14 & 0.03 & 0.00 \\
\hline $5-8$ & 0.24 & 0.30 & 0.20 & 0.26 & $\widetilde{\pi}$ & $5-8$ & 0.09 & 0.63 & 0.25 & 0.04 \\
\hline ․ $9-12$ & 0.21 & 0.29 & 0.26 & 0.24 & & $9-12$ & 0.04 & 0.14 & 0.54 & 0.28 \\
\hline . $13-17$ & 0.13 & 0.15 & 0.29 & 0.43 & & $13-17$ & 0.04 & 0.08 & 0.15 & 0.74 \\
\hline \multicolumn{11}{|c|}{ OECD Countries } \\
\hline \multicolumn{7}{|c|}{2010 Rank } & \multicolumn{4}{|c|}{2010 Rank } \\
\hline & $1-4$ & $5-8$ & $9-12$ & $13-17$ & & & $1-4$ & $5-8$ & $9-12$ & $13-17$ \\
\hline $1-4$ & 0.37 & 0.26 & 0.14 & 0.23 & $\ddot{q}$ & $1-4$ & 0.90 & 0.09 & 0.01 & 0.00 \\
\hline $5-8$ & 0.28 & 0.27 & 0.23 & 0.22 & $\widetilde{\sim}$ & $5-8$ & 0.04 & 0.82 & 0.12 & 0.02 \\
\hline$\supseteq \quad 9-12$ & 0.19 & 0.31 & 0.25 & 0.25 & & $9-12$ & 0.02 & 0.04 & 0.78 & 0.16 \\
\hline 它 $13-17$ & 0.13 & 0.13 & 0.30 & 0.44 & & $13-17$ & 0.03 & 0.04 & 0.07 & 0.86 \\
\hline \multicolumn{11}{|c|}{ Non-OECD Countries } \\
\hline \multicolumn{5}{|c|}{2010 Rank } & & & \multicolumn{4}{|c|}{2010 Rank } \\
\hline & $1-4$ & $5-8$ & $9-12$ & $13-17$ & & & $1-4$ & $5-8$ & $9-12$ & $13-17$ \\
\hline & 0.40 & 0.19 & 0.21 & 0.20 & בै & $1-4$ & 0.77 & 0.18 & 0.05 & 0.00 \\
\hline $5-8$ & 0.20 & 0.33 & 0.18 & 0.30 & 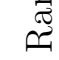 & $5-8$ & 0.13 & 0.47 & 0.35 & 0.06 \\
\hline ․ $9-12$ & 0.23 & 0.28 & 0.27 & 0.23 & 요 & $9-12$ & 0.06 & 0.22 & 0.34 & 0.38 \\
\hline 。 $13-17$ & 0.13 & 0.17 & 0.28 & 0.42 & $\stackrel{2}{二}$ & $13-17$ & 0.04 & 0.11 & 0.21 & 0.65 \\
\hline
\end{tabular}

Notes: Each transition matrix is constructed using 1970-1975 and 2005-2010 sample. 
Table 9: Key Players: Direct Contribution to TFP Growth

\begin{tabular}{|c|c|c|c|c|c|c|c|}
\hline \multicolumn{4}{|c|}{ Simple Average (\%) } & \multicolumn{4}{|c|}{ Weighted Average (\%) } \\
\hline \multicolumn{2}{|c|}{ Top 5} & \multicolumn{2}{|c|}{ "BRICS" } & \multicolumn{2}{|c|}{ Top 5} & \multicolumn{2}{|c|}{ "BRICS" } \\
\hline \multicolumn{8}{|c|}{ Benchmark } \\
\hline USA & 11.29 & Brazil & 2.16 & USA & 20.88 & Brazil & 1.77 \\
\hline Germany & 7.52 & Russia & 1.28 & Japan & 18.31 & Russia & 0.70 \\
\hline Japan & 6.95 & India & 1.77 & Germany & 8.23 & India & 1.15 \\
\hline Italy & 5.26 & China & 3.78 & Italy & 5.10 & China & 5.43 \\
\hline France & 4.73 & S. Africa & 1.13 & France & 4.88 & S.Africa & 0.48 \\
\hline \multicolumn{8}{|c|}{ Country-specific I-O } \\
\hline USA & 11.64 & Brazil & 2.09 & USA & 20.49 & Brazil & 1.70 \\
\hline Germany & 7.71 & Russia & 1.21 & Japan & 18.38 & Russia & 0.67 \\
\hline Japan & 7.39 & India & 1.74 & Germany & 8.09 & India & 1.11 \\
\hline Italy & 5.49 & China & 3.74 & France & 5.05 & China & 5.23 \\
\hline France & 4.87 & S. Africa & 1.06 & Italy & 5.02 & S.Africa & 0.48 \\
\hline \multicolumn{8}{|c|}{ Patent Citation } \\
\hline USA & 10.64 & Brazil & 2.17 & USA & 20.39 & Brazil & 1.73 \\
\hline Germany & 7.24 & Russia & 1.34 & Japan & 17.84 & Russia & 0.76 \\
\hline Japan & 6.53 & India & 1.86 & Germany & 7.98 & India & 1.16 \\
\hline Italy & 5.38 & China & 3.68 & Italy & 5.11 & China & 5.41 \\
\hline UK & 4.67 & S. Africa & 1.16 & France & 4.93 & S.Africa & 0.51 \\
\hline
\end{tabular}

Note: This table covers the period from 1990 to 2010. Centrality measures are calculated using diffusion parameters obtained from calibration and actual trade and production data. I obtain similar rankings if simulated trade and production data is used instead. 
Table 10: Key Players: Direct Contribution to TFP Growth

\begin{tabular}{|c|c|c|c|c|c|}
\hline \multicolumn{3}{|c|}{ Simple Average (\%) } & \multicolumn{3}{|c|}{ Weighted Average (\%) } \\
\hline Country & Industry & Contribution & Country & Industry & Contribution \\
\hline \multicolumn{6}{|c|}{ Benchmark } \\
\hline USA & Measurement & 2.23 & Japan & Vehicles & 3.91 \\
\hline Japan & Vehicles & 1.81 & USA & Vehicles & 3.57 \\
\hline USA & Machinery & 1.44 & USA & Measurement & 2.98 \\
\hline USA & Vehicles & 1.40 & Japan & Electronics & 2.98 \\
\hline USA & Electronics & 1.27 & USA & Food & 2.75 \\
\hline Germany & Machinery & 1.11 & Japan & Machinery & 2.72 \\
\hline Japan & Electronics & 1.09 & USA & Machinery & 1.84 \\
\hline Germany & Vehicles & 1.07 & USA & Printing & 1.75 \\
\hline Germany & Measurement & 1.07 & Germany & Vehicles & 1.74 \\
\hline Japan & Machinery & 1.05 & USA & Electronics & 1.65 \\
\hline \multicolumn{6}{|c|}{ Country-specific I-O } \\
\hline USA & Measurement & 2.26 & Japan & Electronics & 3.86 \\
\hline USA & Electronics & 1.97 & Japan & Vehicles & 3.50 \\
\hline Japan & Electronics & 1.74 & USA & Measurement & 3.34 \\
\hline USA & Machinery & 1.55 & USA & Vehicles & 3.08 \\
\hline Japan & Vehicles & 1.42 & Japan & Machinery & 2.48 \\
\hline Germany & Machinery & 1.18 & USA & Food & 2.38 \\
\hline Japan & Machinery & 1.16 & USA & Electronics & 2.13 \\
\hline Germany & Electronics & 1.12 & USA & Machinery & 1.74 \\
\hline USA & Vehicles & 1.10 & USA & Printing & 1.55 \\
\hline Germany & Measurement & 1.06 & Germany & Vehicles & 1.48 \\
\hline \multicolumn{6}{|c|}{ Patent Citation } \\
\hline USA & Measurement & 1.90 & USA & Measurement & 3.24 \\
\hline USA & Electronics & 1.16 & Japan & Electronics & 2.93 \\
\hline Japan & Vehicles & 1.12 & Japan & Vehicles & 2.17 \\
\hline USA & Machinery & 1.07 & USA & Vehicles & 2.03 \\
\hline Japan & Electronics & 1.05 & Japan & Machinery & 1.94 \\
\hline USA & Chemical & 0.94 & USA & Food & 1.93 \\
\hline Germany & Measurement & 0.89 & USA & Printing & 1.78 \\
\hline USA & Vehicles & 0.86 & Japan & Printing & 1.72 \\
\hline Germany & Machinery & 0.83 & USA & Chemicals & 1.68 \\
\hline Japan & Machinery & 0.83 & Japan & Fabr. Metals & 1.65 \\
\hline
\end{tabular}

Note: This table covers the period from 1990 to 2010. Centrality measures are calculated using diffusion parameters obtained from calibration and actual trade and production data. I obtain similar rankings if simulated trade and production data is used instead. 
Table 11: Key-Player: Counter-factual Change of TFP Growth

\begin{tabular}{lcclcc}
\hline \hline \multicolumn{5}{c}{ Change of TFP Growth from 1990 to $2010(\%)$} \\
OECD & World Average & Own & Non-OECD & World Average & Own \\
\hline Japan & -5.81 & -27.89 & Taiwan & -3.50 & -25.82 \\
USA & -5.13 & -44.70 & Brazil & -1.63 & -50.60 \\
Germany & -3.75 & -57.31 & India & -1.42 & -47.64 \\
France & -2.82 & -54.58 & South Africa & -1.38 & -54.21 \\
Italy & -2.78 & -50.65 & Malaysia & -1.37 & -33.84 \\
UK & -2.71 & -59.05 & Russia & -1.37 & -63.56 \\
Canada & -2.51 & -52.01 & Thailand & -1.36 & -55.31 \\
Korea & -2.16 & -48.09 & Indonesia & -1.35 & -45.46 \\
Spain & -2.09 & -54.34 & Ukraine & -1.28 & -58.68 \\
Switzerland & -1.96 & -26.61 & Egypt & -1.25 & -60.17 \\
Average & -1.94 & -52.15 & Average & -1.18 & -52.20 \\
\hline
\end{tabular}

Note: This table computes the percentage change of TFP growth by assuming that one country becomes autarkic. The diffusion parameter is from the method II of the baseline calibration. The world average decline of TFP growth is weighted by PPP-adjusted GDP. 
Table A1: Sample Coverage

\begin{tabular}{lcllllll}
\hline \hline Non-OECD & Year & Non-OECD & Year & Non-OECD & Year & Non-OECD & Year \\
Argentina & $80-11$ & Bangladesh & $72-07$ & Bolivia & $63-11$ & Brazil & $80-11$ \\
Bulgaria & $90-11$ & China & $73-11$ & Colombia & $63-11$ & Costa Rica & $63-11$ \\
Ecuador & $63-11$ & Egypt & $63-11$ & El Salvador & $63-11$ & Ethiopia & $80-11$ \\
Fiji & $63-11$ & Ghana & $63-11$ & Guatemala & $63-11$ & Honduras & $63-11$ \\
India & $63-11$ & Indonesia & $63-11$ & Jordan & $63-11$ & Kazakhstan & $92-11$ \\
Kenya & $63-11$ & Malaysia & $63-11$ & Mauritius & $63-11$ & Nigeria & $63-11$ \\
Pakistan & $63-11$ & Peru & $80-11$ & Philippines & $63-11$ & Romania & $90-11$ \\
Russia & $96-11$ & Senegal & $70-11$ & S. Africa & $63-11$ & Sri Lanka & $63-11$ \\
Taiwan & $73-11$ & Tanzania & $63-11$ & Thailand & $63-11$ & Trinidad Tbg & $63-10$ \\
Ukraine & $92-11$ & Uruguay & $63-11$ & Venezuela & $63-11$ & Viet Nam & $91-11$ \\
\hline \hline OECD & Year & OECD & Year & OECD & Year & OECD & Year \\
Australia & $63-11$ & Austria & $63-11$ & Belgium-Lux & $63-11$ & Canada & $63-11$ \\
Chile & $63-11$ & Czech Rep & $93-11$ & Denmark & $63-11$ & Finland & $63-11$ \\
France & $63-11$ & Germany & $91-11$ & Greece & $63-11$ & Hungary & $90-11$ \\
Iceland & $63-11$ & Ireland & $63-11$ & Israel & $63-11$ & Italy & $65-11$ \\
Japan & $63-11$ & Korea Rep & $63-11$ & Mexico & $63-11$ & Netherlands & $63-11$ \\
New Zealand & $63-11$ & Norway & $63-11$ & Poland & $90-11$ & Portugal & $63-11$ \\
Slovakia & $93-11$ & Slovenia & $92-11$ & Spain & $63-11$ & Sweden & $63-11$ \\
Switzerland & $80-11$ & Turkey & $63-11$ & UK & $63-11$ & USA & $58-11$ \\
\hline
\end{tabular}


Table A2: Tradeable Industries

\begin{tabular}{ll}
\hline \hline ISIC (Rev. 3) & Industry Description \\
$15-16$ & Food products and beverages, tobacco products \\
17 & Textiles \\
$18-19$ & Wearing apparel, leather, luggage, footwear \\
20 & Wood products except furniture, straw and plaiting materials \\
21 & Paper and paper products \\
22 & Publishing, printing and reproduction of recorded media \\
23 & Coke, refined petroleum products and nuclear fuel \\
24 & Chemicals and chemical products \\
25 & Rubber and plastic products \\
26 & Other non-metallic mineral products \\
27 & Basic metals \\
28 & Fabricated metal products, except machinery and equipment \\
$29-30$ & Office, accounting and computing machinery, other machinery \\
$31-32$ & Electrical machinery, communication equipment \\
33 & Medical, precision and optical instruments, watches and clocks \\
$34-35$ & Transport equipment \\
36 & Furniture, other manufacturing \\
\hline
\end{tabular}


Table A3: Construction of Variables and Data Sources

\begin{tabular}{ll}
\hline \hline Variables/Parameters & Data Source \& Construction Method \\
Bilateral trade share $\pi_{n n^{\prime}, t}^{i}$ & UN Comtrade \& UNIDO INDSTAT2 \\
Trade deficit $D_{n, t}$ & UN Comtrade \\
Trade in value-added & TiVA database (OECD.STAT) \\
Labor income share $\gamma_{t}^{i L}$ & UNIDO INDSTAT2, (wage bill)/(industrial output) \\
Capital income share $\gamma_{t}^{i K}$ & UNIDO INDSTAT2, (value-added - wage bill)/(industrial output) \\
Input-output coefficients $\gamma_{n, t}^{i{ }^{\prime}}$ & BEA 1997 I-O accounts (grouped into 2-digit ISIC Rev.3); WIOD \\
Labor supply $L_{n, t}$ & Penn World Table \\
Capital stock $K_{n, t}$ & Penn World Table \\
Wage rate $w_{n, t}$ & Penn World Table, (labor income)/(employment count) \\
Rental rate $r_{n, t}$ & Pen World Table, (total income - labor income)/(capital) \\
& World Development Indicators; Caselli and Feyrer $(2007)$ \\
Saving rate $s_{n, t}$ & Penn World Table, implied by capital series and depreciation rate \\
Non-tradeable price $P_{n, t}^{I+1}$ & ICP, interpolate and extrapolate for non-survey years \\
Tradable exp share $\phi_{n}$ & OECD national accounts, (fitting for non-OECD countries) \\
Trade elasticity $\theta^{i}$ & $4 ; 8.28 ;$ Industry-specific (Caliendo and Parro, 2014) \\
Elasticity of subst. in consumption $\frac{1}{1-\kappa}$ & 2 (Levchenko and Zhang, 2016); 1 (Caliendo and Parro, 2014) \\
Elasticity of subst. in production $\sigma^{i}$ & 2 \\
Tradeable consumption share $\omega_{n}^{i}$ & Levchenko and Zhang (2016) \\
US industry-level TFP & NBER-CES manufacturing industry database \\
Other country variables & Penn World Table \\
Other bilateral variables & CEPII gravity dataset \\
Industry-level TFP & KLEMS database (EU-, Asia, World- KLEMS) \\
\hline
\end{tabular}


Table A4: Convergence: Alternative Estimates of TFP

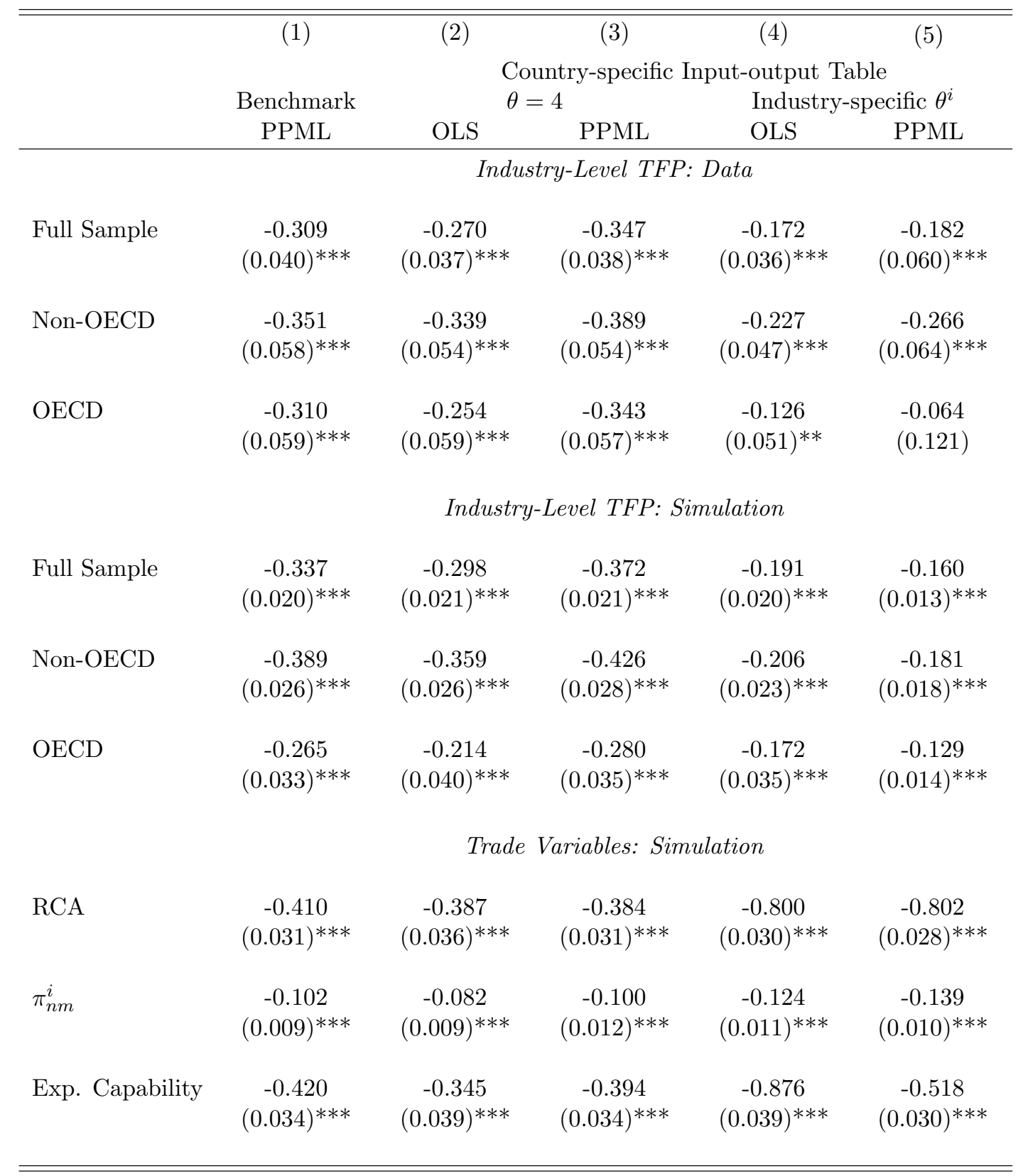

Notes: (1) Growth rate of each variable is calculated between 1990-1995 and 2005-2010. The table only reports the convergence parameter $\alpha$ specified in Equation 23 using Method II; (2) Top and bottom $1 \%$ observations in terms of growth rate are dropped; (3) Industry and country fixed effects are included in each regression; (4) Robust standard errors are reported in the parentheses. *, **, and $* * *$ indicate significance at the $10 \%, 5 \%$, and $1 \%$ levels, respectively. 
Table A5: Unconditional Convergence in RCA by Industry: 1970 - 2010

\begin{tabular}{|c|c|c|c|c|c|}
\hline & $\begin{array}{c}(1) \\
\text { Data }\end{array}$ & $\begin{array}{c}(2) \\
\text { Benchmark }\end{array}$ & $\begin{array}{c}(3) \\
\text { WIOD }\end{array}$ & $\begin{array}{c}(4) \\
\text { Patent }\end{array}$ & Obs. \\
\hline Food, tobacco & $\begin{array}{c}-0.300 \\
(0.110)^{* * *}\end{array}$ & $\begin{array}{c}-0.424 \\
(0.116)^{* * *}\end{array}$ & $\begin{array}{c}-0.453 \\
(0.115)^{* * *}\end{array}$ & $\begin{array}{c}-0.395 \\
(0.119)^{* * *}\end{array}$ & 51 \\
\hline Textiles & $\begin{array}{c}-0.498 \\
(0.131)^{* * *}\end{array}$ & $\begin{array}{c}-0.459 \\
(0.178)^{* * *}\end{array}$ & $\begin{array}{c}-0.459 \\
(0.170)^{* * *}\end{array}$ & $\begin{array}{c}-0.433 \\
(0.181)^{* *}\end{array}$ & 49 \\
\hline Apparel, footwear & $\begin{array}{c}-0.603 \\
(0.222)^{* * *}\end{array}$ & $\begin{array}{l}-0.149 \\
(0.164)\end{array}$ & $\begin{array}{l}-0.155 \\
(0.164)\end{array}$ & $\begin{array}{l}-0.142 \\
(0.162)\end{array}$ & 35 \\
\hline Wood & $\begin{array}{c}-0.515 \\
(0.111)^{* *}\end{array}$ & $\begin{array}{c}-0.584 \\
(0.126)^{* * *}\end{array}$ & $\begin{array}{c}-0.588 \\
(0.124) * * *\end{array}$ & $\begin{array}{c}-0.585 \\
(0.0128)^{* * *}\end{array}$ & 48 \\
\hline Paper & $\begin{array}{c}-0.753 \\
(0.101)^{* * *}\end{array}$ & $\begin{array}{c}-0.811 \\
(0.106)^{* * *}\end{array}$ & $\begin{array}{c}-0.894 \\
(0.104)^{* * *}\end{array}$ & $\begin{array}{c}-0.827 \\
(0.108) * * *\end{array}$ & 49 \\
\hline Printing, Publishing & $\begin{array}{c}-0.423 \\
(0.103)^{* * *}\end{array}$ & $\begin{array}{c}-0.705 \\
(0.137)^{* * *}\end{array}$ & $\begin{array}{c}-0.725 \\
(0.139)^{* * *}\end{array}$ & $\begin{array}{c}-0.714 \\
(0.134)^{* * *}\end{array}$ & 49 \\
\hline Coke, petroleum & $\begin{array}{c}-0.776 \\
(0.166) * * *\end{array}$ & $\begin{array}{c}-0.627 \\
(0.147)^{* * *}\end{array}$ & $\begin{array}{c}-0.605 \\
(0.144)^{* * *}\end{array}$ & $\begin{array}{c}-0.643 \\
(0.152)^{* * *}\end{array}$ & 51 \\
\hline Chemical & $\begin{array}{c}-0.604 \\
(0.073)^{* * *}\end{array}$ & $\begin{array}{c}-0.548 \\
(0.145)^{* * *}\end{array}$ & $\begin{array}{c}-0.509 \\
(0.153)^{* * *}\end{array}$ & $\begin{array}{c}-0.538 \\
(0.151)^{* * *}\end{array}$ & 43 \\
\hline Rubber, plastic & $\begin{array}{c}-0.670 \\
(0.068)^{* * *}\end{array}$ & $\begin{array}{c}-0.706 \\
(0.068)^{* * *}\end{array}$ & $\begin{array}{c}-0.714 \\
(0.066)^{* * *}\end{array}$ & $\begin{array}{c}-0.686 \\
(0.073)^{* * *}\end{array}$ & 48 \\
\hline Non-metallic mineral & $\begin{array}{c}-0.596 \\
(0.057)^{* * *}\end{array}$ & $\begin{array}{c}-0.511 \\
(0.082)^{* * *}\end{array}$ & $\begin{array}{c}-0.506 \\
(0.083)^{* * *}\end{array}$ & $\begin{array}{c}-0.530 \\
(0.082)^{* * *}\end{array}$ & 47 \\
\hline Basic metals & $\begin{array}{c}-0.596 \\
(0.057)^{* * *}\end{array}$ & $\begin{array}{c}-0.839 \\
(0.123)^{* * *}\end{array}$ & $\begin{array}{c}-0.842 \\
(0.124)^{* * *}\end{array}$ & $\begin{array}{c}-0.842 \\
(0.124)^{* * *}\end{array}$ & 42 \\
\hline Fabricated metal & $\begin{array}{c}-0.627 \\
(0.071)^{* *}\end{array}$ & $\begin{array}{c}-0.682 \\
(0.107)^{* * *}\end{array}$ & $\begin{array}{c}-0.666 \\
(0.108)^{* * *}\end{array}$ & $\begin{array}{c}-0.667 \\
(0.111)^{* * *}\end{array}$ & 48 \\
\hline Machinery, equipment & $\begin{array}{c}-0.517 \\
(0.085)^{* * *}\end{array}$ & $\begin{array}{c}-0.986 \\
(0.102)^{* * *}\end{array}$ & $\begin{array}{c}-1.017 \\
(0.097)^{* * *}\end{array}$ & $\begin{array}{c}-0.905 \\
(0.108)^{* * *}\end{array}$ & 41 \\
\hline Electronics & $\begin{array}{c}-0.490 \\
(0.121)^{* * *}\end{array}$ & $\begin{array}{c}-0.946 \\
(0.102)^{* * *}\end{array}$ & $\begin{array}{c}-0.967 \\
(0.134)^{* * *}\end{array}$ & $\begin{array}{c}-0.925 \\
(0.137)^{* * *}\end{array}$ & 40 \\
\hline Medical, precision & $\begin{array}{c}-0.418 \\
(0.066) * * *\end{array}$ & $\begin{array}{c}-0.397 \\
(0.172)^{* *}\end{array}$ & $\begin{array}{c}-0.409 \\
(0.171)^{* *}\end{array}$ & $\begin{array}{c}-0.396 \\
(0.169)^{* *}\end{array}$ & 33 \\
\hline Vehicles & $\begin{array}{c}-0.577 \\
(0.080) * * *\end{array}$ & $\begin{array}{c}-0.654 \\
(0.090)^{* * *}\end{array}$ & $\begin{array}{c}-0.677 \\
(0.087)^{* * *}\end{array}$ & $\begin{array}{c}-0.593 \\
(0.096)^{* * *}\end{array}$ & 46 \\
\hline Other manufacturing & $\begin{array}{c}-0.639 \\
(0.116)^{* * *}\end{array}$ & $\begin{array}{c}-0.702 \\
(0.148)^{* * *}\end{array}$ & $\begin{array}{c}-0.706 \\
(0.146)^{* * *}\end{array}$ & $\begin{array}{c}-0.697 \\
(0.150)^{* * *}\end{array}$ & 47 \\
\hline
\end{tabular}

Notes: (1) Calibration (Method III) is performed on the sample from 1970 to 2010 estimated using country-specific TFP (2) Robust standard errors are reported in the parentheses. *, **, and *** indicate significance at the $10 \%, 5 \%$, and $1 \%$ levels, respectively. 
Table A6: Key Players: Direct Contribution to TFP Growth by Period

\begin{tabular}{|c|c|c|c|c|c|c|c|}
\hline \multicolumn{4}{|c|}{ Simple Average (\%) } & \multicolumn{4}{|c|}{ Weighted Average (\%) } \\
\hline \multicolumn{2}{|c|}{ Top 5} & \multicolumn{2}{|c|}{ "BRICS" } & \multicolumn{2}{|c|}{ Top 5} & \multicolumn{2}{|c|}{ "BRICS" } \\
\hline \multicolumn{8}{|c|}{$1995-2000$} \\
\hline USA & 11.25 & Brazil & 2.23 & USA & 22.06 & Brazil & 1.93 \\
\hline Germany & 7.94 & Russia & 1.71 & Germany & 21.14 & Russia & 0.97 \\
\hline Japan & 7.81 & India & 1.57 & Japan & 9.11 & India & 0.91 \\
\hline UK & 4.61 & China & 2.48 & UK & 4.61 & China & 3.64 \\
\hline Italy & 4.08 & S. Africa & 1.04 & Italy & 4.08 & S.Africa & 0.43 \\
\hline \multicolumn{8}{|c|}{$2000-2005$} \\
\hline USA & 11.64 & Brazil & 2.00 & USA & 20.06 & Brazil & 1.73 \\
\hline Germany & 7.44 & Russia & 0.97 & Germany & 17.93 & Russia & 0.44 \\
\hline Japan & 6.76 & India & 1.75 & Japan & 7.62 & India & 1.18 \\
\hline Italy & 5.72 & China & 3.44 & Italy & 5.27 & China & 4.72 \\
\hline UK & 5.02 & S. Africa & 1.11 & France & 5.19 & S.Africa & 0.42 \\
\hline \multicolumn{8}{|c|}{$2005-2010$} \\
\hline USA & 10.98 & Brazil & 2.25 & USA & 19.43 & Brazil & 1.65 \\
\hline Germany & 7.19 & Russia & 1.16 & Germany & 14.93 & Russia & 0.68 \\
\hline Japan & 6.29 & India & 1.99 & Japan & 7.96 & India & 1.35 \\
\hline Italy & 5.30 & China & 5.43 & Italy & 5.50 & China & 7.93 \\
\hline France & 4.71 & S. Africa & 1.24 & France & 5.31 & S.Africa & 0.60 \\
\hline
\end{tabular}

Note: This table covers the period from 1990 to 2010. Centrality measures are calculated using diffusion parameters obtained from the baseline calibration and actual trade and production data. I obtain similar rankings if simulated trade and production data is used instead. 
Table A7: Key Players: Degree Centrality

\begin{tabular}{|c|c|c|c|c|c|c|c|}
\hline \multicolumn{4}{|c|}{ Cutoff $\zeta=0.02$} & \multicolumn{4}{|c|}{ Cutoff $\zeta=0.005$} \\
\hline \multicolumn{2}{|c|}{ Top 5} & \multicolumn{2}{|c|}{ "BRICS" } & \multicolumn{2}{|c|}{ Top 5} & \multicolumn{2}{|c|}{ "BRICS" } \\
\hline USA & 0.99 & Brazil & 0.19 & USA & 1.00 & Brazil & 0.44 \\
\hline Germany & 0.97 & Russia & 0.04 & Germany & 1.00 & Russia & 0.07 \\
\hline Japan & 0.94 & India & 0.14 & Japan & 1.00 & India & 0.26 \\
\hline Italy & 0.86 & China & 0.53 & UK & 0.99 & China & 0.86 \\
\hline France & 0.84 & S. Africa & 0.06 & France & 0.99 & S.Africa & 0.09 \\
\hline \multicolumn{3}{|c|}{ Cutoff $\zeta=1 e-4$} & \multicolumn{5}{|c|}{ Cutoff $\zeta=1 e-5$} \\
\hline Country & Industry & Degree & & Country & Industry & Degree & \\
\hline USA & Measurement & 0.99 & & USA & Measurement & 1.00 & \\
\hline Germany & Measurement & 0.99 & & Japan & Measurement & 1.00 & \\
\hline Japan & Measurement & 0.97 & & USA & Vehicles & 0.99 & \\
\hline UK & Measurement & 0.96 & & UK & Printing & 0.99 & \\
\hline Japan & Vehicles & 0.96 & & Japan & Vehicles & 0.99 & \\
\hline France & Measurement & 0.95 & & USA & Other Manuf. & 0.99 & \\
\hline Switzerland & Measurement & 0.95 & & Germany & Vehicles & 0.99 & \\
\hline USA & Vehicles & 0.95 & & China & Other Manuf. & 0.99 & \\
\hline Germany & Vehicles & 0.95 & & Germany & Measurement & 0.99 & \\
\hline France & Vehicles & 0.94 & & Switzerland & Measurement & 0.99 & \\
\hline
\end{tabular}

Note: This table covers the period from 1990 to 2010 using the diffusion parameter obtained from the baseline calibration (Method II). Country-level degree measure is normalized by $N=$ 72 and industry-level degree measure is normalized by $N \times I=1224$. 